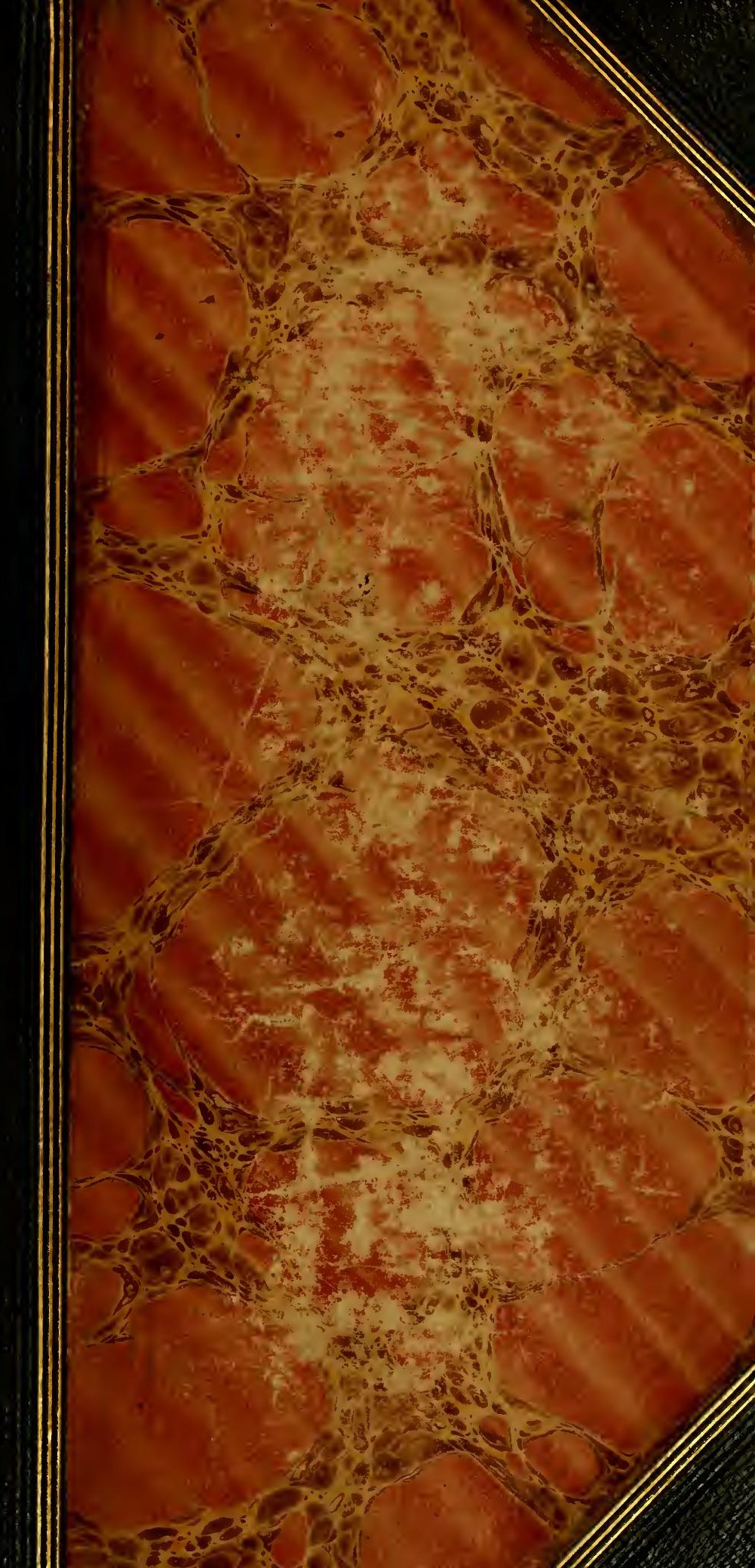




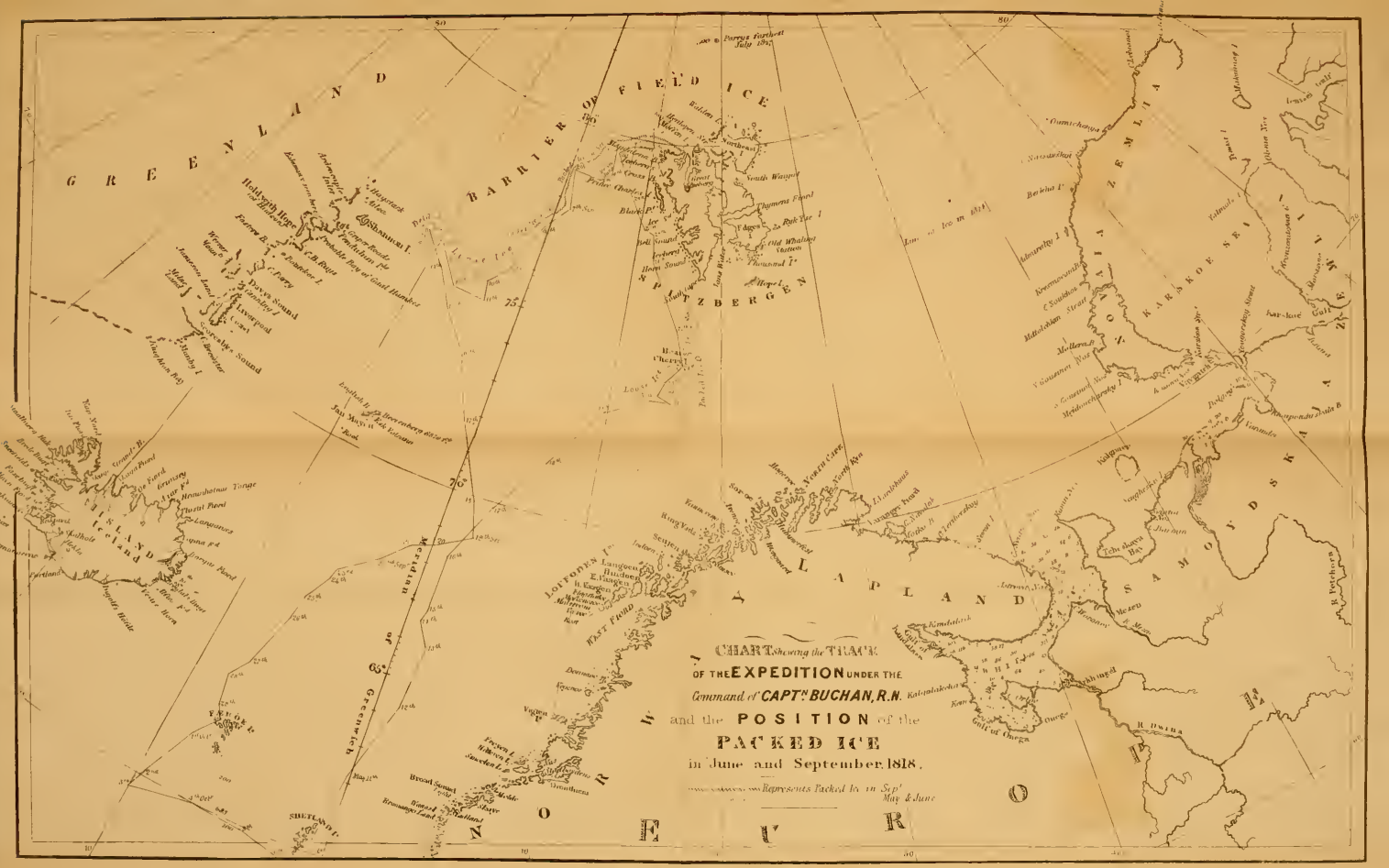




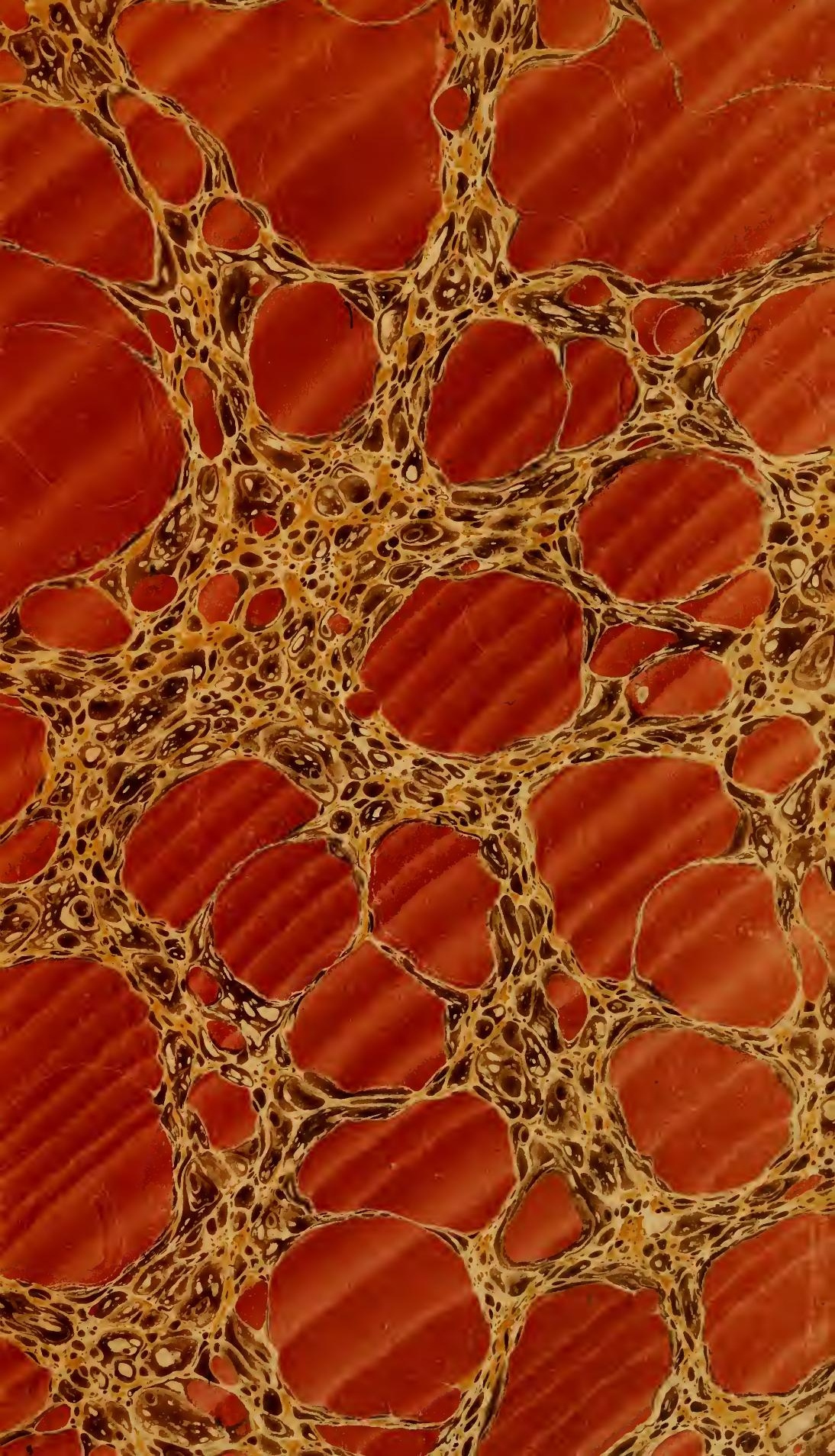


Marine Biological Laboratory Library Woods Jole, Massachusetts

WOYAGES · OF · EXPLORATION
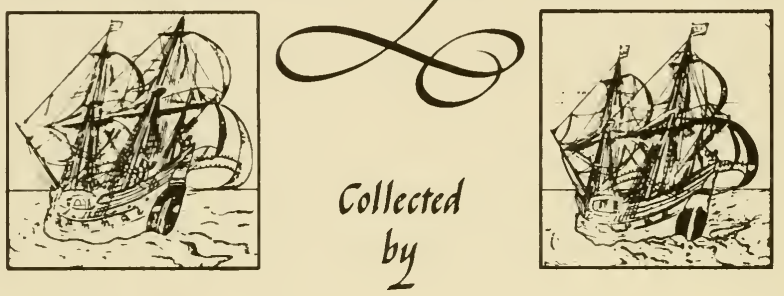

NewComb $\mathcal{T}_{\text {Hompson }} \mathfrak{M}_{\text {Mntgomeri }}$ (1907-1986)

Philadelphia architect, nephew of Thomas Harríson Montgomery (1873-1912), MBL investigator, and Priscilla Braislín Montgomery (1874-1956), MBL librarián. Gift of their sons Hugh Montgomery, M.D. and Raymond B. Montgomery -1987 . 

Marime Biological Laboratory Library Woods Fole, Massachusetts

\section{WOYAGES - OF - EXPLORATION}
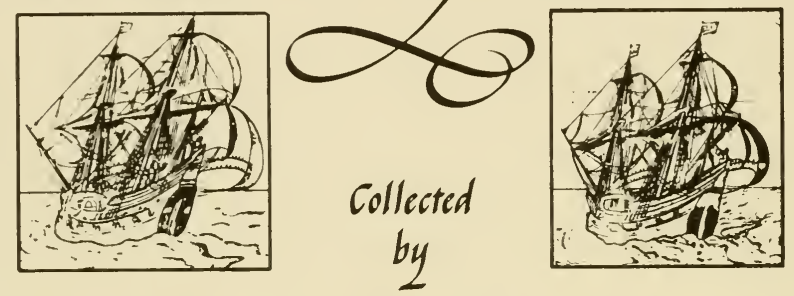

$\mathcal{N}_{\text {EwCOMB }} \mathcal{J}_{\text {Hompson }} \mathfrak{M}_{\text {Montgomer }}$

$$
\text { (1907-1986) }
$$

Philadelphia architect, nephew of Thomas Harrison Montgomery (1873-1912), MBL investigator, and Priscilla Braislín Montgomery (1874-1956), MBL librarián.

Gift of their sons Hugh Montgomery, M.D. and Raymond B. Montgomery $=1987$. 


$-$

$$
\begin{aligned}
& -1
\end{aligned}
$$

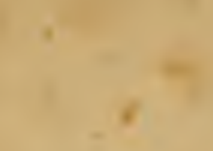

6.
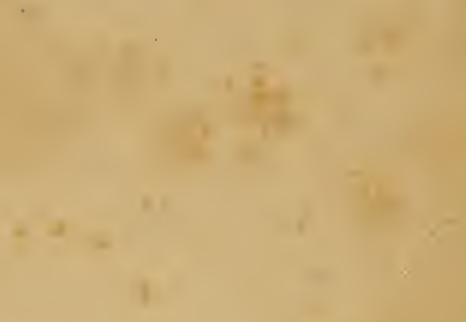

$+2+2$

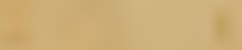

4

$\sqrt{2}$

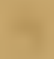




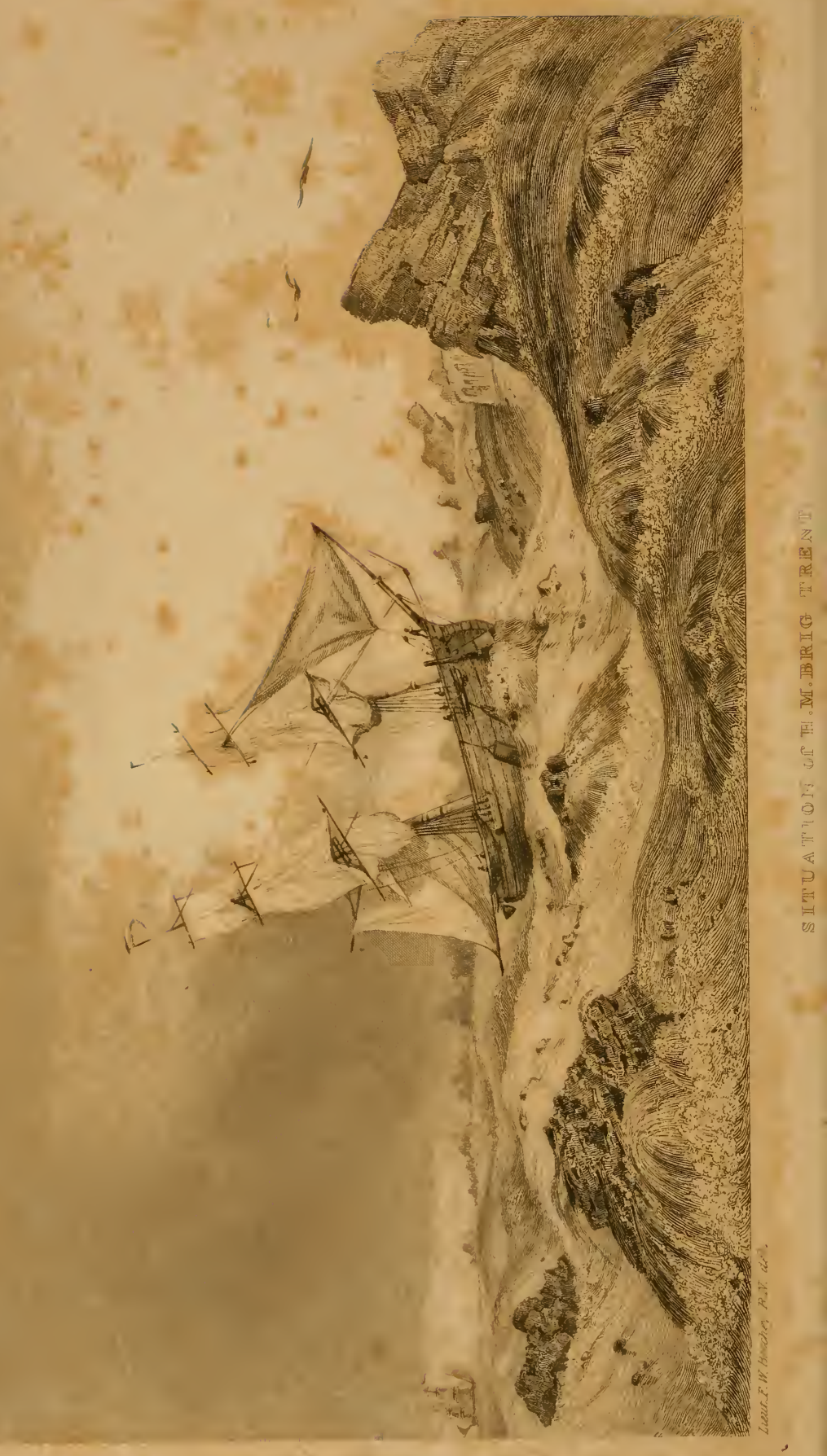




\title{
VOYAGE OF DISCOVERY
}

\author{
TOWARDS
}

\section{THE NORTH POLE,}

PERFOKMED IN HIS MAJESTY'S SHIPS

DOROTHEA AND TRENT,

UNDER THE COMMAND OF

\section{CAPTAIN DAVID BUCHAN, R.N.;}

\section{8 ;}

TO WHICH IS ADDED, A SUMMARY OF ALL THE EARLY ATTEMPTS TO REACH THE PACIFIC BY WAY OF THE POLE.

BY

CAPTAIN F.W. BEECHEY, R.N., F.R.S.

ONE OF THE LIEUTENANTS OF THE EXPEDITION.

PUBLISHED BY AUTHORITY OF THE LORDS COMMISSIONERS OF THE ADMIRALTY.

\section{LONDON :}

RICHARD BENTLEY, NEW BURLINGTON STREET,

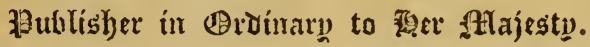

1843. 
LONDON

Priuted by S.\&. J. BentLer, WILcon, and FuEY Bauǵcr-Eouse, Shoe-Lane. 
To

SIR JOHN BARROW, BART., F.R.S., \&c.

THE ORIGINATER AND PROHOTER OF

MODERN ARCTIC DISCOVERY,

THIS VOLUME,

CONTAINING A NARRATIVE OF THE EXPEDITION UNDER

THE COMMAND OF

CAPTAIN DAVID BUCHAN, R.N.

TOWARDS

THE NOR TH POLE,

AND A SUMMARY OF

EARLY ATTEMPTS TO REACH THE PACIFIC BY WAY OF THE POLE,

IS, WITH PERMISSION, RESPECTFULLY DEDICATED

BY

HIS FAITHFUL AND OBLIGED FRIEND,

THE AUTHOR.

March, 1843. 



\section{CONTEN'TS.}

\section{PART I.}

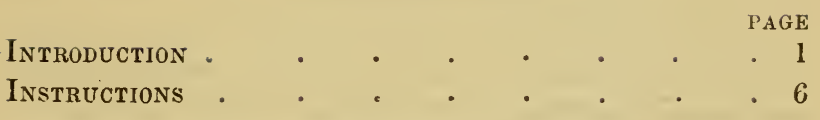

\section{CHAPTER I.}

Expedition determined upon.-Its objects. - Instructions.-Equipment.-Departure.-Visit Shetland.-A leak discovered.-Cherie Island.-Packed Ice.-Spitzbergen. —Magdalena Bay.-Glaciers . . . . .

\section{CHAPTER II.}

Quit Magdalena Bay. - Revisit the Ice. - The Trent driven into the packed ice.-Her dangerous situation.The ice opens.-The ships enter and are beset.-Cause of the leak in the Trent discovered and remedied.-Heavy pressure of the ice. - Intricate situation of the vessels. They regain the open sea.-Walruses make a formidable attack upon the boats of the Trent.-Their habits described.-Expedition proceeds to Fair Haven.-Description of the anchorage. - Numerous graves and remains of habitations discovered $. \quad . \quad . \quad . \quad 61$ 
Sufferings of the party.-Cheerfulness under their misfortunes. - Twelfth day.-Reappearance of the sun.-Extraordinary refraction.-Ice breaks up. - Ship rendered unserviceable. - Abandoned.-Two boats prepared.-Party embark on their return home.- Death of Barentz.Reach Cola. - Meet with Cornelison Ryp.-His unsuccessful voyage.-Return to Holland. - Hudson proceeds on a Polar voyage.-Traces the coast of Greenland to $73^{\circ}$ N.-Visits Spitzbergen, and tries to pass to the north of it.-Repulsed.-Returns by the west side of the Island.Proceeds again towards Greenland. - Imminent peril. Finding no passage, returns, by Cherie Island, to England

\section{CHAP'TER III.}

Hudson's second voyage.-Jonas Poole's first voyage. - Jonas Poole's second voyage.-Poole's third voyage. - Baffin's first voyage. - Baffin's second voyage with Fotherby.-Baffin and Fotherby again.-Suspension of Arctic research.-Voyages resumed.-Wood and Flawes. -Russian enterprise under Tschitschagoff . . 272

\section{CHAPTER IV.}

The British Government equips an expedition, under the command of the Hon. Capt. Phipps, R.N.-Racehorse and Carcass appointed to this service.-Departure.-Spitzbergen.-Barrier of ice.-Fair Haven.-Seven Islands.Ships beset and abandoned. - Crew take to the boats. Ice opens.-They regain their ships.-Effect an escape. 
-Put into port.-The Pendulum set up.-Return of the expedition to England . . . . . . 298

\section{PART III.}

\section{APPENDIX.}

I. Abstract of Experiments made at Spitzbergen . 333

II. Temperature of the Sea $\quad$. $\quad$ - $\quad 339$

III. Currents of the Ocean . . . . . 341

A Letter from Captain Sabine, R.A., on the measurement of an arc of the meridian at Spitzbergen . 344 


\section{ILLUSTRATIONS.}

Situation of H.M. Brig Trent, June 7, 1818, Frontispiece Magdalena Bay . • . . T To face page 45 Woodcut of Walruses . . . . . 55 Red Bay, ships beset off $\quad$. . . . . 68 Trent's Boat attacked by Walruses . . . . 94 H.M.S. Dorothea running into the Ice in a gale. . 124

\section{ERRATA.}

Page 11 line 6, for westward read eastward.

\# 23 , 7, $1793 \quad$ " 1773.

\section{DIRECTIONS TO BINDER.}

The Chart to be put loose in a pocket in the cover at the beginning, with a piece of ribbon to pull it out. 


\section{A VOYAGE}

To

\section{THE NORTH P OLE.}

\section{INTRODUCTION.}

IN submitting to the public the Voyage of Captain Buchan towards the North Pole, I am aware that much of the interest which attached to that expedition has now subsided; and I should not have given it my attention at this late period, had it not been from a sense of duty which, as one of the individuals employed upon the service in question, I owe to the public, who naturally expect from the officers engaged in any national undertaking some account of the manner in which that service has been performed.

It further appears to me incumbent upon the officers engaged in this expedition to take care that this voyage, which was conducted with great 
zeal and perseverance, and attended with a result, if not successful, at least honourable to the nation, should be handed down to posterity with the records of others of a similar kind; and that we ought to avoid the imputation which Hakluyt has deservedly cast upon some of our early writers, who, he says, "should have used more care in preserving the memoires of the worthy actes of our nation."*

Moreover, the public will naturally feel a desire to have the series of Northern Voyages complete. These voyages, which have redounded to the nation's honour, and which are now, unhappily, discontinued, have all, at various times, been published, with the exception of the one now presented to the public; of which no authentic account has ever appeared, beyond a few remarks which I offered in explanation of a panorama of the Polar ice, taken from views which $I$ presented to Mr. Barker, on the return of the expedition in 1818.

It is much to be regretted that Captain Buchan, on his return, should have abstained from publishing his own journal, from a feeling that the matter it contained was not of sufficient interest to engage the attention of the general reader, as the importance of the narra-

* Hakluyt's Voyages, vol. iii. p. 129. 
tive must be inevitably weakened by its having fallen into less experienced hands, and as it is always desirable, moreover, to have from the commander of an expedition a personal statement of the motives which actuated his conduct. I regret also, that my immediate commander, Sir John Franklin, has not had leisure to attend to the publication of a voyage in which he bore so conspicuous a part.

In the following narrative I have endeavoured to make up for the loss occasioned by the omission of Captain Buchan, by scrupulously preserving his opinions upon every point of difficulty which occurred, and by giving his sentiments on every important event; and I was happy to find, after submitting the sheets to his inspection, that their return was accompanied with this observation:- that "all the most prominent features of the expedition were brought forward in perfect accordance with his views."* His letter also contained this gratifying assurance, which it is due to my companions upon that expedition to give in the words of their late commander, viz.:- that " $\mathrm{my}$ only regret in not having published the proceedings of our attempt to reach the Pole, is the privation of making the public acquainted with my entire

* Captain Buchan's letter, dated August 1, 1834. 
approbation of the conduct of the officers and seamen I had the honour to command."*

The narrative, however, although thus far approved by Captain Buchan, is taken from my own private journal; and I hold myself responsible for whatever faults may be found in the course of its pages.

Before I had finished this narrative, it was suggested to me that it would receive additional interest if a sketch of the several voyages which had already been performed in the same direction were appended, in order that the public might be made acquainted with the origin and progress of Northern Discovery without having to wade through ponderous folio volumes, or make a selection from the "Voyages of a mixed character."

To such as have not perused these voyages, I trust they will be of use in assisting their judgment as to the merits of the one now placed before them; and those persons who recognise them as old friends will find them accompanied by remarks which modern surveys have- suggested, and by corrections of some mistakes which appear to have been made in modern compilations. But it must be borne in mind, that it is not intended to give more than a brief

* Captain Buchan's letter, dated August 1, 1834. 
outline of these voyages, which have been detailed by one of our ablest authors in the "Chronological History of Voyages to the North and North-west ;" and it must be further understood, that these voyages are strictly confined to such as have been made towards Spitzbergen and Nova Zembla. 


\section{INSTRUCTIONS}

by the Commissioners for executing the Office of LoRd High Admiral of the United Kingdom of Great Britain and Irfland, \&c.

His Royal Highness the Prince Regent having signified his pleasure to Viscount Melville that an attempt should be made to discover a northern passage, by sea, from the Atlantic to the Pacific Ocean; We have, in consequence thereof, caused four ships or vessels to be fitted out and appropriated for that purpose, two of which, the Isabella and Alexander, are intended to proceed together by the north-westward, and through Davis' Straits; and two, the Dorothea and Trent, in a direction as due north as may be practicable through the Spitzbergen sea. .

And whereas, we have thought fit to entrust you with the command and direction of the latter expedition, and have directed Lieutenant Franklin, who has been appointed to command the Trent, to follow your orders for his further pro- 
ceedings; You are hereby required and directed to proceed to sea, with all convenient despatch, in the Dorothea: and, taking under your orders the Trent above-mentioned, make the best of your way into the Spitzbergen Seas, through which you will endeavour to pass to the northward, between Spitzbergen and Greenland, without stopping on either of their coasts.

In this passage you may expect to meet with frequent obstruction from fields and islands of ice, to get clear of which, and to ensure the safety of the ships and people committed to your charge, will require from you and all who are under your orders the greatest precaution and vigilance. And, as the navigation among ice may be considered as an art to be acquired only by practice, we have directed that there be appointed to each of the ships under your orders a master and a mate of whale-fishing vessels, well experienced in those seas, from whose knowledge and skill you may derive considerable assistance.

As, with the imperfect knowledge we have of the sea beyond Spitzbergen, no specific instructions can be given for your guidance, the time and manner of proceeding to fulfil the ulterior object of your destination, in places where impediments may occur, must be left en- 
tirely to your discretion; in the exercise of which we rely upon your zeal and skill in your profession for the accomplishment, as far as it can be accomplished, of the service on which you are employed, not doubting that every exertion will be made on your part and on that of your officers; while, at the same time, no precaution will be omitted that prudence may dictate to avoid accidents on an enterprise of so arduous a nature as that of conducting ships in safety through fields of ice in unknown seas. It may not, however, be amiss to suggest, as a general observation, that a passage through fields of ice is most likely to be found where the sea is deepest and least connected with land, as there is reason to suppose that ice is found to be more abundant near the shores of the continent and islands, in narrow straits and deep bays; and it may also be expected, that the sea will be most clear of ice where the currents are strongest, as the stream of a river will continue open long after the sides are frozen up.

From the best information we have been able to obtain, it would appear that the sea to the northward of Spitzbergen, as far as $83 \frac{1}{2}^{\circ}$, or $84^{\circ}$, has been found generally free from ice, and not shut up by land. Should these accounts, in which several masters of whaling-vessels 
concur, turn out to be correct, there is reason to expect that the sea may continue open still more to the northward, and in this event you will steer due north, and use your best endeavours to reach the North Pole.

In making this attempt you will be most particularly attentive to ascertain the rate of your chronometers, as, should you reach the Pole, your future course must mainly depend upon the accuracy with which you may be able to carry with you the time at Greenwich. If you should be so fortunate as to reaclr the Pole, and the weather should prove favourable, you are to remain in its vicinity for a few days, in order to the more accurately making the observations which it is to be expected your interesting and unexampled situation may furnish you with.

Among many objects of science or curiosity which are likely to present themselves at or near this point of the earth's surface, you will more particularly direct your attention to the variation and inclination of the magnetic needle, and the intensity of the magnetic force, and how far it is affected by the atmospherical electricity; for which latter purpose you will be furnished with an electrical apparatus peculiarly constructed for this object. 
You will also endeavour to ascertain the set and velocity of any currents which you may observe, and if possible the depth of the sea and the nature of the bottom, and you are to take up several bottles of sea water from the surface, and from different depths, which you will carefully cork up and label.

On leaving the Pole you will endeavour to shape a course direct for Behring's Straits; but should you find that course so much obstructed, either by land or ice, as to prevent your progress, you are to return to the south-westward and endeavour to pass between Greenland and the east coast of America, into the sea called Baffin's Bay, for the northern limits of which, as it appears in the charts, there is little or no authority, and thence by Davis' Strait to England.

Should you find it impossible to approach the Pole, but that you should be able to proceed in a direction affording any prospect of reaching Behring's Strait, you are to adopt it, recollecting that, although it is highly desirable, with a view to the interests of science, and the extension of natural knowledge, that you should reach the Pole, yet that the passage between the Atlantic and Pacific is the main object of your mission; and with this view, if you should 
find the course west of Spitzbergen obstructed to such a degree, as, after reasonable trial, to afford no chance of a passage, you are to return, and endeavour, if too much of the season shall not have elapsed, to make your way to the southward and westward of Spitzbergen. In this case, too, you will endeavour, in the first place, to pass due north over or near the Pole, and only when that attempt shall be hopeless, take such a lateral course as circumstances may open to you.

You will take all possible precaution against being obliged to winter in those seas, particularly in those north of Spitzbergen, concerning which we are in a state of entire ignorance.

Should you, either by passing over or near the Pole, or by any lateral direction, make your way to Behring's Strait, you are to endeavour to pass into the Pacific Ocean; and, in the event of your succeeding to pass this strait, you are then to make the best of your way to Kamschatka, if you think you can do so without risk of being shut up by the ice on that coast, for the purpose of delivering to the Russian Governor duplicates of all the journals and other documents which the passage may have supplied; with a request that they may be forwarded overland to St. Petersburgh to be con- 
veyed to London; and from thence you will proceed to the Sandwich Islands, or New Albion, or such other place in the Pacific Ocean as you may think proper, to refit and refresh your crews; and, if during your stay at such place a safe opportunity should occur of sending these papers to England, you should send duplicates by that conveyance.

If the circumstances of your passage should be such as to encourage your attempting to return by the same course, you may winter at the Sandwich Islands, New Albion, or any other proper place, and early in next spring may proceed direct for Behring's Strait, and use your endeavours to repass the same; and, should you succeed in this attempt, you are to proceed, if possible, to the eastward, keeping in sight and approaching the coast of America whenever the position of the ice will permit you so to do, in order that you may be enabled to ascertain the latitudes and longitudes of some of the most remarkable headlands or inlets that may occur, taking every possible precaution, however, against being beset by the ice, and thus being compelled to winter on that coast.

Before, however, you determine on returning by the same way, you will maturely consider 
and weigh the prudence of making such an attempt. If your original passage should be made with facility, and you see reason to believe that your success was not owing to circumstances merely accidental or temporary, and that there is a probability that you may be able, also, to accomplish the passage back, it would be undoubtedly of great importance that you should endeavour to make it; but if, on the other hand, it shall have been attended with circumstances of danger or difficulty, so great as to persuade you that the attempt to return would risk the safety of the ships and the lives of the crews, you, in this case, are to abandon all thoughts of returning by the northern passage, and are to make the best of your way homeward by Cape Horn.

Previous to your leaving England, or, at any rate, before your departure from Shetland, you are to fix with Captain Ross, to whom the other expedition is entrusted, upon a rendezvous in the Pacific; and, if you should join that officer, you are to put yourself under his orders; but if you should be joined by the Alexander alone, or if Captain Ross should not be in command, you are to take the ship or ships under your orders, and, having detached one ship, with a copy of all your papers, and a complete set of 
despatches, reporting your proceedings, to England, by the route of Cape Horn, you are to proceed with the other ships to re-pass Behring's Strait, as above directed, if you should have determined on that course; but, if you should have resolved to return by the south, you are to take care to interchange with the lieutenant commanding the other vessels copies of your respective journals and despatches; or, if you do not meet Captain Ross, or his ships, you are to deposit copies of your own papers on board the Trent, in order to ensure as far as possible the arrival of these important documents in England by thus multiplying the modes of conveyance.

If, however, either on the passage out, or on the return, it should so happen that, from obstruction of ice, or any other circumstance, your progress should be so slow as to oblige you to winter in those parts, you are in that case to approach the most convenient land, and endeavour to find out some secure bay in which the ships may be laid up for the winter; taking such measures for the health and comfort of the people committed to your charge as the materials with which you are supplied for housing-in the ships, or hutting the men on shore, may enable you to do. And, if you 
shall find it expedient to resort to this measure, and you should meet with any inhabitants, either Esquimaux or Indians, near the place where you winter, you are to endeavour, by every means in your power, to cultivate a friendship with them, by making them presents of such articles as you may be supplied with, and which may be useful or agreeable to them; you will, however, take care not to suffer yourself to be surprised by them, but use every precaution, and be constantly on your guard against any hostility.

You will endeavour to prevail on them by such reward, and to be paid in such manner, as you may think best to answer the purpose, to earry to any of the settlements of the Hudson's Bay Company, or of the North-West Company, (should you winter near the coast of America,) or to any of the Russian settlements of Siberia, (should you winter on the coast of Asia,) an account of your situation and proceedings, with an urgent request, that it may be forwarded to England with the utmost possible despatch.

But you are to recollect, in your first attempt to proceed to the northward, that you are to take care not, on any account, unless accidentally caught in the ice, to remain to 
winter on any part of the coast of Greenland, Spitzbergen, Nova Zembla, or the adjacent coasts, but to leave the ice about the middle, or 20 th of September, or the 1st of October at the latest, and make the best of your way to the river Thames.

Although the first and most important object of this royage, is the discovery of a passage over, or as near the Pole as may be, and through Behring's Strait, into the Pacific, it is hoped that it may, at the same time, be likewise the means of improving the Geography and Hydrography of the Arctic regions, of which so little is hitherto known, and contribute to the advancement of science and natural knowledge.

With this view, we have caused a great variety of valuable instruments to be put on board the ships under your orders, of which you will be furnished with a list, and for the return of which you will be held responsible; and have also, at the recommendation of the President and Council of the Royal Society, ordered to be received on board the Dorothea, Mr. Fisher, who is represented to us as a gentleman well skilled in Astronomy, Natural History, and various branches of knowledge, to assist you in making such observations as may 
tend to the improvement of Geography and Navigation, and the advancement of science in general. In addition to those objects of prominent interest which may be expected to present themselves at the Pole, should you be so fortunate as to reach that point, and which you are also to attend to on every part of your voyage, you are likewise to keep a correct register of the temperature of the air, in various situations, and at different depths; you will cause the dip of the horizon to be frequently observed by the dip sector, invented by Doctor Wollaston, and ascertain what effect may be produced by measuring that dip across fields of ice, as compared with its measurement across the surface of the open sea; you will also cause frequent observations to be made for ascertaining the refraction, and what effect may be produced by observing an object, either celestial or terrestrial, over a field of ice, as compared with objects observed over a surface of water; together with such other meteorological remarks as you may have opportunities of making. You are to attend particularly to the height, direction, and strength of the tides, and to the set and velocity of the currents; the -depths and soundings of the sea, and the nature of the bottom; for which purpose you are 
supplied with an instrument better calculated to bring up substances than the lead usually employed for this purpose.

For the purpose, not only of ascertaining the set of the currents in the Arctic Seas, but also of affording more frequent chances of hearing of your progress, we desire that you do frequently, after you shall have passed the latitude of $75^{\circ}$ north, and once every day, when you shall be in an ascertained current, throw overboard a bottle, closely sealed, and containing a paper stating the date and position at which it is launched; and you will give similar orderis to the commander of the Trent, to be executed in case of separation; and, for this purpose, we have caused each ship to be supplied with papers on which is printed, in several languages, a request that whoever may find it should take measures for transmitting it to this office.

And, although you are not to be drawn aside from the main object of the service on which you are employed, so long as you may be enabled to make any progress, yet, whenever you may be impeded by ice, or find it necessary to approach the coasts of the continent, or islands, you are to cause views of bays, harbours, headlands, \&c., to be carefully taken, to illustrate and explain the track of the vessels, or such charts 
as you may be able to make; on which duty you will be assisted by Lieutenant Beechey, whose skill in drawing is represented to be so considerable, as to supersede the necessity of appointing a professional draughtsman.

You are to make use of every means in your power to collect and preserve such specimens of the animal, mineral, and vegetable kingdoms as you can conveniently stow on board the ships; and of the larger animals you are to cause accurate drawings to be made, to accompany and elucidate the descriptions of them. In this, as well as in every other part of your scientific duty, we trust that you will receive material assistance from Mr. Fisher.

You are to use your best endeavours, and give instructions to the same effect to Lieutenant Franklin, to keep the two vessels constantly together, and prevent their separation: if, however, they should separate you are to appoint Lerwick, in the Shetland Islands, as the first rendezvous; and, after that, Magdalena Bay, in Spitzbergen, beyond which, as nothing is known, no other rendezvous can be appointed; and, in the event of any irreparable accident happening to either of the ships, you are to cause the officers and crew of the disabled ship to be removed into the other, and with her singly to proceed 
in prosecution of the voyage, or return to England according as circumstances shall appear to require. Should, unfortunately, your own ship be the one disabled, you are, in that case, to take the command of the Trent; and, in the event of your own inability, by sickness or otherwise, to carry these instructions into execution, you are to transfer them to the Lieutenant next in command, who is hereby required to execute them in the best manner he can for the attainment of the several objects in view.

As in all undertakings of this nature several emergences may arise, against which no foresight can provide, and no specific instructions can be given, you are, in all such cases, to proceed in such a manner as you may judge to be most advantageous to the service on. which you are employed, most likely to advance the accomplishment of the various objects of the expedition, and most conducive to the security of the ships, and the health, comfort, and safety, of your officers and men.

On your arrival in England, you are immediately to repair to this office, in order to lay before us a full account of your proceedings in the whole course of your voyage; taking care, before you leave the ship, to demand from the officers, and petty officers, the logs and journals 
they may have kept; and also from Mr. Fisher such journals, or memoranda, as he may have kept, which are all to be sealed up; and you will issue similar directions to Lieutenant Franklin and his officers; the said logs, journals, or other documents, to be thereafter disposed of as we may think proper to determine.

His Majesty's principal Secretary of State for Foreign Affairs has been requested to apply to the Courts of Russia, Denmark, and Sweden, to issue orders to their respective subjects to afford any hospitality or assistance which these expeditions may be in a situation to require and receive; the Court of Russia has been particularly requested to give directions to the authorities at Kamtschatka, for the safe conveyance of any despatches you may entrust to them, and the Courts of Denmark and Sweden have been requested to order any of their ships, whether national or private, which you may fall in with, to treat you with amity, and to note carefully in their logs the situations in which they may see any of His Majesty's ships. You will, on your part, behave with cordiality and friendship to any foreign vessels you may fall in with, or the authorities of any port, or place, at which you may touch; and on all such occasions you will not fail to address to our Secre- 
tary, for our information, a general account of your proceedings up to the date at which the opportunity of conveying your despatch may occur.

Given under our hand, this 31st March, 1818, signed Melville.

J. S. YoRKE.

Geo. Hope.

G. Moore.

To David Buchan, Esq.,

Commander of H. M. Sloop Dorothea.

By command of their lordships,

J. W. Croker. 


\section{CHAPTER I.}

Expedition determined upon.-Its objects. - Instructions.Equipment. - Departure. - Visit Shetland.-A leak discovered. - Cherie Island. - Packed Ice.-Spitzbergen.Magdalena Bay.-Glaciers.

THE unsuccessful termination of the expedition which had been sent out in 1793, under the Hon. Captain Phipps, and the decided opinion given by that officer of the impracticability of the undertaking, set at rest for a time the question of a north-west passage, and the general war in which England soon after became involved opened a new field for exertion. The spirit of discovery, however, only slumbered whilst the energies of the country were necessarily devoted to more important objects; for no sooner had the allied powers secured to Europe a general peace, than northern discovery was resumed, and prosecuted with an ardour worthy of a great maritime nation.

At this period, when the whole world was at peace, it was thought that the question of a north-west passage to the Pacific, which had 
engaged the attention of almost all the northern powers of Europe; in which much money had been ventured; many lives and vessels lost, and on which the public curiosity had been so much awakened, that this important and interesting question ought now, for once and for ever, to be set at rest.

Upon a review of all that had been hitherto accomplished, or attempted, it was evident to almost all the world that the great obstacle to a navigable passage was the quantity of ice with which the northern seas were encumbered; for no land had been hitherto discovered between Nova Zembla and Spitzbergen, or between the last-mentioned place and Greenland. Both Hudson's and Baffin's Bays had several openings which, if free from ice, might lead to the westward; and Behring's Strait had been found impassable only on account of the quantity of ice lying to the rorthward of it.

Any alteration either in the position or the compactness of this ice, was, of course, a proper ground for expectation to rest upon; and, without in any way undervaluing the efforts of those worthy men whose voyages will be found recorded toward the end of this volume, it was not unreasonable to suppose that many obstacles, insurmountable to them in ressels so ill-con- 
ditioned, and with crews so inadequate to the undertaking, might be overcome by powerful ships properly manned and equipped. And, as there was also an opinion that this body of ice was merely a belt, which, if it could be broken through, the sea beyond would be found clear and navigable, vessels of the last-mentioned description were more likely to reach it than any that had hitherto made the attempt, with the exception of those under Captain Phipps, which were thought to have gone out in a peculiarly unfavourable season.

At all events, whatever arguments might have been founded upon the subject, and there were many, it was generally acknowledged that the time had arrived when the matter should be decided, or, at least, that the attempt should receive the benefit of that advancement of science and art which had been bestowed upon other experiments, and it was evident that it required only some little impetus to set the machine in motion for this attempt to become a great national undertaking.

It most opportunely occurred in the year 1817, that accounts of a change in the Polar ice, particularly favourable to the undertaking, were brought to England by our whale ships; and, as it has generally happened in this country that 
some individual, more sanguine than the rest of the community, has, by his superior knowledge, greater exertions, or more constant perseverance, succeeded in bringing a project to bear which, in less vigorous or pertinacious hands, would have been suffered to die away, this favourable change was turned to so good an account by an influential member of the government, and whose name is inseparable from northern discovery, that, in the following year, His Majesty George the Fourth, then Prince Regent, was pleased to command that attempts should be made to reach the Pacific, both by the western route through Baffin's Bay, and by a northern course across the Pole.

Four vessels were accordingly prepared for this service, two of which, the Isabella and Alexander, under the command of Captain Ross, and Lieutenant Parry, were to sail upon the former voyage, and the other two, whose proceedings form the subject of the following narrative, were to pursue the more novel course last mentioned.

On the 15th January, 1818, Captain David Buchan, R.N., who had, a short time previously, distinguished himself in charge of an expedition into the interior of Newfoundland, was appointed to the command of the Polar expedition, 
and hoisted his pendant on board the Dorothea, a ship of 370 tons' burthen; and Lieutenant John Franklin, whose name has since attained so high a rank in the annals of Northern Discovery, was placed under his orders in command of the Trent, a brig of 250 tons. Both these vessels were hired into the service for the occasion, and were taken into a dock at Shadwell, where they were literally rendered as strong as wood and iron could make them, consistently with the necessity of preserving sufficient room for the stowage of provision.

The expedition, besides having for its object the determination of a geographical question of importance, was also of a scientific nature: and, being the only one of that description that had been fitted out by England for many years, a variety of suggestions and inventions, likely to prove useful on a service of such novelty, were submitted to the Admiralty and other departments of the Government. The peculiarity of the proposed route afforded opportunities of making some useful experiments upon the elliptical figure of the earth; on magnetic phenomena; on the refraction of the atmosphere in high latitudes, under ordinary circumstances, and over extensive masses of ice; on the temperature and specific gravity of the sea at the surface, 
and at various depths; and on meteorological and other interesting phenomena; to all of which Captain Buchan was directed to pay particular attention; and, that this branch of his duty might be the more effectually performed, Mr. George Fisher was appointed to assist him, in the capacity of astronomer to the expedition.

It could hardly be supposed that any of the officers engaged in this service were, at the outset, much acquainted with the navigation of an icy sea; and, to render the expedition more complete in this particular, a Greenland master and mate, of great experience, were appointed to each vessel.

The total complement of each of these vessels was as follows :-

Dorothea, 55 Men.

Captain David Buchan.

Lieutenant Arthur Morell.

Surgeon. John Duke.

Purser. John Jermain.

Astronomer. George Fisher.

Admiralty Mates. Charles Palmer. William J. Dealy Assistant Surgeon. William G. Borland.

Clerk. Cyrus Wakeham.

Greenland Master. Peter Bruce.

Mate. George Crawford.

Carpenter. Thomas Hebrow.

43 Seamen and Marines. 
Trent, 38 Men.

Lieutenant and Commander John Franklin.

Lieutenant Frederick W. Beechey.

Purser. William Barrett.

Admiralty Mates. Andrew Reid. George Back.

Assistant Surgeon. Alexander Gilfillan.

Clerk. William Cotsell.

Greenland Master. George Fife.

Mate. George Kirby.

Carpenter. James Bowden.

28 Seamen and Marines.

Two years' provisions, and numerous stores, in addition to those usually supplied to men of war, were embarked in each ship, and the expedition being complete in its equipment, and having dropped down to Galleon's Reach, Captain Buchan received his instructions, which are so ably drawn up to meet every contingency, and so additionally interesting as furnishing an insight into the opinions, at that time, entertained by Government regarding the long-sought northwest passage to the Pacific, that I have been induced to insert them at full length, notwithstanding they have, for the most part, been published in Captain Ross's account of his voyage to Baffin's Bay.

On the 25th April the expedition proceeded down the river, and arrived at Lerwick, in the Shetland Islands, on the 1st May. 
We were hardly clear of the river before we had the mortification to find, that a leak in the Trent, which had scarcely shown itself before, now increased to such a degree, as to become an object of serious moment. Considering the manner in which the hull of the vessel had been lined and fortified, it was as much a matter of surprise, as of regret, to all on board; and it was determined to take the first opportunity of ascertaining the cause of so serious an evil. The Port of Lerwick, to which we were then on our way, soon afforded us the means of doing this; and, immediately after our arrival there, the brig was placed on shore at high water and subjected to a thorough examination.

Some rents in the planks, in various parts of the vessel, were found to be open and caulked, but the leak still continued, and baffled all our efforts to discover its immediate cause.

Fortunately, it was not of such magnitude as to endanger the safety of the brig, or the expedition must have suffered considerable detention, still it was of sufficient importance to keep the seamen employed nearly half their watch at the pumpan evil of itself, it must be admitted, sufficiently great under any circumstances, and one which, in our case in particular, was likely to be increased; and when it was further considered that 
numerous instances would probably occur in which the services of the crew could very ill be spared for this extra duty, it did appear to all on board to be a most unfortunate occurrence, and it cannot be denied that, to the seamen especially, it in some degree diminished the pleasure with which we contemplated our future proceedings.

The inhabitants of Lerwick, however, took a still more serious view of the case, and considered the service in which we were engaged sufficiently hazardous in itself, without incurring further risk, by commencing the performance of it in a leaky vessel; and there is no doubt that this conviction, in a great measure, influenced some of their community who had been bred to the sea, and who would otherwise, probably, have accompanied us, for we were short of complement; as many of these people were in the habit of making voyages in our whale ships, where their services have always been considered valuable, especially in boats.

On the 10th May, having completed the business for which we put into Lerwick, we sailed out by the Western Channel; and, when clear of the land, had the good fortune to meet with a fair wind, with which we pursued our course towards the island of Spitzbergen; and crossed the arctic circle on the 14th. 
In a voyage over a portion of the globe so entirely new to us, and so totally different in its natural phenomena from those to which we had been accustomed, either in our own country, or in parts of the earth nearer the equator, we experienced much to interest us at almost every step of our proceedings; but nothing made so deep an impression upon our senses as the change from alternate day and night to which we had been habituated from our infancy, to the continual daylight to which we were subjected as soon as we crossed the arctic circle. Where the ground is but little trodden, even trifles are interesting; and I do not, therefore, hesitate to describe the feelings with which we regarded this change. The novelty, it must be admitted, was very agreeable, and the advantage of constant daylight, in an unexplored and naturally boisterous sea, was too great to allow us even to wish for a return of the alternations above alluded to ; but the reluctance we felt to quit the deck, when the sun was shining bright upon our sails, and to retire to our cabins to sleep, often deprived us of many hours of necessary rest; and when we returned to the deck to keep our nightwatch, if it may be so called, and still found the sun gilding the sky, it seemed as if the day would never finish. 
What, therefore, at first promised to be so gratifying, soon threatened to become extremely irksome, and would, indeed, have been a serious inconvenience, had we not followed the example of the feathery tribe, which we daily observed winging their way to roost, with a clock-work regularity, and retired to our cabin at the proper hour, where, shutting out the rays of the sun, we obtained that repose which the exercise of our duties required.

At first sight it will, no doubt, appear to many persons that constant daylight must be a valuable acquisition in every country; but a little reflection will, I think, be sufficient to show that the reverse is really the case; and to satisfy a thinking mind, that we cannot overrate the blessings we derive from the wholesome alternation of labour and rest, which is, in a manner, forced upon us by the succession of day and night. It is impossible by removing to a high latitude, not to witness the difficulty there is in the regulation of time; the proneness that is felt by the indefatigable and zealous to rivet themselves to their occupations, and by the indolent and procrastinating to postpone their duties, without being truly thankful for that allwise and merciful provision, with which Nature has endowed the more habitable portions of the globe. 
On the 18th the expedition reached the parrallel of $72^{\circ} 36^{\prime} \mathrm{N}$.; up to this period the weather had been so moderate that we had not so much as reefed a topsail; but the aspect of the sky now became changed, sail after sail was gradually reduced as the breeze freshened, until storm staysails only were presented to the increasing gale, and the ships were burying their gunwales deep in the wave.

The mild weather, which had thus far attended the wind from the southward, gradually yielded to a cold current from the north, which cased our sails and cordage with ice, and covered our decks with snow.

Even here we found amusement in examining the curiously-formed flakes that fell, which were different from any we had been accustomed to see, and of which we collected more than twenty varieties. They were crystallised nearly as hard as hail-stones, and were formed into flakes of from four to twelve or more rays; and into other regular figures, some of which were of the most delicate and beautiful texture. Mr. Scoresby, in his voyage to Greenland, has given representations of ninety-six varieties of these curious formations.

A contrary wind obliged us to stand to the eastward until the 24th, when we saw Cherie 
Island deeply buried in snow; and shortly after observed an extensive accumulation of ice connected with its northern extremity, sweeping round the horizon in the direction of Spitzbergen, in so compact a body as to preclude the possibility of passing between the two islands, had such a measure been required.

Cherie Island is a small uninhabited spot of land, situated in latitude $74^{\circ} 33^{\prime}$ N., and longitude $17^{\circ} 44^{\prime}$ E., nearly midway between Spitzbergen and Norway. Its earliest discovery is said to be due to William Barentz, who landed upon it in 1596, and gave it the name of Bear Island; but a passage in Purchas seems to imply that it had been known before Barentz made this voyage; it was afterwards called Cherie Island by Stephen Bennet, who undertook a voyage to the Arctic Seas, in 1603, and named the island after Sir Francis Cherie; and who, in allusion to the desolate appearance of the island, and the miserable condition in which himself and a boat's crew were there placed, named one of the hills Mount Misery.

At the time of its discovery the walruses were so numerous upon its shores that, after the return of Bennet, the Muscovy Company, hoping to derive a lucrative trade from their capture, for several years fitted out vessels for this pur- 
pose; and, we are told, that these adventurers were so successful in their occupation, that not less than nine hundred, or a thousand, animals were captured, in the short space of seven hours, by the crew of a single vessel.

In the course of time, as might be expected, this indiscriminate slaughter frightened away the survivors, and the island soon becoming deserted, the benefit of the trade was lost.

This circumstance, however, proved the forerunner of a source of far greater profit to individuals, and, ultimately, of material benefit to our country at large; and is one of those striking instances which sometimes occur, but which are often suffered to pass unheeded where important results arise from circumstances of the most trivial nature. As Cherie Island was, at this time, the only source whence England derived her supply of oil, the failure above-mentioned induced the merchants to seek that material elsewhere, and hence originated the English whale-fishery, once one of the most important branches of our commerce, and the most approved nursery for our seamen. Purchas, adverting to this event, says, "Now the often using of Cherie Island did make the sea-horse grow scarce and decay, which made the companie look out for further discoveries," *

* Purchas, p. 464, folio. 
and adds, that "In the year 1611 the companie set forth two ships for Greenland, \&c., this was the first year the companie set out for the killing of whales in Greenland; and, about the 12th of June, the Biskayners killed a small whale which yielded twelve tunnes of oyle, being the first oyle that ever was made in Greenland."* But to return to our own proceedings.

Having no object in approaching Cherie Island closely, we took advantage of an easterly wind, and stood toward the south cape of Spitzbergen; in doing which it became necessary to pass through a wide belt of loose ice that had been disengaged from the main body. To such of our crew as had not before visited the Arctic regions the scene that now presented itself was novel and interesting, and the huge masses of ice as they floated in succession past the vessels, were regarded with peculiar attention; partly on account of their grotesque shapes, but principally as they might assist us in forming our judgment of the-nature of the barrier which we anticipated might ultimately present itself to our progress.

The streams through which our course lay consisted of small floes and pieces of ice, sufficiently detached in general to admit of a

* Purchas, p. 455. 
vessel steering between them, but, nevertheless, occasionally interposing material obstruction to our passage.

The progress of a vessel through such a labyrinth of frozen masses is one of the most interesting sights that offer in the Arctic seas, and being at this time wholly new to us, many, even of those persons not naturally curious, were kept out of their beds until a late hour to partake of the enjoyment of the scene.

There was, besides, on this occasion an additional motive for remaining up: very few of us had ever seen the sun at midnight, and this night happening to be particularly clear, his broad red disc, curiously distorted by refraction, and sweeping majestically along the northern horizon, was an object of imposing grandeur, which riveted to the deck some of our crew who would, perhaps, have beheld with indifference the less imposing effect of the icebergs. Or it might have been a combination of both these phenomena; for it cannot be denied that the novelty, occasioned by the floating masses, was materially heightened by the singular effect produced by the very low altitude at which the sun cast his fiery beams over the icy surface of the sea. The rays were too oblique to illuminate more than the inequalities of the floes, and falling 
thus partially on the grotesque shapes, either really assumed by the ice, or distorted by the unequal refraction of the atmosphere, so betrayed the imagination that it required no great exertion of fancy to trace, in various directions, architectural edifices, grottos, and caves here and there glittering as if with precious metals. So generally, indeed, was the deception admitted, that, in directing the route of the vessel from aloft, we for a while deviated from our nautical phraseology, and shaped our course for a church, a tower, a bridge, or some similar structure, instead of for lumps of ice, which were usually designated by less elegant appellations. Our attention was, however, soon called from the contemplation of this engaging scene of novelty and illusion to matter of more immediate importance and reality, arising from the increasing diffculty of our situation.

The streams of ice, between which we at first pursued our serpentine course with comparative ease, gradually became more narrow, and, at length, so impeded the navigation, that it became necessary to run the ships against some of these imaginary edifices in order to turn them aside. Even this did not always succeed, as some were so substantial and immoveable, that the vessels glanced off to the 
opposite bank of the channel, and there became for a time embedded in the ice. Thus circumstanced, a vessel has no other resource than that of patiently awaiting the change of position in the ice, of which she must take every advantage, or she will settle bodily to leeward and become completely entangled. We fortunately overcame these little difficulties, and, though occasionally threatened with a detention, finally succeeded in accomplishing a passage through the stream, and in reaching the open sea by six o'clock the following morning.

This little encounter was not without its salutary effect. It taught those who had been accustomed to the routine of an ordinary navigation, to repel that impatience of delay which so much pervades a maritime life, especially in vessels of war; and it was further useful as an initiation into the manner of navigating a sea encumbered with floating ice.

On the 26th, we came within sight of the southern promontory of Spitzbergen, and, as we ranged along the land to the northward, the dark pointed summits of the mountains, which characterise the island, rose majestically above beds of snow, giving a bleak and dreary aspect to the coast.

As Captain Buchan's instructions directed him 
to make the attempt to reach a high northern latitude on the western side of Spitzbergen first, we plied to windward along that part of the coast until the $28 \mathrm{th}$, when we were overtaken by a violent gale at south-west, in which the ships parted company. At the commencement of this tempestuous weather, we ran before the gale; but, towards evening, many heavy pieces of ice, which we occasionally found it difficult to avoid, led us to conjecture that the pack was not far distant, and that our course could not be continued without danger; we consequently rounded-to until the wind should moderate.

The weather was now very severe; the snow fell in heavy showers, and several tons' weight of ice accumulated about the sides of the brig, and formed a complete casing to the planks, which received an additional layer at each plunge of the vessel. So great, indeed, was the accumulation about the bows, that we were obliged to cut it away repeatedly with axes to relieve the bowsprit from the enormous weight that was attached to it: and the ropes were so thickly covered with ice, thàt it was necessary to beat them with large sticks to keep them in a state of readiness for any evolution that might be rendered necessary, either 
by the appearance of ice to leeward, or by a change of wind.

The following morning the gale abated, and we bore away to the northward in search of the Dorothea; but, at nine in the evening, the weather being foggy, we found ourselves surrounded by ice in latitude $80^{\circ}$ north, and had so much difficulty in extricating the vessel, that it was seven o'clock on the following morning before we regained the open sea. At this time the fog cleared off, and we perceived that the ice in which we had been beset was part of the main body, so that we had indeed reason to congratulate ourselves on the precaution observed by our commander in rounding-to the preceding evening; for, had we encountered this formidable body in thick weather whilst scudding before a gale of wind, there would have been very little chance of saving either the vessel or her crew.

We traced the margin of this body of ice to within a short distance of the land, and then steered for Magdalena Bay, our appointed place of rendezvous, in the hope of meeting the Dorothea. A separation from our consort at this period of the voyage, although of such duration, had to us an unusual degree of interest and anxiety; and it was, therefore, with in- 
creased satisfaction that we rejoined her, even before entering our appointed place of rendezvous. The expedition now stood to the northward, and we shortly saw the main body of ice again, quite compact as before, extending round the northern horizon in one vast unbroken plain, connected so closely with the shore, as to leave no passage whatever for a vessel.

The reader will readily believe that this great mass of ice, which had hitherto prescribed limits to northern discovery, and frustrated every attempt to reach the Pole, was viewed by us with intense curiosity, as the barrier with which it had now become our object and duty to contend in the prosecution of a similar enterprise. We could perceive that it was composed of masses too heavy to be turned aside. by the bows of our vessels, and too thick and too extensive for the saws with which we were provided to be of any practical utility; in short, as regarded the practicability of the passage, it was the same formidable body it had been hitherto represented. At the same time, however, it was not that solid continent of ice described by Phipps, nor was its general appearance so unpromising but that the least sanguine among us might entertain a hope that some lucky opening 
would present itself before long, and enable us to advance a considerable distance beyond the position of the marginal line, which, at that moment, seemed to render our further progress impossible. Some of us, indeed, with that ardour which is often attendant upon inexperience, imagined it might at once be separated floe from floe by a press of canvas; and anxiously looked forward to such an effect being produced, by the changes of the season and other favourable circumstances, which might justify the experiment of dashing amongst it, and putting its irresistibility to the test. It was evident, however, to a practised seaman, that to have entered the pack at that moment would most probably have endangered the safety of the expedition at its very outset; and Captain Buchan, who had had some experience in this matter, very wisely abstained from so rash an enterprise, and reserved his vessels for a more promising occasion.

Convinced that there was no possibility of effecting anything advantageous at this early stage of the season, and desirous of making the most of the short summer before him, Captain Buchan determined upon passing a few days in Magdalena Bay, in order to survey the port and determine its position. We accordingly anchored 


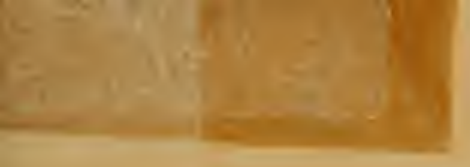

. 


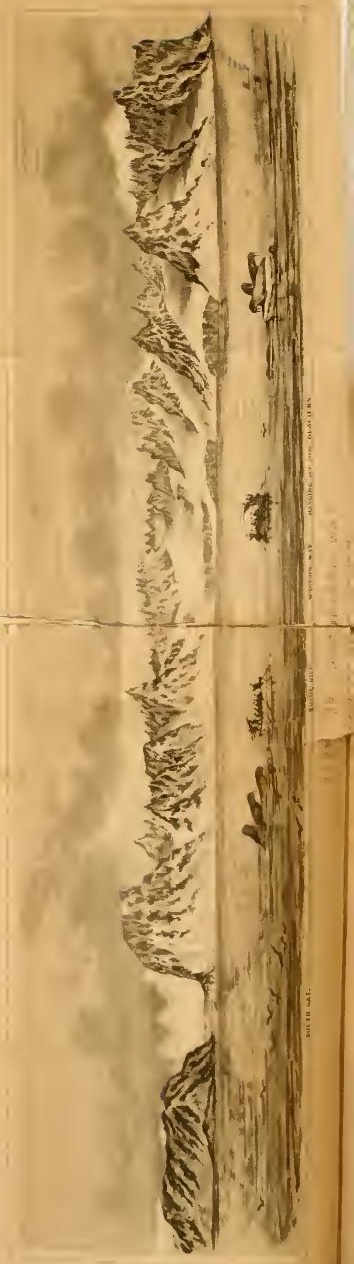


there on the 3rd of June, and immediately commenced these pursuits.

Magdalena Bay is a deep, commodious inlet, on the western side of Spitzbergen, about six miles in length, in an E.S.E. direction, and two miles in width, with a cove at its upper end, in which, when it is clear of ice, ships may undergo a thorough refit with safety.

At the time of our arrival, the ice still occupied the cove and the upper part of the harbour, but it appeared to be decaying rapidly ; and when we re-visited the anchorage in the beginning of August following, it had entirely disappeared.

The bay is rendered conspicuous by four glaciers, of which the most remarkable, though the smallest in size, is situated, two hundred feet above the sea, on the slope of a mountain.*

* The most convenient anchorage in this bay is situated off the S.E. end of the first of these glaciers, the marks for which are the centre of the large glacier at the head of the bay in one with the extremity of the low neck of land called the Burying Ground, and the hanging glacier in a line with and over the S.E. end of the second glacier. Here there are about eleven fathoms' water; and vessels must be cautious not to overshoot this spot, as the buttom is rocky in other places, and the water deepens suddenly, particularly towards the second glacier. In approaching this anchorage, care must also be taken to avoid Shannon Rock, which is just under water, and lies south, a quarter of a mile from a flat rock, which will be seen on the north side of the bay. 
This glacier, from its peculiar appearance, has been appropriately termed the Hanging Iceberg. Its position is such, that it seems as if a very small matter would detach it from the mountain, and precipitate it into the sea. And, indeed, large portions of its front do occasionally break away, and fall with headlong impetuosity upon the beach, to the great hazard of any boat that may chance to be near.

At the head of the bay there is a high pyramidal mountain of granite, termed Rotge Hill, from the myriads of small birds of that namewhich frequent its base, and which appear to prefer its environs to every other part of the harbour. They are so numerous, that we have frequently seen an uninterrupted line of them extending full half way over the bay, or to a distance of more than three miles, and so close together that thirty have fallen at one shot. This living column, on an average, might have been about six yards broad and as many deep; so that, allowing sixteen birds to a cubic yard, there must have been nearly four millions of birds on the wing at one time.

This number appears at first very large; but it will not be thought so by persons who have been accustomed to observe the immense flocks of birds which emigrate to the unfrequented 
parts of the globe. In California, the geese and ducks cover the ground for many square acres so effectually as completely to change its natural colour; and Audubon, speaking of the passenger-pigeon in its visit to the banks of the Ohio, estimated the number of birds upon the wing at one time at one billion, one hundred and fifteen millions, and upwards. The number I have given certainly seems large; yet, when it is told that the little rotges rise in such numbers as completely to darken the air, and that their chorus is distinctly audible at a distance of four miles, the estimate will not be thought to bear any reduction.

As soon as the ships were at anchor measures were taken for the survey of the port, and boats were despatched to all parts of the bay, either on this duty or on shooting excursions. The weather was remarkably fine during the greater part of the time we were at anchor, especially on the anniversary of His Majesty's birthday, which was commemorated by an extra issue of provisions to the ships' companies.

Magdalena Bay was the first port in which we had anchored in the Polar regions, and there were of course many objects to engage our attention. We were particularly struck with the brilliancy of the atmosphere, the peaceful 
novelty of the scene, and the grandeur of the various objects with which Nature has stored these unfrequented regions.

The anchorage is bounded by rugged mountains, which rise precipitously to the height of about three thousand feet. Deep valleys and glens occur between the ranges, the greater part of which are either filled with immense beds of snow, or with glaciers, sloping from the summits of the mountainous margin to the very edge of the sea. Owing to the westerly direction of these ranges, and the precipitancy with which they rise, the sun never shines upon the southern shore of the bay, with the exception of a few hours about midnight during the height of summer, and then only at a very low altitude; whereas its rays are exerted with the fullest effect upon the northern shore, which occasionally radiates a heat of 57 or 60 degrees. There is, consequently, the most marked difference between the sides of the bay, both in point of climate and general appearance; for while, on the one, perpetual frost is converting into ice the streams of water occasioned by the thawing snow upon the upper parts of the mountains which are exposed to the sun's rays, the other side is relieving itself of its superficial winter crust, and refreshing a vigorous vegetation with its moisture. 
This process of contemporaneous thawing and freezing seems, as I shall immediately take occasion to explain, to have been very instrumental in the formation of those stupendous glaciers, which strike with astonishment and admiration every person who has an opportunity of beholding them.

In Magdalena Bay there are, as already observed, four of these glaciers, two of which are situated on the southern shore, at the margin of the sea. The third, which I have mentioned as bearing the appropriate name of "the Hanging Iceberg," appears to have accumulated without any lateral support, as though a stream of water had issued from a particular spot and become congealed as it descended; thus forming a nucleus, which gradually increased, and rose as the stream poured its waters over its accumulating surface, until, in the course of ages, the mass has attained its present bulky dimensions.

The fourth, and largest, occupies the head of the bay, and extends from two to three miles inland. Numerous large rents in its upper surface, occasioned, perhaps, either by its own motion or by the subsidence of its foundation, have caused it to be gratuitously named the "Waggon Way," in accordance with the sup- 
posed resemblance which these fissures bear to the ruts left by a waggon.

From the circumstance of the sea being of great depth immediately off these glaciers, they are prevented making an undue encroachment upon the bay, and, indeed, from filling it up, which, if the water were shallow, would, in the course of time, inevitably be the case, either by the grounding of the pieces which break away from the frontage, or by the berg finding a foundation to advance upon. At present the warmth of the sea prevents the accumulation of ice below a certain depth, and, during the summer, so far undermines the accumulation of the winter, that large masses fall off by their own superincumbent weight, and are carried out to sea; so that the berg is thus kept within due bounds.

The frontage of the Waggon Way presents a perpendicular surface of three hundred feet in height, by seven thousand feet in length. Nevertheless, upon so gigantic a scale is all nature around, that although of these stupendous dimensions, neither this glacier, nor any of the numerous and beautiful variety, creates much astonishment in the mind of the beholder until he approaches within the influence of the blink, or luminous haze, which is invariably radiated by 
large masses of ice. At this distance the wall of ice has an awfully-grand appearance, heightened perhaps by a sense of the personal danger to which so near an approach must expose the spectator; for large pieces have occasionally broken away from this berg, which have done considerable mischief. The soft blue tint of the surface of the ice is here also clearly discerned, whilst the long, sparkling icicles pendant from the roofs of the caverns, and a variety of curious shapes, which may also be traced on the face of the glacier, serve greatly to increase the interest and admiration.

On a perfectly calm day, when the blink of the ice is strong, a curious deception is produced by the combined effect of the ice below the surface of the water, and the perfect reflection of that above. The sea presents a white, creamy appearance; the seals sporting on its surface seem. to be swimming in a thick milky substance; and the ripple as it sweeps along occasions long white lines, so that it is only by looking perpendicularly upon the water around the boat that its transparency is perceived, and the deception is detected.

In another part of my journal it is shown that the danger of approaching these fragile masses of ice is far from imaginary; and that 
there is also a necessity for a strict observance of silence in their immediate vicinity. The fact is, that, as the berg is constantly breaking away during summer, there are generally some pieces all but on the point of falling, and capable of being detached by the smallest concussion of the air; the explosion of a gun scarcely ever failing to bring down one of the masses.

In cloudy or misty weather, when the hills are clothed with newly-fallen snow, nothing can be more dreary than the appearance of the shores of Spitzbergen ; whereas, on the contrary, it is scarcely possible to conceive a more brilliant and lively effect than that which occurs on a fine day, when the sun shines forth and blends its rays with that peculiarly soft, bright atmosphere which overhangs a country deeply-bedded in snow; and with a pure sky, whose azure hue is so intense as to find no parallel in nature. On such an occasion the winds, near the land at least, are very light, or entirely luushed, and the shores teem with living objects. All nature seems to acknowledge the glorious sunshine, and the animated part of creation to set no bounds to its delight.

Such a day was the 4th of June, and we felt most sensibly the change from the gloomy atmosphere of the open sea, to the cheerful 
glow that overhung the hills and placid surface of Magdalena Bay.

Although surrounded by beds of snow and glaciers, with the thermometer scarcely above the freezing point, there was no sensation of cold. The various amplibious animals, and myriads of birds which had resorted to the place, seemed to enjoy, in the highest degree, the transition thus occasioned by a few bright hours of sunshine. From an early hour in the morning until the period of rest returned, the shores around us reverberated with the merry cry of the little auk, willocks, divers, cormorants, gulls, and other aquatic birds; and wherever we went groups of walruses basking in the sun mingled their playful roar with the husky bark of the seal.

There was certainly no harmony in this strange din; but it was, at the least, gratifying to know that it arose from a demonstration of happy feelings. It was a pleasure of the same character as that which must have been experienced by every traveller who, on some fine bright evening in a tropical climate, has listened to the merry buz of thousands of winged insects which immediately succeeds the setting of the sun. And here we cannot fail to notice the manner in which the great Author of Nature has varied His dispensations. In 
the burning region of the torrid zone, the descent of the sun calls into action myriads of little beings which could not exist under the fierce glare of his meridian ray; whereas here, on the contrary, it is the signal for universal repose.

This period of the day had no sooner arrived in Magdalena Bay than there was a stillness which bordered on the sublime - a stillness which was interrupted only by the bursting of an iceberg, or the report of some fragment of rock loosened from its hold. These sounds, indeed, which came booming over the placid surface of the bay, could hardly be considered interruptions to the general silence, for, speedily dying away in the distance, they left behind a stillness even more profound than before.

In the day-time the presence of our expedition was not disregarded. The birds shunned us in their flight, and every noise which was occasionally made, sounding strange to the place, sent to a greater distance the sea-gulls that were fishing among the rocks, and kept on the alert whole herds of animals, many of which would otherwise have been lost in sleep; causing them to raise their heads when anything fell upon our deck, and to cast a searching look over the bay, as if to inquire whence so 



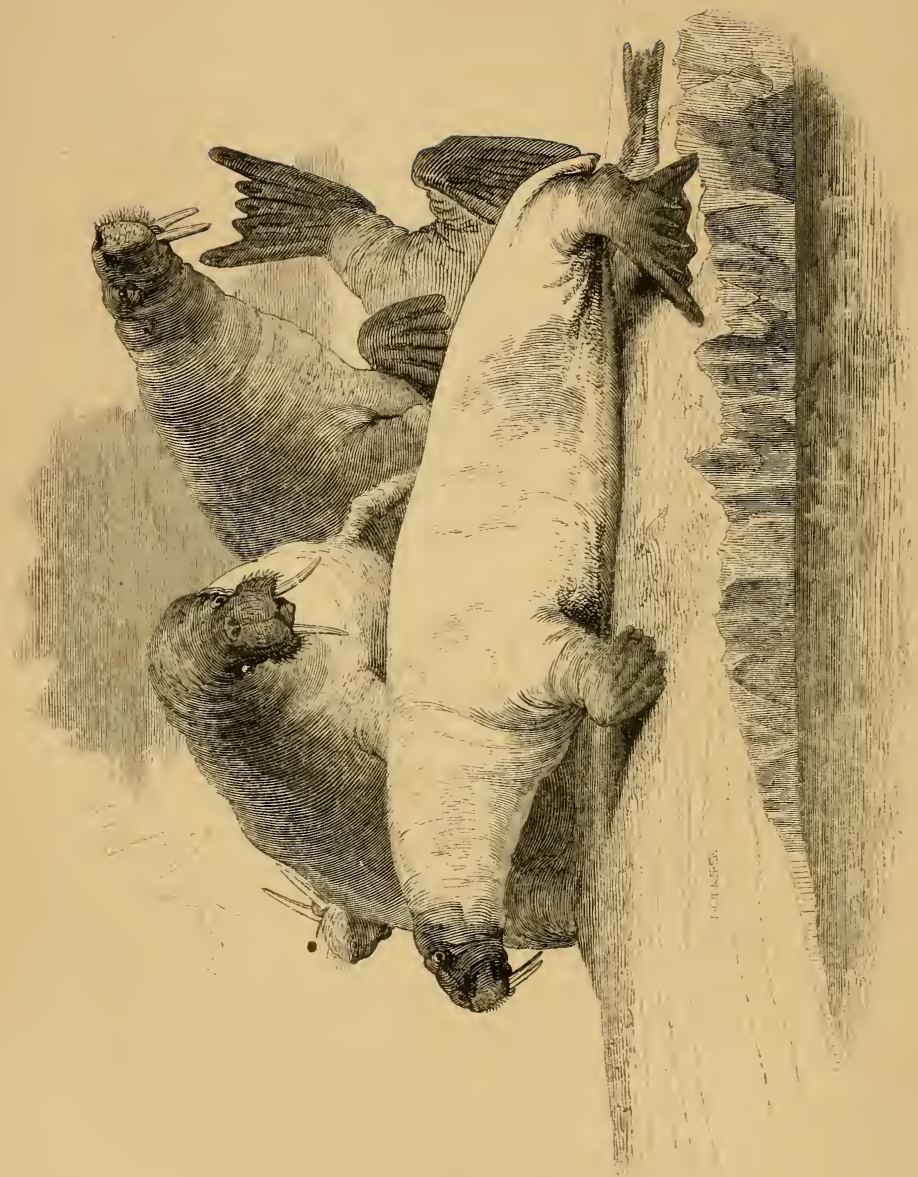

is
c
0
2
2
$\frac{2}{3}$
$\frac{1}{6}$
3 
unusual a disturbance proceeded. These little alarms, which would have passed unheeded in situations frequented by man, proved, more than any other incident, how great a stranger he was in these regions; a feeling which, I must confess, carried with it an agreeable sensation, arising, no doubt, from the conviction that we were treading a ground which had been but rarely visited before.

When we first rowed into this bay it was in quiet possession of herds of walruses, who were so unaccustomed to the sight of a boat that they assembled about her apparently highly incensed at the intrusion, and swam towards her as though they would have torn the planks asunder with their tusks. The wounds that were inflicted only served to increase their rage, and, I frankly admit, that, when I considered how many miles we were from our vessel, and what might be the result of this onset, I wished we had the support of a second boat; we continued, however, to keep them off with our fire-arms, and fortunately came off without any accident. When we afterwards came to anchor, we went better provided, and succeeded in killing several of these animals upon the ice at the head of the bay.

We found some of these monsters fourteen 
feet in length and nine feet girth, and of such prodigious weight that we could scarcely turn them over. In the inside of several there were round granite pebbles, larger than walnuts, and in one we counted two-and-twenty. Their hides were so tough that a bayonet was the only weapon which would pierce them; and we were not a little surprised at the accounts of the early voyagers already mentioned, in which it is stated, that a thousand of these animals were killed in the short space of seven hours, by the crew of one vessel. Nor were we less curious to find out the manner in which they had contrived to pen up on the shore five hundred walruses alive, and keep them prisoners for several days, as appears to have been the case in one of the voyages alluded to. I can only say, that had such a task been imposed upon us, we should have found it utterly impossible to accomplish it.

One of our earliest excursions in this Bay was an attempt to ascend the peak, which I have already described as Rotge Hill, upon which may now perhaps be seen, at the height of about two thousand feet, a staff that once carried a red flag, which was planted there to mark the greatest height we were able to attain, partly in consequence of the steepness of the ascent, but 
mainly on account of the detached masses of rock which a very slight matter would displace, and hurl down the precipitous declivity, to the utter destruction of him who depended upon their support, or who might happen to be in their path below. The latter part of our ascent was, indeed, much against our inclination; but we found it impossible to descend by the way we had come up, and were compelled to gain a ledge, which promised the only secure restingplace we could find at that height. This we were able to effect by sticking the tomahawks with which we were provided into crevices in the rock, as a support for our feet; and some of these instruments we were obliged to leave were they driven in, in consequence of the danger that attended their recovery. We followed the ledge we had thus gained to the head of a bank of snow, which filled up a valley to the east of the hill, and found the snow sufficiently soft for our feet to make an impression upon it, or I really believe we should have been obliged to wait until we could have obtained ropes from the ship to facilitate our descent. As it was, this bed of snow was so steep that, had we missed our footing, we must have rolled down, and been precipitated into the sea, as invariably happened with the birds we shot, unless, 
indeed, when their descent was intercepted by foxes, or burgheimsters, which were always on the watch for their prey.

We noticed many parts of the surface of the snow stained with a deep red substance by the little auk; but such places, though similar in colour, could scarcely be said to bear. any resemblance to the representation of the red snow of Baffin's Bay.*

We had been in possession of the anchorage a few days only, when we were agreeably surprised at the appearance of a strange boat pulling towards the ship. On a nearer approach, we found that she belonged to some Russian adventurers, who were engaged in the collection of peltry and morses' teeth. They appeared equally astonished at the sight of our vessels, but, after scrutinizing us awhile, they took courage and went on board the Dorothea, where, by the well-known mode of signs, they had no difficulty in communicating their desire for some spirits; Captain Buchan gave them a kind reception, and supplied them with whatever they wanted; in return for which, they sent on board the following day a side of venison in excellent condition.

Being desirous of gaining further information

* See Ross's Voyage, 1818. 
of these people, an officer of the Dorothea accompanied them to their abode at the head of a small cove, about four miles to the southward of Magdalena Bay.

They had here a comfortable wooden hut well lined with moss, divided into three compartments; in one of which there were three carcasses of fine venison, and many wild ducks.

It was with extreme pleasure we noticed, in this retired spot, probably the most northern and most desolate habitation of our globe, a spirit of devotion rarely exercised in civilized countries. On landing from the boat, and approaching their residence, these people knelt upon its threshold, and offered up a prayer with fervor and evident sincerity. The exact nature of the prayer we did not learn, but it was, no doubt, one of thanksgiving, and we concluded it was a custom which these recluses were in the habit of observing on their safe return to their habitation. It may, at all events, be regarded as an instance of the beneficial effect which seclusion from the busy world, and a contemplation of the works of Nature, almost invariably produce upon the hearts of even the most uneducated part of mankind,

This is one of the few remaining establish- 
ments at Spitzbergen still upheld by the merchants of Archangel; who, during the last century, and under the auspices of the Russian government, formed a settlement in Bell Sound, upon this coast,* and who still send annually $\dagger$ a small vessel to bring home the peltry and sea-horse teeth that have been collected by their servants during the year.

* Coxe’s Russian Discoveries. $\quad$ † 1818. 


\section{CHAPTER II.}

Quit Magdalena Bay. - Revisit the Ice. - The Trent driven into the packed ice.-Her dangerous situation.-The ice opens. - The ships enter and are beset. - Cause of the leak in the Trent discovered and remedied. - Heavy pressure of the ice. - Intricate situation of the vessels. - They regain the open sea. - Walruses make a formidable attack upon the boats of the Trent.-Their habits described. - Expedition proceeds to Fair Haven. - Description of the anchorage. - Numerous graves and remains of habitations discovered.

June 1818.-THe expedition quitted Magdalena Bay on the 7 th June, to renew the examination of the ice; and, after steering a few leagues to the northward, found it precisely in the same situation and state as we had left it on the 2nd instant.

We were no sooner clear of the land, than we concluded, by a heavy swell rolling up from the south-west, that it had been blowing hard at sea during the time we were snugly at anchor, and that we had thus escaped at least one gale of wind. The breeze was now mo- 
derating, and we stood along the margin of the ice, searching for an opening, and remarking as we went what very little effect had been produced upon it by the gale.

While thus occupied the breeze suddenly deserted us, and the vessels being rendered unmanagable by the heavy swell which continued to roll towards the ice, they were, in spite of all our efforts, driven into the pack. With a view of averting this occurrence, the boats had been employed in towing the vessels until the latest moment, but unfortunately those of the Trent were cut off from communication with her by the breaking of the line.

By the aid of a light breeze of wind off the ice, both vessels succeeded in gaining the open sea, but they had scarcely proceeded an hour before they were again becalmed, and, in spite of every exertion, they were a second time driven into the packed ice.

The turbulent scene from which we had but recently escaped was but a faint prelude to that which now presented itself. During the interval the swell had materially increased, and now rolled furiously in upon the ice. The pieces at the edge of the pack were at one time wholly immersed in the sea, and at the next raised far above their natural line of flotation, while 
those further in, being more extensive, were alternately depressed or elevated at either extremity as the advancing wave forced its way along. The see-saw motion which was thus produced was alarming, not merely in appearance, but, in fact; and must have proved fatal to any vessel that had encountered it, as floes of ice, several yards in thickness, were continually crashing and breaking in pieces, and the sea for miles was covered with fragments ground so small that they actually formed a thick, pasty substance - in nautical language termed "brash ice"-which extended to the depth of five feet.

Amidst this giddy element, our whole attention was occupied in endeavouring to place the bow of the vessel, the strongest part of her frame, in the direction of the most formidable pieces of ice-a manœuvre which, though likely to be attended with the loss of the bowsprit, was yet preferable to encountering the still greater risk of having the broadside of the vessel in contact with it. For this would have subjected her to the chance of dipping her gunwale under the floes as she rolled; an accident which, had it occurred, would either have laid open her side or have overset the vessel at once. In either case the event would probably have proved fatal to all on board, as it 
would have been next to impossible to rescue any person from the confused moving mass of brash ice, which covered the sea in every direction.

With much difficulty we effected our laborious task; until we were fortunately spared the anticipated collision by the brash ice becoming thicker as we proceeded, and at length quite impenetrable, so that the brig by this means was kept at a distance of about a hundred yards from the heaviest pieces. Thus situated, we passed the night in the greatest anxiety, at one time fancying the distance between the ice and the vessel was diminishing, and at another that it was somewhat increased, and only earnestly hoping throughout, that a breeze would spring up from the northward, and release us from our perilous position.

The attention of the seamen was in some degree diverted from the contemplation of this scene of difficulty by the necessity of employing them all at the pump; for the leak was by no means diminished, and the duties of the day having called them from this occupation, a considerable quantity of water had by this time found its way to the well.

Towards morning, our hopes of a breeze off the ice were realized, and by seven o'clock we had the satisfaction to get quite clear of the 
ice. We shortly rejoined our commodore, who had escaped the danger to which we had been exposed by being at a greater distance from the pack when the wind failed.

The ships now steered to the westward to reconnoitre the state of the ice in that direction, and, in longitude $4^{\circ} 30^{\prime} \mathrm{E}$., fell in with several whale-ships, by which we were informed that the ice was quite compact to the westward, and that fifteen vessels were beset in it. This unpromising intelligence, coupled with the apparent tending of the ice to the southward, satisfied Captain Buchan that our best chance of success was by keeping near the land of Spitzbergen, and he in consequence once more directed the course of the vessels to the eastward. We made Prince Charles' Island on the 10th of June, and got sight of those remarkable hills which are known by the name of "The three Crowns;" but why this number has been specified was not quite clear to us, five peaks being distinctly visible. Nor was it more evident why the term "Crown" had been applied, as they bore no resemblance whatever to that emblem of royalty. They seemed to consist of a range of outliers traversed by horizontal conformable strata, with deep valleys between; as though they had originally formed one range of hills, or 
elevated plateau, and had been separated by the degradation of the intermediate soil. The snow having lodged upon the upper surfaces of the strata, from the base even to the summits of the peaks, occasioned a regular series of black and white stripes, which, viewed against a clear sky, presented a singular appearance, and such as must render these hills peculiarly adapted for landmarks.

The following evening we were close to the ice off Cloven Cliff. The pack was still impenetrable; but it was some satisfaction to observe that the margin was removed several miles to the northward of its former position, and that there was a channel of water between it and the land. Several days had now been passed without any apparent advantage to the expedition, and, considering the shortness of the season, it was evident that the opportunity thus afforded of getting to the northward of Spitzbergen, though at the risk of being beset, was not to be neglected. As Captain Buchan had reason to think the channel just cleared away might lead to an open sea beyond, not a moment was lost in taking advantage of the opening. The ships passed Cloven Cliff,-a remarkable isolated rock which marks the north-western boundary of Spitzbergen, - and for some time steered along an intricate channel between 
the land and the ice; but scarcely had they passed Red Bay, so named from the colour of its cliffs, when, at two in the morning of the 12th June, the further advance of the vessels was stopped, and the channel by which they had entered became so completely closed up as to preclude the possibility of retreating. The ice soon began to press heavily upon us, and, to add to our difficulties, we found the water so shallow, that the rocks were plainly discerned under the bottoms of the ships. It was impossible, however, by any exertion on our part, to improve the situations of the vessels; they were as firmly fixed in the ice as if they had formed part of the pack, and we could only hope that the current would not drift them into still shallower water and damage them against the ground.

Our position was off a part of the northern coast of Spitzbergen, where Baffin, Hudson, Poole, and indeed almost all the early voyagers to this country had been stopped; for it appears that, with scarcely any exception, they succeeded in navigating the western coast of this island, and in doubling Cloven Cliff; but in no well-authenticated voyage is there any record of their having passed much beyond our present situation. We were also not far from the spot where Captain Phipps so nearly abandoned his vessels, 
as to have actually commenced drawing his boats over the ice towards the open water, in the expectation of being able to proceed in them to a port in Spitzbergen, where he knew he should find some Dutch whalers at anchor. Our hopes of being able to effect anything of consequence in a north-eastern direction were, therefore, considerably diminished, and setting aside the appearances from our mast-head, we were aware, from reading the narratives of the old voyagers, that there never had been so material an alteration in the position of the ice in this part as to promise any great advance toward the attainment of the object we had in view. It was, however, our duty to make the attempt, and ever sanguine of success whilst the ice admitted of the smallest progress, we thought we might be more fortunate than those who had preceded us.

As the tide changed, the pieces of ice immediately around us began to separate, and some of them to twist round with a loud grinding noise, urging the vessels, which were less than a mile from the land, still nearer and nearer to the beach. Captain Buchan, seeing the imminent risk to which this movement exposed the expedition, left nothing untried that seemed likely to increase our distance from the shore; and succeeded in fastening his lines to a large piece 


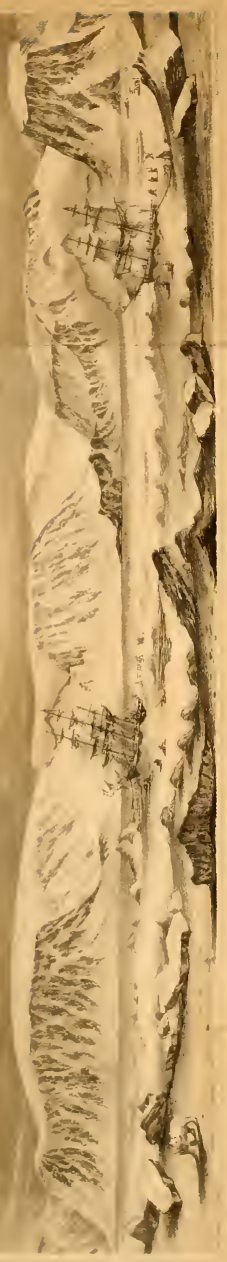



of ice that was twisting round, and which, as it turned, brought his ship gradually on the outside of it. The Trent endeavoured to follow her example; but so rapid was the motion of the ice that although only a few yards from the Dorothea, she found it wholly impracticable, and it was not until after twenty hours' hard labour that we succeeded in again placing the vessels together.

Both vessels were now hauled into small bays in the floe, and secured there by ropes fixed to the ice by means of large iron hooks, called ice-anchors.

The advantages of such a situation must be evident to every seaman, the vessel being by this means protected from the passing ice by the projecting points a-head and a-stern of her; and the floes being sometimes deeper in the water than the ships, there is in such a case no danger of their touching the ground.

We continued fast to this floe of ice for thirteen days, shifting the ships from one part of it to another, as the motion brought them between it and the shore. As this could be effected only by main force, the crew were so constantly engaged in this harassing duty, that their time was divided almost entirely between the windlass and the pump; until the men at 
length became so fatigued that our sick-list was seriously augmented. The subject of the leak was never for any length of time absent from our thoughts; but we now began to reflect seriously on the propriety of hoisting out part of the provisions upon the ice, in the hope of making some discovery that might lead to the remedy of so serious an evil. While this was in contemplation, it fortunately happened that, on one very still night, as we lay quietly by the side of the floe, the surgeon's assistant thought he heard the water rushing into the vessel beneath where he slept.

Elated at the idea of at least discovering the defect, the spirit-room was immediately cleared, and it was not long before our suspicions were confirmed. On cutting through the lining opposite the spot whence the noise proceeded, the water rushed into the hold in a stream full four feet in height. We now found that a bolt-hole had been left open in the bottom of the vessel, and that the water had found its way down between the timbers into the well. Fortunately, its dimensions did not admit of a greater quantity of water passing through than could be kept under by the pumps, otherwise the vessel must have foundered at sea. We could easily account 
for the leak having scarcely shown itself before the brig quitted the river, by supposing the hole to have been partly pitched over, a covering which, of course, very soon washed away at sea. By this fortunate discovery we were able in a few minutes to apply an effectual remedy, and to partake of the satisfaction arising from finding ourselves in as tight and safe a vessel as we could wish-a satisfaction which, I am sure, the reader will fully appreciate.

On the 13th, an officer of the Dorothea obtained permission to proceed with a few seamen over the ice to the shore, which was distant about three or four miles from the ships-a journey which, whilst the day was fine and the breeze light, seemed to be of very easy accomplishment. Early in the afternoon he set out with his party, and commenced his excursion pleasantly enough, travelling at a good rate and surmouniting every obstacle. Scarcely, however, had he reached half way to the shore when the appearance of a fog in the horizon induced the prudent part of his companions to return to the ships, and, shortly afterwards, obliged the remainder to desist from proceeding further.

The fog approached quicker than was expected, and soon obscured every distant object; so that 
the party, having failed in every other mode of preserving the direction of the ships, attempted, as a last resource, to retrace their footmarks in the snow; but this was found to be equally impracticable, in consequence of the pieces of ice over which they had passed having changed their position, and of the occurrence of other tracks, such as those of bears and seals, which at distances were mistaken for their own. Thus circumstanced, they felt the full extent of the danger to which they had thoughtlessly exposed themselves - a danger of no trifling magnitude, as it threatened to involve the lives of the whole remaining party. Still, endeavouring to preserve the direction in which the ships had last been seen, they wandered about, making a very circuitous course, which was rendered still more indirect than it might otherwise have been by the difficulty of getting from one piece of ice to the other, and the necessity of searching for the most convenient places for that purpose.

To travel over ragged pieces of ice, upon which there were two feet of snow, and often more, springing from one slippery piece to the other, or, when the channels between them were too wide for this purpose, ferrying themselves across upon detached fragments, was 
a work which it required no ordinary exertion to execute. Indeed, the getting from one piece to the other was, throughout, by no means the least hazardous part of their journey; the difficulties too were much increased, and many accidents occurred, through that hurry, and anxiety to overcome them speedily, which occasioned the neglect of many precautions, that leisure had before enabled them to observe, in order to ensure their safety. Some fell into the water, and were with difficulty preserved from drowning by their companions; while others, afraid to make any hazardous attempt whatever, were left upon pieces of ice, and drifted about at the mercy of the winds and tides. Foreseeing the probability of a separation, they took the first opportunity of dividing, in equal shares, the small quantity of provision which they had remaining, as also their stock of powder and ammunition. They also took it in turns to fire muskets, in the hope of being heard from the ships, which they knew would return the fire, and that they would thus at least learn in what direction to proceed, even though it might be impracticable to derive assistance from them. These discharges were distinctly heard on board; but it is a remarkable fact that, although they were answered by volleys of mus- 
ketry, and even by cannon, not one report was heard by the party, who, consequently, concluded themselves at a much greater distance from the ships than they really were.

Our adventurers continued to travel in the supposed direction of the ships, keeping within view of each other, and rendering one mother all the assistance possible, until a breeze sprung up, and set the pieces of ice in rapid motion. Unable to contend with this new difficulty, and overcome with wet, cold, and sixteen hours of fatigue, they sat down, in a state of despondency, upon a piece of ice, determined to submit their fate to Providence.

It is difficult to imagine a more distressing situation than that of the party at this moment; almost perishing with cold and fatigue, with the bare snow for their only resting-place, their supply of provision exhausted, and themselves drifting about in a thick fog, they knew not whither, perhaps far away from their ships, and with the prospect of being carried out to sea, where death would have been inevitable.

The muskets we had heard on board the ship had, of course, made us extremely anxious to afford relief to our suffering companions; but, for many hours, no person dared venture over the ice, on account of the fog, and the difficulty 
of getting back to the ship; but when, by the report of the muskets becoming more audible, we found that the party were drifting towards us, the anxiety to rescue them was so great that the Greenland master and mate of the Trent ventured out, with poles and lines, and had the good fortune to fall in with the party, who, by this time, were drifted nearly within sight of the vessels. They found them seated upon a piece of ice, as already described, cold, wet, and so overcome that, in a few hours more, the greater part of them must have perished. Their joy at unexpectedly beholding their companions come to their relief, and still more at finding themselves so near their ship, may readily be imagined, and inspired them with fresh vigour, which enabled them, with the assistance of their shipmates, to effect the remainder of their journey. After eighteen hours' absence, they all got safely on board, fully determined, in future, to rest satisfied with the view of the shore which was afforded them from the ship, and without the slightest desire to attempt to approach it again by means of the ice.

The evening of the 14th being very fine, and everything quiet, we set on fire some sea-horse fat, in order to entice within reach of our muskets any bears that might be ranging the ice, as 
these animals possess a very keen scent, and are invariably attracted by burnt animal matter. About midnight we had the satisfaction of seeing one of them drag his huge carcass out of the water, and slowly make his way towards us. The sight of the tall masts of the ships appeared to alarm him a little at first, for he occasionally hesitated, threw up his head, and seemed half inclined to turn round and be off; but the agreeable odour of the burnt blubber was evidently so grateful to his olfactory nerves and empty stomach that it overcame every repugnance, and gradually brought him within range of our muskets. On receiving the first shot, he sprang round, uttered a terrific growl, and half raised himself upon his hind legs, as if in expectation of seizing the object that had caused him such excruciating pain; and woe to any human being who had at that moment been within reach of his merciless paws. The second and third balls laid him writhing upon the ice, and the mate of the Dorothea jumped out of the vessel and endeavoured to despatch him with the butt end of a musket; but it unfortunately broke short off and, for a moment, left him at the mercy of his formidable antagonist, who showed, by turning sharply upon his assailant and seizing him by the thigh, that he was not yet mastered; 
and he would most certainly have inflicted a serious wound, had it had not been for the prompt assistance of two or three of his shipmates, who had followed him. The animal was by no means one of the largest of his species, being only six feet in length, and three feet four inches in height. His stomach was quite empty, with the exception of a garter, such as is used by Greenland sailors to tie up their boat stockings. In his left side there was a cicatrised wound of considerable magnitude. From what we saw of the activity and ferociousness of this animal, added to the well-known strength of his species, we readily gave credit to the accounts of Barentz, and other early visitors to these regions, and it may be considered a fortunate circumstance for the hero of the Nile and Trafalgar, that a natural barrier was interposed between him and the object of his chace, when, in his youth, he ventured alone, over the ice in these regions, in pursuit of such formidable game.

The journals of the early voyagers in northern latitudes abound with anecdotes illustrative of their encounters with these animals, of which the most remarkable occurred in Nova Zembla, and is thus described by Gerat de Vere, in his account of Barentz' second voyage : 
" The 6th of September, some of our men went on shore, upon the firme land to seeke for stones, which are a kinde of diamond, whereof there are many also in the States' lland: and, while they were seeking the stones, two of our men lying together in one place, a great leane white beare came suddenly stealing out, and caught one of them fast by the necke; who, not knowing what it was that tooke him by the necke, cryed out and sayd, "Who is it that pulls mee so by the necke?' wherewith the other, that lay not farre from him, lifted up his head to see who it was; and, perceiving it to bee a monstrous beare, cryed out, and sayd, ' $\mathrm{Oh}$, mate! it is a beare,' and therewith presently rose up, and ranne away.

"The beare at the first falling upon the man, bit his head in sunder, and suckt out his blood; wherewith the rest of the men that were on the land, being about twentie in number, ranne presently thither, either to save the man, or else to drive the beare from the body; and having charged their pieces, and bent their pikes, set upon her, that still was devouring the man, but, perceiving them to come towards her, fiercely and cruelly ranne at them, and got another of them out from the companie, which she tore in pieces, wherewith all the rest ranne away. 
"We perceiving, out of our ship and pinnasse, that our men ranne to the sea-side to save themselves, with all speed entred into our boates, and rowed as fast as wee could to the shoare to relieve our men. Where, being on land, we beheld the cruell spectacle of our two dead men that had been so cruelly killed and torne in pieces by the beare. We, seeing that, encouraged our men to goe backe againe with us, and with pieces, curtelaxes, and halfepikes, to set upon the beare, but they would not all agree thereunto; some of them saying, our men are already dear, and we shall get the beare well enough though wee oppose not ourselves into so open danger; if wee might save our fellowes' lives then wee would make haste; but now we need not make such speed, but take her at an advantage, with most securetie for ourselves, for we have to doe with a cruell, fierce, and ravenous beast. ' Whereupon three of our men went forward, the beare still devouring her prey, not once fearing the number of our men, and yet they were thirtie at the least; the three that went forward in that sort were Cornelius Jacobson, William Geysen, and Hans Van Nuflen, William Barentz, purser: and, after that the sayd master and pylat had shot three times, and mist, the purser, stepping somewhat further forward, and seeing the beare 
to be within the length of a shot, presently levelled his piece, and, discharging it at the beare, shot her into the head, betweene the eyes, and yet she held the man still fast by the necke, and lifted $\mathrm{vp}$ her head with the man in her mouth; but shee began somewhat to stagger, wherewith the purser and a Scottish man drew out their curtelaxes and strooke at her so hard that their curtelaxes burst, and yet she would not leaue the man; at last William Geysen went to them, and with all his might strooke the beare vpon the snout with his piece, at which time the beare fell to the ground, making a great noyse, and William Geysen leaping vpon her cut her throat." *

The following evening we were greatly amused by the singular and affectionate conduct of a wallus towards its young. In the vast sheet of ice which surrounded the ships, there were occasionally many pools; and, when the weather was clear and warm, animals of various kinds would frequently rise and sport about in them, or crawl from thence upon the ice to bask in the warmth of the sun. A walrus rose in one of these pools close to the ship, and, finding everything quiet, dived down and brought up its young, which it held to its breast by press-

* Purchas, his Pilgrimes, vol. iii. p. 481. 
ing it with its flipper. In this manner it moved about the pool, keeping in an erect posture, and always directing the face of the young toward the vessel. On the slightest movement on board, the mother released her flipper and pushed the young one under water; but, when everything was again quiet, brought it up as before, and for a length of time continued to play about in the pool, to the great amusement of the seamen, who gave her credit for abilities in tuition, which, though possessed of considerable sagacity, she hardly merited.

It was some consolation to us, amidst the mortification we endured from our protracted detention in the ice, to find that there were very few hours in which some little incidents of an amusing nature did not occur to divert our attention from the monotony of the daily duties of the ship. At one time the wanderings of bears would be watched with all the eagerness of a sportsman beating a cover; at another, the gambols of seals and walruses would take up our attention; and occasionally the appearance of whales or narwhals in small pieces of water about us, would invite pursuit. The bears would sometimes approach so near as to sniff at the linen drying upon the ice; and 
more than once we were tempted to give chase to some that had been wounded.

On one occasion we thought we were sure of our game, from his hind leg being shot through, and from the quantity of blood which flowed from the wound, but bruin outran us all upon three legs, and gained so much ground that every now and then he could afford to rest and rub his leg in the snow, which, after a while, as appeared by his track being no longer stained, had the effect of stanching the blood. But there were very few of the incidents which gave greater amusement to those who happened to see it than the one which follows. The bears, when hungry, seem always on the watch for animals sleeping upon the ice, and endeavour, by stratagem, to approach them unobserved, for, on the smallest disturbance, the animals dart through holes in the ice, which they always take care to be near, and thus evade pursuit. One sunshiny day a walrus, of nine or ten feet length, rose in a pool of water not very far from us, and after looking around, drew his greasy carcass upon the ice, where he rolled about for a time, and at length laid himself down to sleep. A bear, which had probably been observing his movements, crawled carefully upon the ice on the opposite side of the pool, and 
began to roll about also, but apparently more with design than amusement, as he progressively lessened the distance that intervened between him and his prey. The walrus, suspicious of his advances, drew himself up, preparatory to a precipitate retreat into the water, in case of a nearer acquaintance with his playful, but treacherous visitor; on which the bear was instantly motionless, as if in the act of sleep; but after a time began to lick his paws, and clean himself, and occasionally to encroach a little more upon his intended prey. But even this artifice did not succeed; the wary walrus was far too cunning to allow himself to be entrapped, and suddenly plunged into the pool; which the bear no sooner observed than he threw off all disguise, rushed toward the spot, and followed him in an instant into the water, where I fear he was as much disappointed in his meal as we were of the pleasure of witnessing a very interesting encounter.

On the sixth day after the ships became hampered in the ice, they were drifted to the westward so much that the open sea was again in view from the mast-head. 'The ice, however, continued too closely packed to allow of our attempting the liberation of the vessels with any probability of success; and a most fortunate cir- 
cumstance it eventually proved that we had been prevented nearing the margin of the ice, for on the following morning it blew a hard gale from the southwest, and such a heavy sea rolled in upon the pack, that, although the ships were nine miles distant from the margin of the surf, it was distinctly heard like distant thunder.

The pressure of the ice around the ships now became very great; every pool of water was closed, and the enormous force acting upon the floes was occasionally apparent by large pieces of ice being forced upon those with which they were in contact. In anticipation of an occurrence of this nature, we had taken the precaution of placing the vessels in small bays, formed in the field, to which they were secured, and were thus, in a great measure, protected by the points of ice on either side of us. But, notwithstanding this advantage, it was evident, by the grinding noise against their sides, that they sustained considerable pressure throughout the gale.

At one time, when the Trent appeared to be so closely werlged up that it did not seem possible for her to be moved, she was suddenly lifted four feet by an enormous mass of ice getting under her keel; at another, the fragments of the crumbling floe were piled up under 
the bows, to the great danger of the bowsprit. The Dorothea was in no less imminent danger, especially from the point of a floe, which came in contact with her side, where it remained a short time, and then glanced off, and became checked by the field to which she was moored. The enormous pressure to which the ship had been subjected was now apparent by the field being rent, and its point broken into fragments, which were speedily heaped up in a pyramid, thirty-five feet in height, upon the very summit of which there appeared a huge mass, bearing the impression of the planks and bolts of the vessel's bottom!

It is remarkable that, although we had indisputable evidence that it was blowing a gale of wind at sea-by the enormous pressure upon the ice, the roaring of the sea upon the edge of the pack, and the aspect of the sky, - the ships were so perfectly becalmed that the vane at the mast-head was scarcely agitated. There was also a most marked difference in the state of the atmosphere over the packed ice and that over the open sea. Over the ice the sky was perfectly cloudless; whilst the sea was overcast with stormy-looking clouds, which passed heavily along with the gale, until they reached a line nearly perpendicular to the edge of the packed ice. 
At this point, or line of demarcation of the two atmospheres, it was curious to mark the rapid motion of the clouds to the right or left, and how immediately they became condensed, or were dispersed on arriving at it; and although masses of clouds were continually borne towards the spot by the impetuosity of the tempest, the line of termination did not encroach upon that of the serene atmosphere overhanging the pack. This contrast between the two atmospheres, so remarkable in cloudy weather especially, is termed the "ice blink," and enables the experienced mariner to judge of the nature and position of the ice, even at a distance.

The effect of a southwest gale upon the ice, especially when it is of long continuance, is first to pack it so closely as to exclude every pool of - water, and then to propel the whole body to the northward. But, as soon as the wind ceases the floes separate, with an apparent elasticity; the prevailing current, which has been pressed up by the gale, resumes its course; the ice opens in every direction, and may be seen travelling at a rate scarcely credible.

Thus, on the 23rd, we found the field to which we were fast, setting to the southward at the rate of three miles an hour, and the 
pack beginning to open in every direction. This dispersion, and the occurrence of a fresh northeast wind, afforded us the only opportunity of extricating the vessels that had occurred since they were beset, and Captain Buchan gladly availed himself of it, so that in a few hours both vessels reached the open sea, after thirteen days' detention in the pack.

The northerly wind increased to a gale, and drifted a great quantity of ice away to the southward. We passed several pieces, upon which we noticed our own footmarks, and could thus judge of the effect produced by the change of wind. In the hope of its working a considerable alteration in our favour, we kept close to the edge of the pack.

On the 26th we had a fall of snow, and at noon, for the first time since crossing the Arctic Circle, a shower of rain, which, although the summer was so far advanced, cased every rope in ice as it fell.

The gale abated, and the next day, having a breeze from the southward, we approached the ice about Cloven Cliff, and found it drifted close down upon the land. Here it fell calm, and several herds of walruses being seen, as usual, upon detached pieces of ice near the main body, permission was given to the boats to go in pur- 
suit of them. We had already been engaged in several encounters with these animals, but the incidents were of too trifling a nature to allow of their being introduced.

As these encounters, however, afforded traits of sagacity, and frequently of extraordinary affection towards their own species, I shall relate a few facts in this place for the entertainment of the reader, while the vessels are detained inactively at the margin of the ice.

The walrus has been very accurately and amusingly described by De Veer, an early writer of northern voyages:

"The sea-horse," he says, "is a wonderful strong monster of the sea, much bigger than an oxe, which keeps continually in the seas, having a skin like a sea calfe, or seale, with very short hayre, mouthed like a lion; and many times they lye upon the ice; they are hardly killed, unlesse you strike them just upon the forehead; it hath four feete, but no eares, and commonly it hath two young ones at a time. And when the fishermen chance to finde them upon a flake of ice with their young ones, shee casteth her young ones before her into the water, and then takes them in her arms, and so plungeth up and downe with them; and 
when she will revenge herselfe upon the boates, or make resistance against them, then she casts her young ones from her againe, and with all her force goeth toward the boate, (whereby our men were once in no small danger, for that the sea-horse had almost stricken her tecth into the sterne of their boat,) thinking to overthrow it, but by means of the great crie that the men made, she was afraide, and swomme away againe, and tooke her young ones againe in her armes. They have two teeth sticking out of their mouthes, on each side one, each being about halfe an ell long, and are esteemed to be as good as any ivarie or elephants' teeth."*

The walruses are more numerous on the western coast of Spitzbergen than in Baffin's Bay, Behring's Strait, or in any other part of the Arctic seas with which I am acquainted, Cherie Island perhaps excepted; and, in fine weather, resort to large pieces of ice at the edge of the main body, where they may be seen in herds, consisting occasionally of upwards of a hundred animals each.

In these situations they appear greatly to en-

* Three voyages made by the Dutch into the northern seas. Translated by Phillips, 1607 . 
joy themselves, rolling and sporting about, and frequently making the air resound with their bellowing, which bears some resemblance to that of a bull. These diversions generally end in sleep, during which these wary animals appear always to take the precaution of having a sentinel to warn them of any danger to which they may be liable. So universal seems the observance of this precaution amongst their species that I scarcely ever saw a herd, however small, in which I did not notice one of the party on the watch, stretching his long neck in the air every half minute, to the utmost extent of its muscles, to survey the ground about him. In the event of any alarming appearances, the sentinel begins by seeking his own safety, and, as these animals always lie huddled upon one another, the motion of one is immediately communicated to the whole group, which is instantly in motion towards the water. When the herd is large, and an alarm is given, a most ludicrous scene occurs. From the unwieldy nature of the animals, the state of fear into which they are thrown, and their being so closely packed together at first, they tumble over one another, get angry, and in their endeavour to regain their feet flounder about in each other's way, till having at last scrambled to the edge of the ice, they plunge 
into the water head first, if possible, but otherwise, in any position in which chance may have placed them, occasioning one of the most laughable scenes of the kind it is possible to conceive. The gallop of a sea-horse is probably the most awkward motion that is exhibited by the animal tribe, from the great difficulty they experience in bringing the hind feet forward, which arises no doubt from the immense weight of the animal, and the great disproportion between the length of their bodies and their legs. In order to facilitate the bringing up of the hinder parts of the body, the head is alternately lowered and raised, and the animal, being exceedingly pliant, and thickly covered with blubber, a serpentine and wavy motion is thus given to the body, which very much reminds an observer of the hurried movement of a large caterpillar, a ludicrous association, that tends greatly to heighten the burlesque effect.

On the evening in question, several herds of these animals had crawled upon the ice to enjoy the fine evening, and rest themselves after their exertions in the late boisterous weather. The boats, properly equipped, and manned with some of the officers and seamen, pushed off in pursuit of them. The first herd which was selected disappointed the sportsmen, but another was so 
intent upon its gambols, that, notwithstanding the extreme vigilance I have noticed, several of the crew managed to effect a landing upon the ice without any alarm being given to the animals ; but immediately on the first musket being fired the affrighted group made such a desperate rush towards the edge of the ice that they nearly overturned the whole of our party, purposely stationed there to intercept them. The seamen finding this charge more formidable than they expected, were obliged to separate, to allow their opponents to pass through their ranks, and being thus, in their turn, taken by surprise, they suffered them, almost unmolested, to perform their summersets towards the sea. What with their uncertain movements, the extreme toughness of their skin, and the respectful distance at which the men were obliged to keep, to avoid the lashing of the head and tusks of the animals, it was, indeed, no easy task to inflict any serious injury upon them. One, however, was desperately wounded in the head with a ball, and the mate of the brig, being determined, if possible, to secure his prey, resolutely struck his tomahawk into his skull, but the enraged animal, with a twist of its head, sent the weapon whirling in the air, and then lashing his neck, as though he would destroy 
THEY BECOME THE ATTACKING PARTY. 93

with his immense tusks everything that came in his way, effected his escape to the water. The seamen followed, and pushed off in their boats; but the walruses finding themselves more at home now than on the ice, in their turn became the assailants, and the affair began to assume a serious aspect. They rose in great numbers about the boats, snorting with rage, and rushing at the boats, and it was with the utmost difficulty they were prevented upsetting or staving them by placing their tusks upon the gunwales, or by striking at them with their heads. It was the opinion of our people, that in this assault the walruses were led on by one animal in particular, a much larger and more formidable beast than any of the others; and they directed their efforts more particularly towards him, but he withstood all the blows of their tomahawks without flinching, and his tough hide resisted the entry of the whale lances, which were unfortunately not very sharp, and soon bent double: The herd was so numerous, and their attacks so incessant, that there was not time to load a musket, which, indeed, was the only effectual mode of seriously injuring them. The purser, fortunately, had his gun loaded, and the whole now being nearly exhausted with chopping and sticking at their assailants, he snatched it 
up, and thrusting the muzzle down the throat of the leader, fired into his bowels. The wound proved mortal, and the animal fell back amongst his companions, who immediately desisted from the attack, assembled round him, and in a moment quitted the boat, swimming away as hard as they could with their leader, whom they actually bore up with their tusks, and assiduously preserved from sinking. Whether this singular and compassionate conduct, which in all probability was done to prevent suffocation, arose from the sagacity of the animals, it is difficult to say, but there is every probability of it, and the fact must form an interesting trait in the history of the habits of the species.

After the discharge of the purser's gun there remained of all the herd only one little assailant, which the seamen, out of compassion, were unwilling to molest. This young animal had been observed fighting by the side of the leader, and from the protection which was afforded it by its courageous patron, was imagined to be one of its young. The little animal had no tusks, but it swam violently against the boat, and struck her with its head, and indeed would have stove her, had it not been kept off by whale-lances, some of which made deep incisions in its young sides; these, however, had not any immediate 


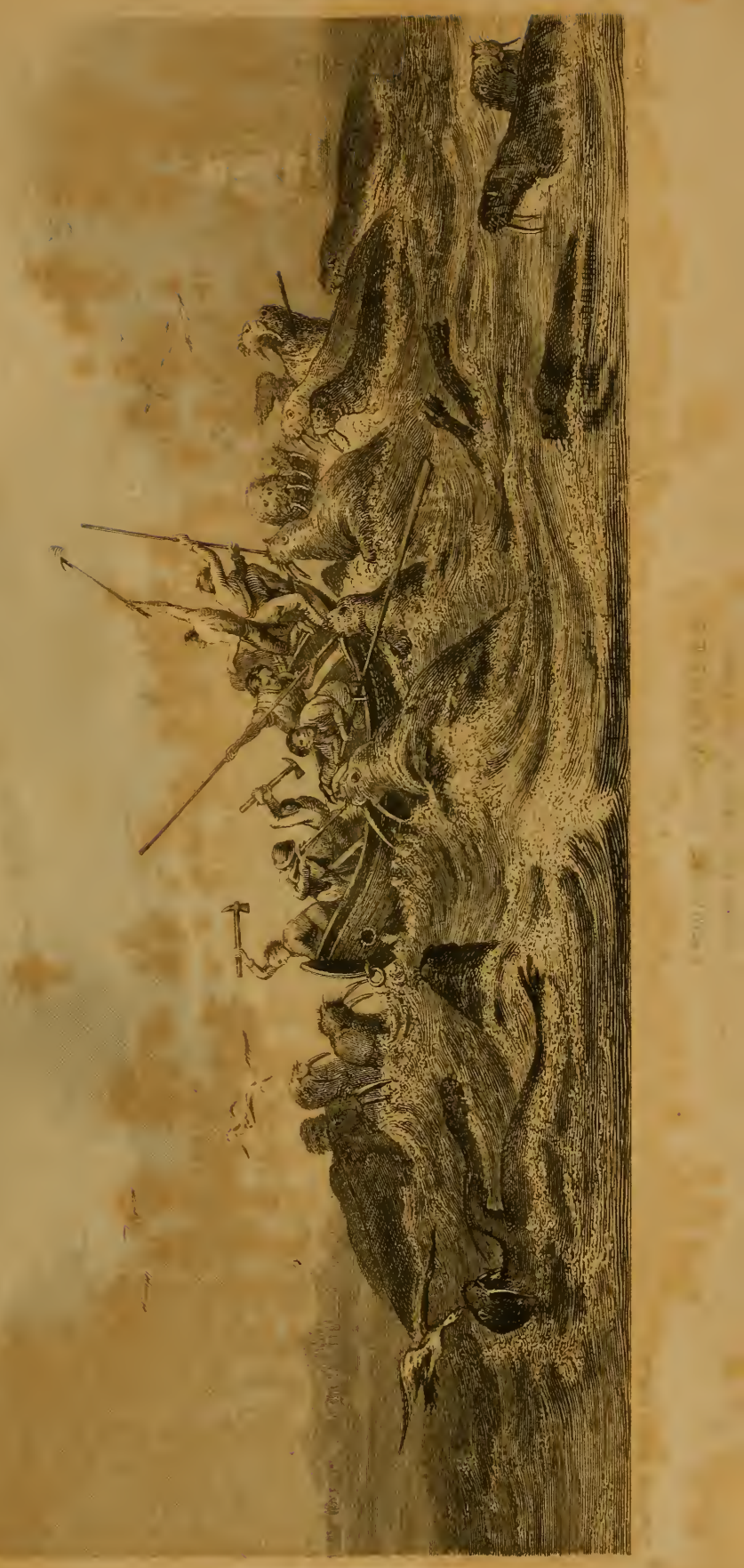



effect; the attack was continued, and the enraged little animal, though disfigured with wounds, even crawled upon the ice in pursuit of the seamen, who had relanded there, until one of them, out of compassion, put an end to its sufferings.

The reciprocal affection of parent and offspring was certainly never more strongly displayed than by these animals. On another occasion, one of our boats attacked a male and a female, and wounded the latter in the head whilst she was suckling her young, which she retained against her breast with her flipper. The male immediately plunged into the sea, apparently to revenge the aggression upon the boat; while the female deliberately placed her young more carefully under her left fin, and in that manner made her way to the edge of the ice, in spite of three lances that were planted against her breast, and nearly swamped the boat by her fall into the water. When there, she relinquished her hold of the young one, who rushed toward the boat, snorting with its little nostrils, and so enraged that it seemed as if it would have swallowed her up if it had possessed the power; but, receiving a blow upon the head, it swam away and rejoined its parent, who, suffering from the wounds she had received, was endeavouring to 
get upon every piece of ice that came in her way. The male, however, as if aware of the danger of another attack in such situations, always counteracted these efforts by pulling her back with his tusks; but, nevertheless, appeared determined to secure her escape by buoying her up in the water, and by propelling her forward until she was beyond our reach. We observed many similar acts of compassion in these animals towards their wounded companions; and on one occasion, in particular, when several walruses were attacked upon a beach near Magdalena Bay. The first discharge of muskets drove all those which could crawl, into the sea, but immediately upon their panic subsiding they returned to the shore and dragged their wounded companions into the water, either by main force, or by rolling them over with their tusks.

This compassionate conduct towards the maimed has been mistaken by seamen, and has given rise to a belief, that these animals, like the porpoises, cannot endure the sight of blood, and chace and worry the wounded to death; but I have not the smallest doubt myself, that it is an act of compassion alone, exercised for the purposes I have already mentioned, arising from an extraordinary instinct peculiar to themselves, as we have in several instances 
seen the wounded, when out of danger, quietly crawl upon the ice. I might relate other instances of sagacity and affection in these animals, but these are perhaps some of the most remarkable.

In the year 1608 one of these animals was brought to England alive, and exhibited at the Court, "where the king, and many honourable personages, beheld it with admiration for the strangenesse of the same, the like whereof had never before beene seene alive in England. Not long after, it fell sicke and died. As the beast in shape is very strange, so is it of strange docilitie, and apt to be taught, as by good experience we often proved."*

Our sportsmen had succeeded in capturing two walruses only when the boats were recalled, in consequence of the ice being observed to connect itself with Cloven Cliff, and the floes to be closing together, so as to prevent the possibility of entering between them. Captain Buchan, however, judged, from general appearances, that a favourable change would soon occur; and, being anxious to keep as near as possible to the pack, that he might be in readiness to take advantage of the first opening that offered, he determined to anchor between the islands con-

* Purchas. 
tiguous to Cloven Cliff. This position not only afforded an opportunity of watching the state of the ice from the hills more narrowly than could be done from the ships, but possessed the additional advantage of enabling us to do so without incurring the risk of being driven off the coast by northerly winds. The expedition was, in consequence, directed to proceed to Fair Haven, where it anchored on the 28th, in fifteen fathoms water, between Vogel Sang and Cloven Cliff.

This anchorage is entirely free from hidden danger, easy of access, and tolerably well sheltered from southerly and westerly winds, and the high rolling seas which attend gales from those quarters; but it is quite open to the north. In consequence of this exposure, the road is liable to be incommoded by pieces of ice, which are occasionally drifted in from that direction; and some degree of danger is also to be apprehended from the fragments of landbergs, which are sometimes carried thither by the tides.

All the islands about the anchorage are high. and precipitous; but they are, nevertheless, covered with lichens, and other rich pasturage for rein-deer, a species of animal so abundant, upon Vogel Sang in particular, that that island alone 
supplied us with forty carcasses. They were at this time in such high condition, that the fat upon the loins of some measured from four to six inches, and a carcass, ready for being dressed, weighed two hundred and eighty-five pounds. In August, however, they were so lean that it was rare to meet with any fat upon them.

From the wary disposition, and the very keen scent of these animals, we found it extremely difficult to get within gun-shot of them, especially from to windward; and were obliged either to separate into two or three parties, and to harass them until they took to the water, where they were easily overtaken by the boats, or to secrete ourselves behind large stones, contiguous to one of their walks, and there wait until they approached. They were, at this time, in pairs, and when one was shot the other would hang over it, and occasionally lick it, apparently bemoaning its fate; and, if not immediately killed, would stand three or four shots rather than desert its fallen companion. This compassionate conduct, it is needless to say, doubled our chance of success; though, I must confess, it was obtained in violation of our better feelings. Their sympathy must, indeed, have been very strong to have induced them to remain so long by their wounded; for if at other times our shots missed, 
the panic occasioned by the discharge of the guns was so great, that they fled in all directions, and there was no chance of getting near them again. When pressed, they readily took to the water to swim to islands that were three or four miles distant. In this way, we managed to get four unhurt on board the Trent, where we had recourse to every contrivance in our power to retain them alive; but they were so wild that they broke their limbs, and inflicted other serious wounds, which obliged us to kill them in order to put an end to their sufferings.

Upon the small rocky islands near the anchorage the birds were no less abundant, in proportion, than the rein-deer upon Vogel Sang. The king eider-ducks (Somateria spectabilis) had possessed themselves of one of these islets, and were so numerous, that it was scarcely possible to walk without stepping upon their nests; and, could we have divested ourselves of all consideration for the young birds, we might have filled several sacks with that valuable commodity, eider-down, of which their nests were composed. It was the period of incubation; and we had many opportunities of witnessing the determined manner in which they defended their nests, frequently remaining upon them until they were knocked over with sticks. Even the 
burgermeisters, strontjaggers, sea-swallows, and other birds, which were always hovering about and watching for opportunities of devouring the eggs or the young birds, dared not molest the ducks whilst upon their nests, and could only secure their prey when foxes or some of the larger animals drove them into the sea. A practice, common to these birds, which I have not seen mentioned in their history, marks the provision which nature has made against some of the casualties to which their species are liable, and from which the young might be destroyed in their embryo state by the parents being kept away from their nests in so cold a climate. When immediate danger compelled them to seek their own safety in flight, they hastily drew the down of the nest over the eggs, and glued it there with a yellow fluid, which they deposited as they arose. This precaution not only kept in the warmth of the eggs, by interposing between them and the air a thick covering, which the cold would require some time to penetrate, but it was otherwise useful from its being of so very offensive a nature that the foxes would not touch the eggs that were tainted with it. If it happened that they were suddenly surprised, and compelled to take wing without making this provision for the safety of their young, they flew 
to a short distance only, and, unless the danger was very imminent, would return almost immediately and cover up their nests, after which they took flight with apparently less solicitude. In Norway, these birds make their nests and lie amongst the juniper bushes; but here they build them amongst the rocks and loose stones upon the small islets off the coast. The down is of that tenacious character that it adheres to every rough substance it touches, and thus effectually prevents the nests being overturned or blown away by strong winds. The quantity of down required for one of these nests deprives the parent of a great portion of the down upon its breast, which is in consequence left nearly bare for a considerable time; and it is quite pitiable to observe the condition of those which have, probably, been obliged to make a second nest. The males may also be seen occasionally with their breasts denuded of down, from their having contributed to the formation of the nest. They are the constant attendants upon the ducks whilst they are sitting, and frequently procure food for them; they also assist in the defence of the young, and may sometimes be seen keeping the eggs warm whilst the ducks have gone to a distance to procure food. Here, however, their attentions appear to end for the season, for to- 
ward the close of the summer the drakes assemble and take their selfish departure, leaving the ducks to find their own way, and to help their young along in the best manner they can. In due time, however, they also take their departure, and immense flocks of adults and young may be met a hundred miles or more from land, slowly migrating to the southward, some of the young birds being quite weak upon the wing.

As this species of eider-duck is almost a stranger on the shores of Britain, they probably pass the winter in some parts of the rocky coast of Norway, but at any rate they must traverse about a thousand miles of open sea, and brave many a tempest before they reach their winter home. 


\section{CHAPTER 1 II.}

Put to sea from Fair Haven.-Renew the attempt to get to the northward.-Difficulty of proceeding.-Beset in the ice.-Regain the open sea, after having been three weeks beset.-A storm compels the expedition to take refuge in the ice.-Perilous situation of the vessels.-Their fortunate deliverance.-The shattered condition of the ships obliges them to go into port.

During the time the expedition continued at Fair Haven, the hills were ascended almost daily for the purpose of surveying the state of the ice in the offing: and, on the 6th July, finding it had been driven to the northward, the ships put to sea, and sailed as far as $80^{\circ}$ $15^{\prime} \mathrm{N}$. Here the same impenetrable barrier that had before impeded their advance was encountered, with as little success as before; and the ships, in their endeavour to extricate themselves from the loose ice that skirted the edge of the main body, received heavier concussions than they had hitherto sustained.

Thus, in every attempt to reach a high 
northern latitude, and even to penetrate between the ice and the coast of Spitzbergen we had been repulsed, and obliged to retrace our steps at the risk of staving the ships. The summer was now well advanced; and the effect produced upon the ice by temperature and southwesterly gales during the six weeks we had been upon the coast was so trifling, that we began to entertain serious doubts of being able to effect anything of consequence on the western side of Spitzbergen : the vessels, however, were kept close to the pack. On approaching it the following day we were most agreeably surprised to find that its aspect was now as promising as on the preceding day it had been discouraging. So rapid had been the motion of the ice during the night, that channels of water were observed in every quarter, and the wind, moreover, was favourable for entering those which led in the direction we had been so long and anxiously endeavouring to proceed.

Captain Buchan, whose patience had been severely tried, and whose perseverance throughout the most disheartening circumstances had never once relaxed, but, on the contrary, had been such as to inspire the fullest confidence in the minds of every person under his command, lost not a moment in directing his vessel 
towards one of these channels, which he entered in the most determined manner, spreading every sail his masts would bear, in which he was most cheerfully followed by the enterprising commander of his consort, and to the great joy of all on board. However unfavourable might have been the prognostications of success entertained the evening before, the flattering prospect now before us, and the resolute conduct of our commodore, entirely removed them, and we at length cherished an expectation which everything promised fair to realise.

The ships continued to advance rapidly along the narrow channels between the floes, trimming their sails at each turn of the canal, and receiving occasional assistance from a light line cast to a few active men upon the ice, whose exertions were at one time necessary in order to check the bow or quarter of the vessel, and otherwise assist the helm when the turnings of the channel were abrupt; at others, to prevent the vessel falling to leeward when her way had been deadened by the resistance of some heavy piece of ice which she had encountered in her path. A proficient in the art of marine drawing might here have found a beautiful subject for his pencil. The endless and ever-varying forms of the ice; the glassy smooth canals 
winding among the floes, and reflecting the bright blue colour of their banks; the vessels in various positions, trimming their sails to maintain their course; groups of figures, busily occupied upon the ice; and many other objects which would have presented themselves to a practised eye, would have supplied materials for a picture which I shall not spoil by attempting to describe.

Noon came, and still the prospect was favourable even from the most elevated point of our mast-head. As the day advanced, however, we had our misgivings: some occasional closing of the canals, and other obstructions, foreboded disappointment; and, toward evening, it became too evident that we had overrated the advantages of the morning. The scene was indeed changed; the channels by degrees disappeared, and the ice, with its accustomed rapidity, soon became packed, encircled the vessels, and pressed so closely upon them, that one boundless plain of rugged snow extended in every direction. Even the sea, in which we had sailed but a few hours before, was now far beyond our horizon, and its position could be determined only by a dark lowering sky that overhung the southern quarter.

After a few hours the ice opened, but the 
channels were narrow and very partial. We waited some little time in the hope that they would increase, and that the ships might again use their sails, but were soon convinced of the hopelessness of getting to the northward by such means alone.

As we were now fairly entered into the pack, and the summer was already well advanced, Captain Buchan determined to prove, by a desperate effort, what advance it was possible to make, by dragging the vessels through the ice whenever the smallest opening occurred. We accordingly took the earliest opportunity of commencing this laborious experiment, which was performed by fixing large ropes to iron hooks driven into the ice, and by heaving upon them with the windlass, a party removing obstructions in the channels with saws. After working several hours in this manner, we reached a tolerably clear channel, and with the aid of our sails ran a few miles to the northward, encountering in the way heavy pieces of ice, which we could not avoid running against. Our progress, however, was arrested before noon by the closing of the channels; and a very heavy pressure of the pieces about us rendered it necessary to put the vessels into a small bay, formed in a field of ice that was at hand. 
This was the most northerly position reached by the expedition during the voyage, and it would have been a great gratification could we have obtained an observation of the sun to determine the exact latitude; a measure which was rendered still more desirable by a difference of several miles which occurred in the reckoning of the two ships. By that kept on board the Dorothea the latitude was $80^{\circ} 31^{\prime} \mathrm{N}$.; while that of the Trent was $80^{\circ} 37^{\prime} \mathrm{N}$., the mean of which is $80^{\circ} 34^{\prime} \mathrm{N}$.

We had not been long secured to the field of ice before we had the mortification of finding ourselves drifting fast to the southward, both by the lead-line and by the bearings of the land; and the next day, though by warping we thought we had gained several miles, our latitude was less by nearly four leagues than it was when we first made fast, viz. $80^{\circ} 23^{\prime} \mathrm{N}$.

The 9 th and 10 th were passed in dragging the vessels through the ice with ropes and iceanchor's as before, but this tedious duty was repaid with very ill success, for although we left the ice far behind us, yet the current set so fast to the southward that, in spite of the labour of two long days, we lost three miles of ground, and observed in latitude $80^{\circ} 20^{\prime} \mathrm{N}$. It was this constant tendency of the water to 
the southward that occasioned the failure of the expedition under Captain Parry, in 1827, and against which it is quite useless for any vessel to contend, unless occasionally favoured with open water.

Captain Parry remarks, in his Journal, "On the 26th we obtained the meridional altitude of the sun, by which we found ourselves in latitude $82^{\circ} 40^{\prime} 23^{\prime \prime} \mathrm{N}$., so that since our last observation, at midnight on the $22 \mathrm{nd}$, we had lost by drift no less than thirteen and a half miles." And again, "Thus it appeared, that for the last four or five days we had been struggling against a southerly drift, exceeding four miles a day." * He also says, "It had for some time past been too evident that the nature of the ice with which we had to contend was such, and its drift to the southward, especially with a northerly wind, so great, as to put beyond our reach anything but a very moderate share of success in travelling to the northward."

What may be the cause of this current can, at the best, be but a conjecture; and we must at present remain satisfied with the knowledge of the simple fact. It is a fortunate circumstance that, during the period in which the ice

* Parry's Attempt to reach the North Pole, 1827. 
is brought down by this stream, there is a prevalence of southerly winds in the lower latitudes, otherwise the quantities of ice which are now accumulated on the coast of Greenland would be carried down close upon our own shores, and no doubt affect our climate.

While engaged in the occupation of dragging the vessels we saw several bears, some of which approached very near to the seamen who were left on the ice to watch the ice-anchors. It not unfrequently happened that one man only was thus employed, and we were occasionally apprehensive, from the very close approach of these animals, that they would prove mischievous; but they seemed disposed to gratify their curiosity only, for, after advancing near enough to scent them, they threw their long necks from side to side, and leisurely pursued their stalking pace in some oblique direction. The pace of these animals seldom exceeds a walk, but from the length of their strides even this rate is quicker than that of a man. Nothing seems to impede their progress, nor do they ever take the trouble to go round a hillock or a pool of water, but either climb over the one or dash into the other, and swim to the bank on the opposite side, which they ascend without difficulty and resume their course. They were, how- 
ever, always diverted by the scent of the track of the seamen upon the ice, or by the rubbish that had been thrown upon the floes, which the keenness of their scent enabled them to detect at a considerable distance, and it was rare, when we moved from a place, that it was not speedily visited by one of these animals.

During the period of our detention in the ice we found that with westerly or southerly winds, and occasionally upon the change of the tide, the fields of ice would sustain such a pressure that their points would yield and be crumbled to atoms; the bay ice would slide upon, and form a layer over the field that was in contact with it; immense hummocks would be overset, and sometimes forced under water; and in other parts, again, fragments would be piled up thirty or forty feet in height. As nothing made of wood can withstand these pressures, a vessel, if caught, must either be crushed, or rise and allow the ice to advance until it meets an opponent as unyielding as itself. Fortunately, the wedge-like form of a vessel is favourable to her rising, and the outline of the fields is generally so irregular that some points of it are nearly certain to receive the strain before it presses much upon the ressel; the squeezes are, however, occasionally very dangerous. On the even- 
DAMAGE FroM PRESSURE OF THE ICE. 113

ing of the 10th the Trent sustained one which made her rise four feet, and heel over five streaks; and on the 15 th and 16 th both vessels suffered damage, especially the Dorothea, from her being longer and more wall-sided than the Trent. On that occasion we observed a field fifteen feet in thickness break up, and the pieces pile upon each other to a great height, until they upset, when they rolled over with a tremendous crash. The ice near the ships was piled up above their bulwarks, to the great danger of the bowsprit and upper works. Fortunately the vessels rose to the pressure, or they must have had their sides forced in; the Trent received her greatest damage upon the quarters, and was so twisted that the doors of all the cabins flew open, and the panels of some started in the frames, while her false stern-post was moved three inches, and her timbers cracked to a most serious extent. The Dorothea suffered still more : some of her beams were sprung, and two planks on the lower deck were split fore and aft, and doubled up, and she otherwise sustained serious injury in her hull. It was in vain that we attempted any relief, our puny efforts were not even felt, though continued for eight hours with unabated zeal; and it was not until the tide changed that the smallest effect was pro. 


\section{SPECIMENS OF CORAL BROUGHT UP.}

duced. When, however, that occurred, the vessels arighted and settled in the water to their proper draft.

From the 12th to the 19 th we had westerly winds, and thick foggy weather, with some hard showers of rain, and the ice remained so close that for nearly a week we saw neither land nor water. Our soundings increased from 80 to 300 fathoms; from which it was judged that we were driving to the westward, as the water shoaled in the opposite direction; and this we afterwards found to be correct. From these depths we brought up several species of living zoophytes, a star-fish, a lobster, a piece of sponge, and a branch of dead coral attached to a stone.

That a coral of this species, the growth of which is generally limited to a mild climate, should be brought up from a great depth in the latitude of $80^{\circ}$ north, may form a subject of curious speculation to the naturalist.

We certainly know of no current in the Atlantic save that of the strongest part of the gulfstream, which could transport such a stone, with its appendage, so many miles from the supposed place of its growth; and if we did, the tender ramification of its perfect branches would not permit the conclusion that it had suffered such a violent mode of transportation. The inference, 
therefore, seems to be, that the specimen was reared near where it was found, and that either the zoophyte is capable of enduring a greater degree of cold, and has a wider range of habitation, than has hitherto been generally supposed, or else the temperature of the Polar region has undergone a very considerable change.

On the 19th the weather cleared up, and we had the mortification to find the ice close in every direction, and that there did not appear the smallest chance of our being able to proceed one mile further to the northward. Captain Buchan, therefore, began seriously to contemplate the utility of further prosecuting the attempt in this direction. The ice had undergone no perceptible change with the advance of the season, and we could not expect to derive any material advantage from a diminution of its thickness. As little improvement could we expect from the influence of winds, which had a very trifling effect in separating the ice at this distance from its margin. In the meanwhile several days' hard labour had proved that unless some material alteration took place the ships could not even maintain their position against the current which was setting to the southward, much less gain any ground in the opposite direction.

Under these discouraging circumstances, Cap- 
tain Buchan thought it expedient to endeavour to regain the open sea as quickly as possible, in order to renew the attempt in another direction. But from this we were now about thirty miles distant, without any opening presenting itself which would aid the ships in effecting their release. We, however, loosed from the floe of ice which had so materially befriended us during heavy pressures, and commenced warping the ships in the desired direction; but the difficulty of moving them was such, that, after five hours' hard labour, we had succeeded in gaining only one mile towards our release.

For nine successive days from this period the crews were occupied day and night in endeavouring to extricate the ships; and at the expiration of that time we were gratified by the discovery of the open sea from the mast-head. As we neared the margin the changes in the state of the ice became greater, so that we were at one time sailing with a press of canvas, and the next sustaining heavy squeezes between fields of ice; at length a few "streams" only intervened between the ships and the open water, and having a fair wind we forced through them, striking some of the pieces so forcibly that on two occasions the brig had stern-way. Thus by six o'clock in the evening we had the satisfaction 
of finding ourselves again in a clear sea, after having been three weeks encircled by ice, extending to the horizon in every direction. The pleasure we felt at again having our vessels under command cannot be equalled by any arising from the ordinary occurrences of a maritime life. They at first appeared to bound through the water, and every passing wave brought with it a peculiar gratification. As we increased our distance from our icy prison we observed a wide channel leading to the eastward, between the land and the ice, which would probably have enabled us to advance nearly as far as the Seven Islands. But this route had been attempted several times, and had always occasioned disappointment, and ended in great difficulty in extricating the ships.

Captain Buchan did not therefore bestow upon it a second thought; but, on the contrary, being of opinion that he had given the ice a fair trial in the vicinity of Spitzbergen, and that it was utterly useless to persevere any longer in a northern direction from thence, he determined upon examining the ice towards Greenland; and, in the event of finding it equally impenetrable there, to proceed round the south cape of Spitzbergen, and make an attempt between that island and Nova Zembla. 
We accordingly steered to the west, elated at the prospect of this new adventure; but, scarcely had we time to contemplate the change in our destination, when the situation of the vessels demanded our most serious attention. In order to execute the first part of Captain Buchan's intentions, it was necessary to trace the ice, and minutely to examine its outline; and we were thus sailing along it at a reasonable distance, when a gale of wind from the south-west arose so suddenly that we were at once reduced to storm-staysails. The sea got up equally fast, and rendered ineffectual our endeavour to maintain our position with regard to the ice, on the western tack at least, and we in consequence wore round, early in the morning of the $30 \mathrm{th} \mathrm{July}$, in the hope of being more successful on the other.

An hour had scarcely elapsed from this manœuvre, when the main body of ice, which had been lost sight of for a short time, was seen close upon the lee-beam, with the sea beating furiously upon it. The imminent danger to which the vessels were now exposed induced us to press them with all the sail they would bear, by setting the close-reefed main-topsail and foresail, but they availed us nothing; we settled down gradually upon the danger, and were soon 
amongst the large pieces of ice, which in windy weather skirt the edge of the pack. These pieces consist of the heaviest ice, or that which has the greatest hold in the water, and remain at the edge in consequence of their being less operated upon by the wind. As we could not afford to lose an inch of ground by bearing up to avoid these masses, we received many very heavy concussions in turning them out of our course.

The Dorothea, having been more to leeward than the Trent when the gale sprung up, was so close to the ice at half past nine o'clock in the forenoon that, in order to escape immediate shipwreck, it became necessary for her to take refuge amongst it, - a practice which has been resorted to by whalers in extreme cases, as their only chance of escaping destruction. As she bore away, we watched the result of the evolution with the greatest anxiety, - since, from the formidable aspect of the ice under our lee, it did not appear possible for any ship to survive an encounter with it, and we could not but be aware that the fate of our own vessel might soon be connected with the issue of her daring exploit. We were, however, left in the most distressing uncertainty as to both, for the Dorothea was almost immediately obscured by the foam 
and spray of the sea, which were carried up to a great height. Thus circumstanced, our first impulse was to run our own ship into the ice by the side of our consort, in the hope that by so placing the vessels they might be of service to each other; but, calling to mind that the frame of the brig was weak in comparison with that of the Dorothea, we did not think it probable that we could render her any assistance; and, consequently, as the wind at the moment favoured an expectation of our own vessel being able to reach into smoother water, we held on our course a little longer.

We, however, soon found that we had nothing left but to follow the example of the Dorothea, and began to make every preparation in our power to withstand the encounter. It evidently appeared that we should have most to apprehend from the first concussion; and, in order to avert the effect of this as much as possible, a cable was cut up into thirty-feet lengths, and these with plates of iron four feet square, which had been supplied to us as fenders, together with some walrus's hides, were hung round the vessel, especially about the bows. The masts, at the same time, were secured with additional ropes, and the hatches were battened and nailed down. By the time these precautions had been 
taken, our approach to the breakers only left us the alternative of either permitting the brig to be drifted broadside against the ice, and so to take her chance, or of endeavouring to force fairly into it by putting before the wind, as the Dorothea had done. Had we been permitted to witness the fate of that ship, we should not have hesitated to follow her example, but, as it was, a momentary doubt rested upon our minds as to the prudence of so desperate a measure. At length, the hopeless state of a vessel placed broadside against so formidable a body became apparent to all, and we resolved to attempt the latter expedient.

While we were yet a few fathoms from the ice, we searched with much anxiety for a place that was more open than the general line of the pack, but in vain ; all parts appeared to be equally impenetrable, and to present one unbroken line of furious breakers, in which immense pieces of ice were heaving and subsiding with the waves, and dashing together with a violence which nothing apparently but a solid body could withstand, occasioning such a noise that it was with the greatest difficulty we could make our orders heard by the crew. This scrutiny, although but of momentary duration, allowed us more narrowly to examine the scene around us 
and I wish I could in this place communicate to the reader any just conception of it, but I am utterly at a loss for words in which to embody its description.

No language, I am convinced, can convey an adequate idea of the terrific grandeur of the effect now produced by the collision of the ice and the tempestuous ocean. The sea, violently agitated and rolling its mountainous waves against an opposing body is at all times a sublime and awful sight; but when, in addition, it encounters immense masses, which it has set in motion with a violence equal to its own, its effect is prodigiously increased. At one moment it bursts upon these icy fragments, and buries them many feet beneath its wave, and the next, as the buoyancy of the depressed body struggles for reascendancy, the water rushes in foaming cataracts over its edges; whilst every individual mass, rocking and labouring in its bed, grinds against and contends with its opponent until one is either split with the shock or upheaved upon the surface of the other. Nor is this collision confined to any particular spot; it is going on as far as the sight can reach; and when from this convulsive scene below, the eye is turned to the extraordinary appearance of the blink in the sky above, where the unnatural clearness of a calm 
and silvery atmosphere presents itself, bounded by a dark hard line of stormy clouds, such as at this moment lowered over our masts, as if to mark the confines within which the efforts of man would be of no avail, the reader may imagine the sensation of awe which must accompany that of grandeur in the mind of the beholder.

At this instant, when we were about to put the strength of our little vessel in competition with that of the great icy continent, and when it seemed almost presumption to reckon on the possibility of her surviving the unequal conflict, it was gratifying in the extreme to observe in all our crew the greatest calmness and resolution. If ever the fortitude of seamen was fairly tried, it was assuredly not less so on this occasion; and I will not conceal the pride I felt in witnessing the bold and decisive tone in which the orders were issued by the commander of our little vessel, and the promptitude and steadiness with which they were executed by the crew.

We were now so near the scene of danger as to render necessary the immediate execution of our plan, and in an instant the labouring vessel flew before the gale. Each person instinctively secured his own hold, and with his eyes fixed upon the masts, awaited in breathless anxiety the 


\section{THE TRENT DASHES INTO THE ICE.}

moment of concussion. It soon arrived, - the brig, cutting her way through the light ice, came in violent contact with the main body. In an instant we all lost our footing, the masts bent with the impetus, and the cracking timbers from below bespoke a pressure which was calculated to awaken our serious apprehensions. The vessel staggered under the shock, and for a moment seemed to recoil ; but the next wave, curling up under her counter, drove her about her own length within the margin of the ice, where she gave one roll, and was immediately thrown broadside to the wind by the succeeding wave, which beat furiously against her stern, and brought her lee-side in contact with the main body, leaving her weather-side exposed at the same time to a piece of ice about twice her own dimensions. This unfortunate occurrence prevented the vessel penetrating sufficiently far into the ice to escape the effect of the gale, and placed her in a situation where she was assailed on all sides by batteringrams, if I may use the expression, every one of which contested the small space which she occupied, and dealt such unrelenting blows that there appeared to be scarcely any possibility of saving her from foundering. Literally tossed from piece to piece, we had nothing left but patiently to abide the issue, for we could scarcely keep our 


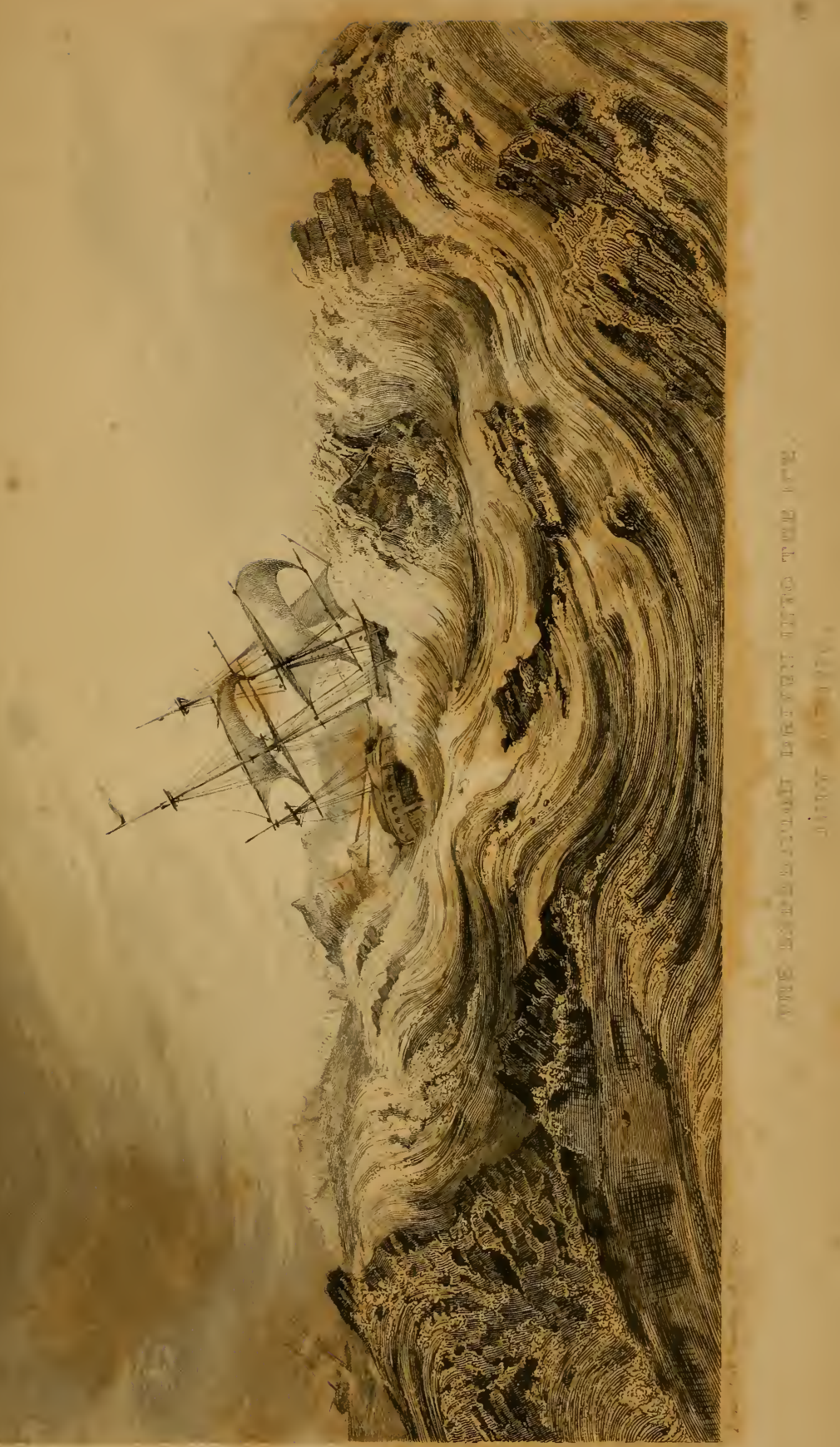





\section{A LAST RESOURCE.}

feet, much less render any assistance to the vessel. The motion, indeed, was so great, that the ship's bell, which in the heaviest gale of wind had never struck of itself, now tolled so continually that it was ordered to be muffled, for the purpose of escaping the unpleasant association it was calculated to produce. In anticipation of the worst, we determined to attempt placing the launch upon the ice under the lee, and hurried into her such provisions and stores as could at the moment be got at. Serious doubts were reasonably entertained of the boat being able to live amongst the confused mass by which we were encompassed; yet, as this appeared to be our only refuge, we clung to it with all the eagerness of a last resource.

After some time had elapsed without any improvement in our situation, and when, on the contrary, it became more and more evident, from the injury the vessel repeatedly received, that she could not hold together very long, we were convinced that our only chance of escape depended upon getting before the wind, and penetrating further into the ice. To effect this, with any probability of success, it became necessary to set more head-sail, though at the risk of the masts, already tottering with the pressure of that which was spread. Watching an opportunity, 
some of our expertest seamen gained the foretopsail-yard for this purpose, and let a reef out of the sail, while the jib was dragged half way up its stay by means of the windlass. This additional pressure upon the fore part of the vessel happily succeeded beyond our expectations. The brig came into the desired position, and with the aid of an enormous mass under the stern, she split a small field of ice, fourteen feet in thickness, which had hitherto impeded her progress, and effected a passage for herself between the pieces.

The situation of the ressel was now greatly improved, so much so that, by carefully placing the fenders, particularly the walrus hides, between the ice and her sides, the strokes were so much diminished that we had scarcely any doubt of saving her, provided the gale did not last long. How often and anxiously did we at this time turn our telescopes in the direction in which we had last seen our consort; for although conscious that neither could render the other any immediate assistance, yet it would have been a great consolation to have known that she was still afloat, and that in the event of the worst happening to one, there was yet a remote chance of ultimate relief from the other vessel. But between the Dorothea and ourselves there was 
interposed a dense cloud of spray, which limited our view to a few fathoms only, and effectually prevented our obtaining any information as to her condition.

After about four hours of the most anxious solicitude, the gale began to moderate; the vessel became comparatively easy; and the mist arising from the breakers clearing away, we had the gratification to observe the Dorothea still afloat. We, however, soon learnt, by signal, that she had suffered very severely. The storm which had arisen suddenly, now as speedily abated, and our efforts were immediately directed towards the liberation of our vessel, lest the wind should again increase and complete the work of destruction, so effectually begun. It was a difficult task which we had to perform, and one that was by no means yet free from danger; but the blows which the vessel now encountered were so comparatively light with respect to those she had already withstood, that we thought little of them; besides, the necessity of the measure seemed so urgent that we persevered in our endeavours, and about four o'clock succeeded in getting the Trent quite clear of the ice. The Dorothea, however, was too much damaged to risk the heavy blows which attended this operation, and continued embayed in the ice until six o'clock the follow- 
ing morning, when, with the assistance of our boats, she also effected her release.

Thus, by the blessing of Divine Providence, both vessels were again in an open sea; and that heart must indeed have been obdurate which did not, secretly, at least, return thanks to the Almighty for a deliverance from such imminent danger. But we could not conceal from ourselves that although now unfettered by ice, our prospects were widely different from those with which, but a few hours before, we navigated an open sea. Then everything was before us, and the mind was buoyant with the prospect of fresh enterprises. Now both vessels were disabled, and one, at least, was in a foundering condition. So that although ignorant of the full extent to which either had suffered, it was nevertheless quite evident that, as regarded the main object of the Expedition, they were both useless.

In a leaky state, we made the best of our way to Fair Haven, in Spitzbergen, and thence to a secure anchorage in South Gat, in the same island. In approaching this anchorage the Trent, under full sail, bounded over a sunken rock, and struck so hard that, had not our recent encounter been fresh in our minds, we should have felt uneasy for the consequence; but it now passed off without much attention. 


\section{CHAPTER IV.}

Extent of damage ascertained.-Captain Buchan's determinanation thereupon. - Description of the anchorage, and of the adjoining coast.-Geological feature.-Line of perpetual snow.-Glaciers, their formation, \&c.-Danger of approaching them.

As soon as the Expedition was securely moored at South Gat, an inspection of the hulls of both vessels took place. The Trent was found to have sustained less injury than the Dorothea, which had the greater part of her timbers either broken or shook, and several of her beams sprung. The larboard side had been forced in so much, that several spare oak planks, four and five inches in thickness, which were stowed in the wing, were found broken in various places. The spiritroom, which was built in the centre of the ship, was forced in; many casks of provision, stowed in the body of the hold, were stove, and even some that were bedded in coals in the ground tier had their staves broken. It is hardly possible to imagine such extensive mischief occur- 
ing to any vessel without her immediately foundering, and it is quite evident that, under Providence, nothing but the judicious precaution of lining the vessels with felt prevented the occurrence of that disaster.

As soon as the extent of the damage the Dorothea had. sustained was communicated to Captain Buchan, he began seriously to consider the propriety of complying with that part of his Instructions which directed that, in the event of his own vessel being disabled, he should abandon her, and prosecute the voyage singly in the Trent.* The subject was naturally one of great anxiety, from the conflicting arguments which arose in the course of its consideration; and the urgent request of the commander of the Trent that he might be allowed to proceed in his own vessel upon the interesting service still unexecuted, rather increased than diminished the embarrassment. To have taken command of the Trent himself would have been Captain $\mathrm{Bu}$ chan's straightfor'ward line of duty as pointed out by the Instructions; but, either to have done this, or have complied with Lieutenant Franklin's solicitation, would have subjected the Dorothea to the necessity of returning home unaccompanied, which might have proved fatal to

* See Instructions. 
all her crew; and, in addition, by taking command of the Trent himself, Captain Buchan felt he would incur the appearance of wishing to escape the danger to which his crew would be exposed. To this, therefore, he determined on no account to accede; and as to Lieutenant Franklin's request, he preferred taking upon himself the responsibility of appearing to deviate from his Instructions, rather than subject his crew to the risk of proceeding home singly in a vessel so shattered and unsafe. He finally determined, therefore, upon remaining in his own ship, and sharing the fate of those who had accompanied him in so many trials and dangers, retaining also the Trent as a convoy.

The next consideration was, whether something more might not yet be accomplished by a boat expedition over the ice; but, upon consulting with Lieutenant Franklin, and examining into the resources of the ships for such an enterprise, they were found so inadequate to the purpose that the project was speedily given up. Captain Buchan was thus reluctantly compelled to abandon all further discovery, and to proceed to England as soon as the nècessary repairs of his vessel should be completed.

It was now proposed to make the most of the few days which the vessels had to remain 
at the anchorage. Mr. Fisher, the astronomer, was directed to fix his observatory upon Dane's Island, and to commence his observations on the pendulum, the dip, and the intensity of the needle, the results of which I have briefly given in the Appendix, as they have been published elsewhere by that gentleman; and Lieutenant Franklin and myself were employed to construct a plan of the port and the adjacent islands,- which indeed was much required, as the charts that were before in use were extremely incorrect, so much so that even the number of islands was erroneously given. We also assisted Mr. Fisher in determining the geographical position of the observatory.

In the prosecution of our duties we were led to all parts of the coast which could be conveniently reached by a boat. We found the shores of this part of Spitzbergen in general very steep, for, with the exception of here and there a narrow flat bordering upon the sea, they speedily rise into mountains of from two thousand feet and upwards in height, increasing to a far greater altitude in the interior. These hills are, for the most part, inaccessible, either on account of the abruptness of the ascent, or of the treacherous nature of their surfaces, upon which large stones and fragments of the mountain are so 
lightly poised, that the smallest additional weight precipitates them to the bottom of the hill. I have already described the difficulty of the ascent of Rotge Hill; the same difficulty we found to beset the ascents in other parts of the coast. This impediment did not escape the notice of early navigators, some of whom lost their lives in their endeavour to overcome it. Martens, speaking upon this subject, recommends chalking the footsteps during the ascent, in order that the descent may be more easy and certain, and others have had recourse to various expedients. But, how far these recommendations are to be followed it is not my intention to inquire; I mention the circumstance merely to show, that the unusual precipitancy of the elevations has incurred general observation.

The summits of the mountains, which form an extensive range, traversing the island in a north and south direction, terminate in remarkably sharp peaks, from which, as I have elsewhere observed, the island has derived its name. The lateral ridges which branch off from this great chain are less pointed, and sometimes partake of the appearance of a house-top, of which there is a remarkable instance on the north side of Magdalena Bay. These ridges, however, are sufficiently surmounted by peaks to form a strong 
contrast between the main and the islands lying off it; which, although steep, have smooth, rounded surfaces; upon several of which the snow remains throughout the year.

Spitzbergen appears to follow the rule which prevails in many parts of our globe, in having its culminating points towards the western limit of its territory; so far at least as our knowledge of its formation extends. On passing to the eastward the descent is very perceptible, the sharp peaks disappear, and a more gentle undulation may be traced as far as the coast has as yet been explored. This alteration of external appearance is accompanied by a change in the geological character of the beds. To the westward we have almost exclusively the primitive rock, forming both the islands, and the lateral ridges which come down to the coast line; and, no doubt, the higher chain from which they diverge is of the same character. As we proceed to the eastward, at Red Bay for instance, which is characterized by its table land, we find secondary formations, then tertiary, and so on until we have, as Professor Jameson has remarked, no less than five of the great classes comprised within the limits occupied by Spitzbergen and its islands. The order in which these formations occur upon the surface is, how- 
ever, not free from interruption, as the primitive frequently recurs, and indeed forms one of the most north-easterly islands of the group; but there the rocks of this nature are by no means so elevated as those of similar formation to the westward. Such appears to be the general conformation of the northern face of the island.

Wherever the rocks upon the western coast have been examined, they have been found almost exclusively primitive. Mr. Scoresby, in his "Arctic Regions," has given a list of some specimens which he collected on this coast in the vicinity of King's Bay; from which it appears that gneiss, mica slate, and quartz"rocks, principally composed the mountains of that part of Spitzbergen, but he met with no true granite, nor any secondary formations. In the neighbourhood of Fair Haven we found perfect granite, as upon Dane's Island, and on the eastern side of South Gat; but still there were no secondary rocks, which appear first about Red Bay. Captain Phipps states, that he met with marble upon Amsterdam Island, which dissolved readily in marine acid. We were not equally fortunate; our specimens from that island were red felspar and compact actinate, quartz rock striped black by mica, and a coarse-grained gra-nite. Our list of specimens from this part of 
the coast is, however, very limited; and, unfortunately, there were no observations made as to the order in which the varieties occurred. It may, nevertheless, be interesting to the geologists to be informed of the nature of the rocks which composed the several islands, and some of the mountain ridges on this part of the coast, especially as there have been so few opportunities of examining them, and as it is an intermediate station between the places visited by Mr. Scoresby and Sir Edward Parry. At the northern entrance of Magdalena Bay, the termination of one of those remarkable ridges which branch off from the Iarge chain traversing the island throughout in a north and south direction, our specimens consisted of granite, with predominant white felspar, mica slate, and gneiss with black mica. Those of Dane's Island were mica slate and gneiss, passing into perfect granite, with black mica, and specimens intermediate between these two, together with some quartz. There were also found here two specimens of coal (probably alluvial), the one glance coal, the other a slatz variety. On the eastern side of South Gat, which separates Dane's Island from the main land, we found mica slate and gneiss, of the same varieties as at Dane's Island. Upon Amsterdam Island, as already stated, Vogel Sang 
afforded specimens of granite with red felspar, gneiss with black mica, common quartz, and a large grained white felspar, with a little admixed quartz. Upon a small islet. near the Norways, common quartz, with some disintegrated felspar. At the termination of the mountain ridge, which forms the eastern side of Foul Sound, we procured, near the summit, quartz rock with some mica, fine grained granite, and white felsparic rock, with quartz; and, from a considerable block at its base, large grained white felspar, with a little admixed quartz. About twenty miles north of Cloven Cliff, we brought up, from a depth of one hundred and eighty-four fathoms, two specimens of rock, the one common granite, the other fine grained grey sandstone.

In other parts of Spitzbergen, the coast has as yet been so imperfectly explored, that we are not even sure we know its limits, and, perhaps, mountains higher than those above-mentioned may yet be found to exist.

About Fair Haven the mountains which came under our observation appeared to be rapidly disintegrating on the surface; perhaps from the great absorption of wet during the summer, and the dilatation occasioned by the frost in the winter. Masses of rock were, in consequence, re- 
peatedly detached from the hills, accompanied with a loud report, and falling from a great height were shattered to fragments at the base of the mountain, there to undergo a more active process of disintegration. In consequence of this deteriorating process, we find at the foot of the hills, and in all the places where it will lodge, a tolerably good soil, upon which grow several varieties of Alpine plants, grasses, and lichens, that in the more southern aspects flourish in great luxuriance. Nor is this vegetation _confined to the bases of the mountains; it is found ascending to a considerable height, so that we have frequently seen the rein-deer browsing at an elevation of fifteen hundred feet. This elevation, it will occur to many of my readers, must be above the region of perpetual snow. And so, no doubt, it is ; * but, during three or four months of the year, the radiation of the sun at Spitzbergen is always very intense, and its effect is greatly heightened by the very clear atmosphere that prevails over every extensive mass of snow or ice, so that we find the mountains bared at an elevation nearly equal to that of the snow-line of Norway; and as vegetation does not appear to de-

* In De La Beche's Geology, p. 24, it is given at four hundred and fifty feet. 
pend upon the mean temperature of the situation alone, but rather upon the prevalence of a sufficiently mild atmosphere during a certain portion of the season, there seems to be nothing anomalous in the fact, although at first it certainly has the appearance of anomaly. Plants which can endure considerable frost, and remain at rest during the period of an arctic winter, vegetate very rapidly when subjected to a mild temperature; hence we find them bursting into flower almost as soon as the snowy covering is removed from above them, perfecting their seed, and preparing for a quiescent state again, all within the space of a few weeks. At Melville Island I dug up a plant of the Saxifraga oppositofolia in the depth of winter, when the thermometer was sixty-two degrees below the freezing point, and brought it into the cabin, where we were raising mustard and cress over the pipe of the stove. In four hour's it began to push, and the next day it had perceptibly grown, but the want of air and light, of course, prevented its coming to perfection. In some sheltered situations at Spitzbergen the radiation of the sun must be very powerful during about two hours on either side of noon, as we have frequently seen the thermometer upon the ice in the offing at fiftyeight degrees, sixty-two degrees, sixty-seven de- 
grees, and once, at midnight, it rose to seventythree degrees, although in the shade at the same time it was only thirty-six degrees.

It has been already observed that, in consequence of this powerful operation of the solar rays upon surfaces at Spitzbergen which have a favourable aspect and inclination, we find mountains divested of their snowy covering at elevations far above the line at which perpetual frost may otherwise be presumed to exist. And we shall be very much deceived if we suppose the line of perpetual snow to ascend to the elevations at which we perceive this to take place; for while extensive tracts are sometimes seen perfectly bare at the height of three thousand feet, we at the same time find others in situations where the surface is nearly horizontal, on which the snow remains hard at an elevation of only fourteen hundred feet, as, for example, upon the island of Amsterdam; and we should probably find it much lower if we could meet with a surface similarly inclined at an inferior elevation; but upon this part of Spitzbergen plains of such a nature so rarely occur, that we are very much limited in our observations. In very high latitudes during the summer solstice the sun is nearly perpendicular to the surfaces of steep mountains for many lours 
on either side of noon, and the atmosphere being remarkably clear, the removal of the snow from such situations can consequently afford no measurement of the line in question. It is only upon level surfaces, or upon such as, in consequence of the obliquity of the angles, they present, its rays operate with but little effect, that we can form any accurate estimation of its height. The reverse is naturally the case in low latitudes. In consequence of the radiation of the great plain of Tartary we find the snow line upon the north side of the Himaleh mountains higher by three thousand feet than it is on the south. And the great plain of Titicaca causes the snow line to be two thousand feet higher in the latitude of $16^{\circ}$ than it is under the equator.

Mr. Scoresby, in his "Arctic Regions," has supposed the upper limit of the snow line at Spitzbergen to be at the height of seven thousand seven hundred and ninety-one feet, which, if it be not a misprint, is, I presume, to be understood as the elevation beyond which solar radiation ceases to produce a thawing temperature in the stratum immediately in contact with the hills exposed to it. If otherwise, and we are to assume this as the line of perpetual snow, in the general acceptation of the term, we shall have this line 
under the latitude $78^{\circ}$, at an elevation as great as it is upon the Carpathian Alps in $49 \frac{1}{2}^{\circ}$, while in the intermediate latitudes, in $71^{\circ}$, for instance, it descends to two thousand four hundred feet, which can hardly be. There will be much difficulty, I apprehend, in determining this line at Spitzbergen; it is certainly not above fourteen hundred feet in latitude $79 \frac{1}{2}^{\circ}$; while, on the other hand, it far surpasses the elevation at which it would be placed by theoretical computations; one of which fixes it at four hundred and fifty feet.

Almost all the valleys in Spitzbergen, which have not a southern aspect, are occupied either by glaciers or immense beds of snow. These beds afford almost the only feasible mode by which the summits of the mountain ridges can be gained; even these are very steep; and in descending by them extreme care is necessary to avoid being precipitated from the top to the bottom, especially when the snow has been rendered hard by a succession of thawing and freezing. This process frequently takes place in the summer, and occasionally glazes the surfaces so highly, that when the sun shines they reflect a brilliant lustre, and give to the coast a curious and pleasing aspect, which, though upon an incomparably more extensive scale, brings to the 
recollection of those persons who have visited Quebec, the singular effect produced by the mass of tinned roofs and steeples which used to crown the heights of that place.

Of the danger which attends the traversing these acclivities we had nearly received a serious proof, for we narrowly escaped losing one of our best and most active seamen in an attempt to descend by one of these inclined planes. While some observations were being made upon the beach, a sailor of the name of Spinks had obtained leave to accompany the boat's crew in pursuit of a herd of deer that were browsing upon the hills. The ardour of the chase led the party beyond the limit of the prescribed range, and when the signal was madse for their return to the boat some of them were on the top of the mountain. Spinks, an active and zealous fellow, anxious to be first at his post, thought he would outstrip his comrades by descending the snow which was banked against the mountain, at an angle of about $40^{\circ}$ with the horizon, and rested against a small glacier on the left. His height was about two thousand feet, and in the event of his foot slipping, there was nothing to impede his progress until he reached the beach, either by the slope, or the more terrific descent of the face of the glacier. He 
began his descent by seating himself and digging his heels into the snow, the surface of which had been glazed and rendered hard by the process before mentioned. He got on very well at first, but presently his foot slipped, or the snow was too hard for his heel to make any impression, and he began to descend at a rapid pace, keeping his balance, however, by means of his hands. His speed becoming accelerated, in a very short time his descent was fearfully quick; the fine snow flew about him like dust, and there seemed to be but little chance of his reaching the bottom in safety, especially as his descent now appeared to take the direction of the iceberg. We ran with all our strength to render him the earliest assistance, and for a moment having lost sight of him behind a crag of the mountain, we expected nothing less than that his lifeless body would be found at the foot of this icy precipice; but Spinks, with great presence of mind and dexterity, to use his own expression, "by holding water first with one hand, and then the other," contrived to escape the danger, and, like a skilful pilot, to steer his vessel into a place of refuge, amidst a bed of soft snow which had recently been drifted against the hill. As soon as he could extricate him- 
self from the depth into which he had been plunged by the force he had acquired, he made his way towards us, rubbing his chafed sides and holding together his tattered garments, and, to our great satisfaction, laughing heartily at the figure he supposed he must cut, for he had worn away two pairs of trowsers and something more. The danger being over, we cordially joined in his laugh, yet in our hearts congratulated ourselves upon his miraculous escape, for he was a great favourite with all his officers as well as his equals in the ship. This young man afterwards volunteered his services with Sir John Franklin, and became coxswain of Captain Back's boat in the dangerous navigation which was conducted along the northern coast of America. Captain Back spoke highly of Spinks' conduct on that occasion; and states that, in addition to zeal, fortitude, and perseverance, he possessed an unusual degree of good-humour, and was of the utmost use in keeping up the spirits of his fellow-boatmen, and in diverting their minds from the difficulties and privations which attended that service, either by giving a cheerful and ludicrous turn to every little incident, or in recounting his own real or supposed adrentures. The value of such a character under the distressing circumstances attending Captain Frank- 
lin's journey to the Polar Sea can be estimated only by those who were present; and it is a great satisfaction to learn that, on his return to England, he was promoted to the rank of Gunner, and appointed to H.M.S. Philomel, where he became no less a favourite. He unfortunately died not long afterwards at Gibraltar; and the respect and esteem of his shipmates, officers as well as seamen, was manifested by the marked attention that was paid to his funeral. As an old shipmate of my own, I am happy of an opportunity of paying this tribute, though indeed small, to his memory; and, I trust, the short digression which it has occasioned will not be regretted.

Our anchorage was in a part of the channel named South Gat, formed by Dane's Island and Spitzbergen. It was completely land-locked, of moderate depth of water, and as secure a port as a vessel under ordinary circumstances could require; and, with the exception of a cove on the western side of Dane's Island,* which was discovered too late to be examined, it seems to be the safest port on the north-west coast

* In this cove, which was visited by Mr. Dealy only, there were found two large wooden huts, and three boats, lashed together and drawn up on the beach. " There was also near the huts a burying-ground, surmounted by three crosses. 
of Spitzbergen, and has the advantage of being accessible either from the north or south; though the southern channel is somewhat intricate.

Near Dane's Gat there are several glaciers, similar to those already described in Magdalena Bay, the largest being about ten thousand feet in length, by two to three hundred feet in perpendicular height. Like the former, they all occur between steep mountains, and partake of the peculiarity of all the glaciers in Spitzbergen, none of them having a southern aspect, but all invariably occupying such valleys as are either very obliquely inclined to the noonday sun, or are entirely screened from it by the surrounding hills.* Hence the formation of these stupendous masses would appear to be the natural, if not the necessary, result of the position of the generating mountains; and the reason seems to be, that the heat occasioned by the radiation of the sides of those mountains which are exposed to the meridian sun during the summer months extends over the whole surface, and is even greater at the lower than at the upper parts; so that, whatever portion of the winter snow may be dissolved will be carried at once into the sea, without being arrested in its progress by frost; whereas, in oblique or in greatly shaded

* See the View of Magdalena Bay, p. 45. 
situations, the heat of the sun serves only to melt the snow upon the more exposed parts of mountain summits and elevated plains, causing streams of water which, in their descent, percolate the snow beneath and enter a region of perpetual frost, where the whole mass speedily becomes converted into an icy substance, more or less opaque, according to the suddenness and profuseness of the thaw of the exposed parts.

Insignificant as the streams occasioned by so partial a thaw may be thought, yet, when it is considered that they are of almost daily occurrence from June to October, it is evident that a large accumulation of ice must annually take place; which, being repeated year after year, and counteracted only in the early stage of the berg by a trifling diminution of its surface from the effect of the summer temperature, it is clear that in the course of time a body may arrive at such a magnitude that its further increase will be prevented only by the breaking away of its own overgrown dimensions.

Whilst upon this curious subject, it may be interesting to see how far the opinions above-mentioned, formed on the spot, and recorded many years ago, are borne out by the recent observations of travellers who have had opportunities of minutely examining the glaciers in the southern 
parts of Europe; formations which, although they differ in many respects in outward appearance from those of the north, agree, nevertheless, with them in their essential character. Like the Spitzbergen glaciers, for instance, those of Switzerland are formed between lofty mountains; they both attain the region of perpetual snow; and alike owe their sustenance and increase to the conversion of snow into ice.

There have been recently published on the Continent several works upon glaciers; * and the Edinburgh Review, CLI., contains a very interesting and learned article on the glacier theory and motion, written in review of those works. We learn from them, that the glacier of the south is of nearly pure ice at the lower extremity; passes into a granular substance of snow in transition state into ice higher up; and above that again is bounded by a region of perpetual snow; "from which," observes the Review (on every theory), "the glacier depends in some way or other for its sustenance and increase." And, speaking of the névé, or unconsolidated part of the glacier, we learn that its granular structure results from " the partial thaw to

* Etudes sur les Glaciers, par M. Agassiz.-Essai sur les Glaciers, par J. de Charpentier.-Théorie des Glaciers de la Savoie, par M. de Chanoine; and others. 
which it has been subjected, in consequence of the water which the heat of the sun produces, percolating pretty freely through the mass;" which is nearly what has been stated as to the manner in which the snow of the Spitzbergen glacier has been converted into the icy form in which it now appears.

It would be scarcely prudent to venture upon a minute detail of ideas which have been suggested by a partial examination of the northern glaciers, and by a consideration of their peculiar position with regard to that luminary to which they owe their existence; for in the arctic regions all ordinary sources of fresh water are locked up by the iron hand of perpetual frost. But, if we were required to trace the glacier formation to its origin, and follow it through its several courses up to its present stage, we should, in the first place, imagine a valley filled with snow, and a temperature below the freezing point to reign, nearly at all times, within it, or at all events to preponderate throughout the day, for this seems essential. As the sun rises, and casts his beams on the mountain tops, communicating its warmth to the elevated plains, and all parts to which it can gain access, it sets in motion streams of water, which descend into the valley, and passing 
through the snow accumulated there, convert the lower portion into layers of ice, and the upper, through which it had percolated freely, into a granular substance. This process is repeated year after year, each one adding new layers of ice to that of the preceding, until, in the course of time, a mass arises in height and extent to that precise point at which either the sun's rays obtain access to its surface and prevent a further increase; or the progressive motion of the glacier, (admitting the possibility of such a motion in the Arctic regions,) advancing upon an inclined plane, gradually brings a lower portion of the berg forward, there to receive its perpendicular increase. In extent, we may imagine the glacier to be limited by the work of destruction that is going on throughout the summer along the whole line of its facial surface by the breaking away of fragments, which are precipitated into the ocean whenever the dimensions of the glacier exceed a given limit; and thus we may imagine the glacier to be kept in check both in its vertical and longitudinal extent.

Professor Leslie, writing upon the formation of icebergs, has given a neat and elegant theory to account for their increase. He pre-supposes the berg to be partly immersed in the ocean, 
as the fronts of those at Spitzbergen generally are, and says, "The lower parts of the field being nearer the tempered mass of the ocean, are not so cold as those which project into the atmosphere; and consequently the air which ascends becoming chilled in sweeping over the eminences, there deposits its moisture, forming an icy coat. But this continued incrustation, in the lapse of ages, produces a vast accumulation, till the shapeless mass is at length precipitated by its own weight." But, rational as this theory seems, and correct to a certain extent, it does not appear sufficient to compensate for the loss which we had daily opportunities of witnessing during our stay at Spitzbergen, and we must, I think, look to the thawing snow mainly for the sustenance of the glacier.

With regard to the glaciers of Switzerland, the most remarkable phenomenon seems to be the progressive motion of the entire mass toward the plain beneath; a fact which, extraordinary as it must appear, has been satisfactorily ascertained by M. Hugi and M. Agassiz. The former, in 1827, had occasion to construct a hut on the glacier of the Finster Aar; in $\mathbf{1 8 3 0}$ he visited the spot, and found this chamber several hundred feet below its original position. In 1836 it was found two thousand two hundred feet from the foot of 
the rock from which it had been originally measured; and, in 1839, twelve years from its construction, it was found by M. Agassiz to have travelled upwards of four thousand feet, or the whole mass to have moved, on an average, upwards of three hundred feet a-year.

We have no means of determining whether there exists a similar movement on the Spitzbergen glacier; but the extensive fissures, (crevasses, in the Waggon-way in particular, seem to indicate a forward propulsion of the outer part of the body. On the other hand, it is hardly possible to imagine a power capable of moving so large a body, firmly united at its base, as it must be, by perpetual frost to the ground.

In the Arctic regions, the upper surface of the glacier presents a smooth and slightly convex plain, free from those ridges and pinnacles which characterize the southern glacier. It often extends two or three miles inland, in an inclined direction until it attains the mountain ridge, and is surmounted only by the dreary rocky peaks from which the glacier in part receives its supply.

The surface of this plane is occasionally rendered hard and crisp by frost, and is then capable of being traversed on foot, but in so doing it is necessary to guard against the danger of falling 
into the fissures, which are sometimes both numerous and of considerable depth.

Like the southern glacier, streams of water from the thawing snow around fall in bold cascades into these fissures, and rush into the icy bowels of the berg, there to be converted anew into ice, or to find an exit at the face of the glacier. In the large iceberg at Dane's Gat, one of these streams was in constant operation during the day, gushing out of the perpendicular face of the glacier and falling into the sea, while another was discharged at the head of a cavern at the surface of the sea.*

The face, or front, of the glacier is generally perpendicular, and occasionally projects a considerable distance into the sea, apparently descending to a great depth also. Throughout the whole extent of its surface it presents a wall of pure ice. Caverns sometimes occur near the water's edge, and the sea washing into them occasions long pendent icicles, which have a pleasing effect.

The sea in the vicinity of almost all the glaciers which fell under our observation was deep. In some places we could find no bottom with our deep sea-lines, as close as we dared go; and

* In Captain Phipps' view of this glacier, taken in 1773, a cave and cascade are both represented. 
in others, as in Magdalena Bay, the water deepened from the centre of the bay to the large glacier at its upper extremity, and towards all the bergs formed in that harbour there was a tendency to an increase of depth; whereas, on the opposite side of the bay, where there are no glaciers, there is comparatively shallow water from one end to the other. I notice the circumstance here, as in other parts of Spitzbergen Mr. Scoresby found the water in front of the bergs generally shallow.* But, if this were the case in the bays to the northward, where the bergs are large, the space in front of them would soon be encumbered with fragments, and pile would rise upon pile until the dimensions of the berg would have no bounds.

In consequence of the immense pieces of ice which occasionally break off these glaciers, it is very dangerous for a boat to approach them. On two occasions we witnessed avalanches on the most magnificent scale. The first was occasioned by the discharge of a musket at about half a mile distance from the glacier. Immediately after the report of the gun a noise resembling thunder was heard in the direction of the iceberg, and in a few seconds more an immense piece broke away and fell headlong

* Scoresby's “Arctic Regions," vol. i. p. 103. 
into the sea. The crew of the launch, supposing themselves beyond the reach of its influence, quietly looked upon the scene, when, presently, a sea rose and rolled towards the shore with such rapidity that the crew had not time to take any precautions, and the boat was in consequence. washed upon the beach, and completely filled by the succeeding wave. As soon as their astonishment had subsided they examined the boat, and found her so badly stove that it became necessary to repair her in order to return to ship. They had also the curiosity to measure the distance the boat had been carried by the wave and found it ninety-six feet.

On another occasion we were viewing the same glacier, and had approached tolerably near when a similar avalanche occurred, but, fortunately we were not near the shore, and, by attending to the direction of the boat's head, we rode over the wave it occasioned without any accident.

This occurred on a remarkably fine day, when the quietness of the bay was first interrupted by the noise of the falling body. Lieutenant Franklin and myself had approached one of these stupendous walls of ice, and were endeavouring to search into the innermost recess of a deep cavern that was near the foot of the 
glacier, when we heard a report as if of a cannon, and, turning to the quarter whence it proceeded, we perceived an immense piece of the front of the berg sliding down from a height of two hundred feet at least into the sea, and dispersing the water in every direction, accompanied by a loud grinding noise, and followed by a quantity of water, which, being previously lodged in the fissures, now made its escape in numberless small cataracts over the front of the glacier. We kept the boat's head in the direction of the sea, and thus escaped the disaster which had befallen the other boat; for the disturbance occasioned by the plunge of this enormous fragment caused a succession of rollers which swept over the surface of the bay, making its shores resound as it travelled along it, and at a distance of four miles was so considerable that it became necessary to aright the Dorothea, which was then careening, by immediately releasing the tackles which confined her.*

The piece that had been disengaged at first wholly disappeared under water, and nothing was seen but a violent boiling of the sea, and a shooting up of clouds of spray, like that which occurs at the foot of a great cataract. After a short time it reappeared, raising its head full

* From Captain Buchan's letter. 
a hundred feet above the surface, with water pouring down from all parts of it; and then, labouring as if doubtful which way it should fall, it rolled over, and, after rocking about some minutes, at length became settled.

We now approached it, and found it nearly a quarter of a mile in circumference, and sixty feet out of the water. Knowing its specific gravity, and making a fair allowance for its inequalities, we computed its weight at 421,660 tons. A stream of salt water was still pouring down its sides, and there was a continual cracking noise, as loud as that of a cart-whip, occasioned, I suppose, by the escape of fixed air.

Some of the icebergs on the western coast of Spitzbergen are of enormous dimensions. Mr. Scoresby has described one, which is situated a little to the northward of Horn Sound, as being eleven miles in length, and presenting a front to the sea of four hundred and two feet, perpendicular height, by his own measurement; and states that it extends back to the summits of the mountains to about sixteen hundred feet in height. 


\section{CHAPTER V.}

Early attempts to settle Spitzbergen.-Fishing-ground contested.-A party winter in Bell Sound.-Their sufferings. -Attempt to colonize Jan Mayen.-Sufferings and death of the party.-A similar attempt made at Spitzbergen.-Death of the party.-Ships repaired.-Put to sea.Trace the barrier of ice toward Greenland.-Return to England.-Sir Edward Parry's attempt to reach the Pole over the ice.-Concluding remarks.

IT will be seen, on referring to the survey of this coast, which was made by the expedition, that there are seven islands lying off the north-west part of Spitzbergen. The various anchorages which have been referred to in the course of this narrative, with the exception of Magdalena Bay, are formed between those islands and the main land. In the early navigation of this sea, these ports were resorted to by vessels principally from Holland, Norway, and Denmark, so that there have been occasionally as many as forty at anchor at a time. Upon some of the islands around the anchorage there were found the remains 
of brick buildings, and a great many coffins, of which we counted upwards of a thousand upon the islands of Amsterdam, the Norways, and the low lands about Smeerenburg. Out of this number of graves a few only bore English inscriptions, the others were principally Dutch. By the dates on the head-boards, it appeared that the greater part had been deposited on the shore about the middle of the eighteenth century. The interment of Dutch subjects, however, is not confined to these islands, for Sir Edward Parry found them as far to the eastward as Treurenburg Bay, where he discovered thirty coffins upon a point of land on the north side of that harbour bearing Dutch inscriptions, from which it appeared that the dates nearly corresponded with those above-mentioned.

We are told in various publications that attempts have been repeatedly made to form establishments upon Spitzbergen for the purpose of reducing the whale blubber to oil on the spot, and of collecting the skins of bears, foxes, and walruses; but the individuals upon whom the experiments of colonization were made generally fell victims to that dreadful malady the scurvy, which the climate of Spitzbergen seems particularly calculated to promote.

A few years after the commencement of the 
CONTESTED RIGHT OF FISHING GROUND. 161

whale-fishery upon this coast, the ground was resorted to by vessels from almost all the maritime powers of Europe. The whales having been then very little molested, resorted to the bays and sounds in great numbers, and the ships in consequence remained in port instead of keeping the sea, as is done at present, and pursued their occupation in boats despatched from the ships at anchor. There was in consequence a continual interference between the boats of the several nations; and jealousies arose, which soon heightened into contentions of a serious character. Ships went armed, and, latterly, powerful fleets for those days, were sent out, and the weakest were either plundered of their cargoes or obliged to quit the ground. At one time the English were masters of the coast, at another the Dutch; so that the warfare between the vessels of different nations appears to have been almost incessant. Companies for the prosecution of this species of commerce were established in the several countries, and royal patents granted, securing to each the exclusive privilege of fishing in those seas. Each nation claimed to itself the right of so doing from priority of discovery, or some such pretext. The English maintained theirs from the alleged discovery of Spitzbergen by Sir Hugh Willoughby; 
the Dutch, with more justice, from that by Barentz; the Danes, from the supposed connexion between Spitzbergen and Greenland, which belonged to them by right of colonization; * the French, from the Biscayners having been the first fishers in those seas; in short, each had a ready excuse for excluding the other from a participation in the trade. At length, after many seizures and engagements, the trade was thrown open, and certain bays and sounds were, by agreement, allotted to the different nations. The English, from their being the first in that country, $\uparrow$ had the best bays; the Dutch found harbours further north; the Danes, though late, got in between them, and the French and Spaniards were compelled to put up with some stations upon the northern coast.

The capture of the whales being thus confined to the coast, it became very convenient to reduce the blubber into oil on the spot, and "cookeries" were erected for this purpose. The English had their principal station in Bell Sound; the Dutch had theirs upon Amsterdam island, and

* In Munster's Geographia, printed in 1540, Greenland is joined to the north of Europe, making the Northern Ocean appear one large bay.

† Anderson's Commerce. 
others were erected upon the Norways, and Dane's Island in its immediate vicinity. Nothing now remained but to induce some persons to inhabit these establishments in order to their becoming regular settlements; and, as an encouragement to settlers, large rewards were held out by the Russia company to any persons who would pass one entire year in their possessions; but none were found willing to endure the privations of such a banishment, or to expose their lives in so hazardous an undertaking. Failing in this, they obtained from the government the promise of a reprieve to any culprits who would volunteer, and actually perform this service; and accordingly several, in order to escape the extreme sentence of the law, accepted of the offer, and were carried to the place. But when they arrived on the spot, and were landed, they were so struck with horror at the desolate appearance of their intended abode, and with the hopeless prospect which it presented, that they begged to be taken back again, declaring they would rather undergo the penalty of their crimes than subject themselves to the lingering death which must inevitably attend their wintering in so wretched a place.* They were accordingly taken home * Churchill's Collection, vol. iv. p. 748. 
again in the vessel which brought them out; and we are told that the company afterwards obtained their reprieve.

It happened that this experiment, which no reward could induce any person to attempt, was shortly doomed to undergo a trial by a party of British seamen, consisting of nine persons, who were left behind in this miserable country by a whaler, and all of whom were found dead the following year, with their bodies cruelly disfigured and torn by bears and foxes.* In 1630 also, some little time after this melancholy occurrence, it was again fated to be tried. The master of the same whale vessel happened to send a boat on shore, at a place near Black Point, famous for the numerous herds of deer which frequented it, with orders to procure a supply of venison, and return on board. The party, consisting of eight persons, landed, and, with the assistance of two dogs, succeeded in taking fourteen of these animals; being then overcome with fatigue they determined to pass the night on shore, and return to their vessel on the following day. It, however, unfortunately happened, that a change of wind occurred in the course of the night, and brought down such a quantity of ice, that the vessel

* Churchill's Collection, vol. iv. 
could not come near the land, added to which a thick fog shortly arose and continued for several days. The party seeing the vessel could not approach the coast, on account of the ice and fog, and being limited to time, determined to proceed to a place called Green Harbour, where they supposed there were several vessels at anchor, and whither they knew their own ship would proceed before she returned home, to take on board twenty-four of her crew.

They coasted the shore along in their boat, and on the seventeenth day arrived at the harbour; when, to their disappointment and dismay, they found that all the vessels had departed. There were yet three days wanting of the time for the final departure of the vessels from the coast; and, supposing there might still be some in Bell Sound, they made the best of their way thither. Unfortunately, however, there arose a difference of opinion as to the situation of the Sound, and they, in consequence, wandered up and down the coast until the day appointed for the final departure of the vessels had expired, so that when they reached the Sound they found all the ships were gone.

Dismay, horror, and despair, alternately possessed their minds, and they stood gazing at each other as if to inquire what was to be done in 
the dreadful dilemma in which they were placed. At length self-preservation, the most powerful of all principles, operated simultaneously upon the party. "Arousing ourselves from this lethargy," says the narrator, "and impressed with the hopelessness of our situation if we, in any way, gave way to despair; we at once set about taking the most effectual measures for preserving our lives, during the long and severe winter which was before us." It was now the end of August, and the party determined at once to proceed to the vicinity of Green Harbour and lay in a stock of venison for their winter consumption. They were successful in this undertaking, having procured nineteen deer and four bears, with which they returned to Bell Sound, on the 3rd September, intending, however, to make another trip to Green Harbour for a second supply; but they were prevented putting this in execution by cold weather, which made them fear the sea might freeze over and prevent their return. Their next consideration was to construct a house, that should enable them to pass the winter in tolerable comfort, and in this matter they were particularly fortunate in finding a quantity of building materials,--brick, lime, plank \&c., which had been left at the establishment; and, to crown all, there was a spacious 
shed, built of stout materials, and roofed with tiles, which had been erected for the use of the company's artificers. It was too large for them to live in, being fifty feet by forty-eight, but they very wisely built their own house within it; two sides were of brick, and the other. two of stout plank, nailed a foot apart and filled in with sand; the ceiling consisted of stout layers of plank. ' The only light that was admitted came through the chimney, to which it found access by the removal of some tiles from the outer roof. Four cabins were built within this dwelling, and the door was rendered tight by the application of a mattress which was found there.

Thus did the party contrive to convert to their purpose, in the best manner, the various materials which fell within their reach; and to construct a dwelling between which and the external atmosphere there was an intermediate stratum of air, which, in a very great degree, moderated the intensity of the cold, so that we do not find them once complaining of the severity of the weather during the winter. Next to a supply of provision, nothing could have been more fortunate than their meeting with this shed and the building materials; for whilst it interposed a medium between their dwelling and the outer atmosphere, it at the same time afforded them a 
place in which they were able to take exercise when the severity of the weather prevented their stirring abroad; and no doubt it is owing to this fortunate occurrence, not only that the lives of the party were preserved, but that none of them were afflicted with that dreadful malady the scurvy, which proved so fatal to other parties who attempted to winter in the same island.

Being now provided with a house, their next care was to make beds and clothing for themselves; for which purpose they dried the skins of the deer and bears they had taken, and sewed them together with bone needles, and thread made from the yarn of rope. On the 12th of September all their arrangements were finished. On that day some ice drove into the bay, and upon it two walruses which they succeeded in taking, and added to their stock of provision. This was a very acceptable addition, for they found upon looking over their stock, that, with the utmost economy, they would not have enough to last them half through the winter, without having recourse to the refuse of whale blubber, after the oil had been extracted from it; upon examination, also, it was found, that they would have to subsist upon this loathsome food four days in the week, and that upon the other three they might feast upon venison and bears' flesh. 
On the 10th of October the weather was so cold that the sea froze over, and they were compelled to pass much of their time in the house; this was dreary enough; as they had neither book, pen, nor paper, to divert their minds from the miseries of their situation, and from the prospect of a painful and lingering death, which they had every reason to apprehend from the fatality which attended other parties, who had attempted to pass the winter upon this island. From the 14th of October, to the 3rd of February (O.S.) they did not see the sun, and from the 1st to the 20th of December (O.S.) there did not appear to be any daylight. The new year set in so extremely cold, that if they touched a piece of metal it would stick to their fingers like birdlime; if they exposed themselves to the air large blisters were raised upon their skin, and when, from necessity they went to fetch snow or water, they returned sore, as if they had been beaten with sticks.

Until the 10th of January they found fresh water under the ice, in a lake near the beach. This water, it appears, flowed from a hole in a cliff of ice and lodged in the lake, until the intense frost consolidated it into ice. After this, snow thawed with hot irons was used for drinking. 
On the 3rd of Febuary our narrator, overjoyed at the reappearance of that luminary so essential not to comfort only, but to life itself, exclaims -

"Aurora smiled once again upon us with her golden face, for now the glorious sun, with his glittering beams, began to gild the highest tops of the lofty mountains; the brightness of the sun, and the whiteness of the snow both together were such as would have revived a dying spirit."

The return of the sun to a part of the earth from which it has totally disappeared, and especially for so long a period as occurs at Spitzbergen, is attended with many exhilarating circumstances, and we cannot wonder at any raptures which may be indulged in by persons who are witnesses of its effects. The pleasure of being able to stir abroad in daylight; the cheerfulness which the sunshine sheds over the country around; the modifying tendency of his rays upon the atmosphere; the return of the animals, and the prospects which it opens out, all operate upon the mind, and produce a combined sensation of joy and thankfulness which can only be fully appreciated by those who have experienced it. To add to the happiness of the party, two bears were seen upon the ice, and they succeeded in taking one, which was a valuable acquisition; but they suffered from eating 
the liver, as many persons had done before, the effect being soon apparent by the skin pealing off their bodies. No other inconveniences, however, were felt. Toward the beginning of March their provision again became extremely scarce; but, as if Providence had watched over their necessities, at this time there came so many bears about their dwelling, that they succeeded in killing a sufficient number to serve them for a length of time, and put beyond doubt the chance of their being again reduced to want. The feathery tribe now, also, revisited the coast, and, with their arrival, the foxes came forth from their holes in great numbers. The party by means of traps, and whalebone springs, managed to take a great many of both foxes and birds, especially of the latter; one species of which, probably the Puffin, was easily captured, from their difficulty in rising from the land, "owing," as our narrator observes, "to the misplacement of their legs."

They were, now able to stir abroad with comfort; and, as the month of May approached, they began to ascend the hills to look out for vessels, but it was not until the 24th of that month that there was any chance of one being seen, for the ice extended as far as the eye could reach. On this day, however, it broke up, and 
the next day the Sound was more than balf cleared. It now blew a gale, and the party had retreated to their house, and were sitting over the fire, when they heard themselves hailed in English by a strange voice. It immediately occurred to them that some vessel had arrived in the Sound; and, filled with delight and surprise, they rushed out and found their expectations realized.

Thus after ten months' residence on this desolate island, and after enduring all the severities of a winter, under the $77^{\circ}$ of latitude, did these hardy seamen return on board their vessel, in good health, and without the loss of a single individual of their number.

The extraordinary manner in which they escaped sickness throughout the winter must be attributed to the warmth and comfort of their dwelling, and to the natural strength and cheerfulness of their minds, which has a most powerful effect upon the scurvy, a disease from which they had the worst to apprehend, as they had no vegetables or antiscorbutics of any kind; and the gross and loathsome food upon which they subsisted for a great part of the time would materially encourage that complaint.

The possibility of wintering in Spitzbergen being now no longer a matter of doubt, the 
SETTLEMENT TRIED AT JAN MAYEN. 173

Dutch Greenland Company determined to send out persons to their establishment at Amsterdam Island, and published their intention throughout their fleet in 1633. Seven seamen accordingly volunteered for this service, and were landed upon Amsterdam Island, with an ample supply of provision and every necessary. At the same time, seven other seamen offered to pass a winter upon the Island of St. Maurice, now called Jan Mayen, upon which the Dutch had also a cookery; and as this is the first instance of any winter being passed in this island, it will not be irrelevant to give a sketch of the climate, and of the success which attended this as well as the other experiment.

The island is situated in latitude $71^{\circ} \mathrm{N}$., and is about thirty miles long by three broad, with a remarkable mountain, called by the Dutch Beerenburg, or Bear's Mount, rising from the northern part of it to the height of six thousand eight hundred and seventy feet.* The island is in the immediate vicinity of the edge of that immense barrier of ice which extends across the northern part of the Atlantic, and it appears from the narrative of these men, that it is accessible to shipping during great part of the winter season. It seems to be subject to a great vicissitude of * Scoresby's " Arctic Regions." 
climate, and, considering its latitude, an unusual proportion of mild unsettled weather.

The party who had offered to winter here were landed in 1633, and the fleet which brought them out quitted the island on the 26th August the same year, and took a last farewell of these devoted men. As soon as the ships were gone, the party began to examine the ground about them ; and, aware of the necessity of making use of all the antiscorbutics they could, they selected a place near Red Hill, to which they frequently resorted for "saletting." About the middle of September, the sun was so powerful and the weather so warm, that they pulled off their shirts, but this did not last long : towards the beginning of October the cold became very severe, and in one night froze so hard that the ice would bear on the south side of the island. This was succeeded by a change equally rapid; on the 7 th the frost was all gone, and there fell a great quantity of rain; and yet on the 9 th it froze so hard that the party were compelled to stay in doors, and sit over the fire to keep life. within their bodies: their casks of beer which stood in their apartment were frozen nearly solid, and in short they experienced all the severity of an Arctic winter.

These extraordinary vicissitudes, which indeed 
continued more or less throughout the winter, had a prejudicial effect upon the constitutions of the party, and they very early began to experience giddiness in the head, and other symptoms of bodily debility. The sun set for the last time that season about the 10 th November, and the bears, as appears to be their custom, about this time became extremely numerous, and were so fierce that the party scarcely dared venture outside their abode. The gulls did not quit the island during the winter, but had nests in the mountains, from whence they came in great numbers to fish about the sea-side whenever the weather was mild, but always returned to the mountains at night; and in March whales were seen in the bays. The winter, though chequered with thaws and heavy rains even in the coldest months, was occasionally very severe; and there was such an abundance of snow, that it was often up to their arm-pits, and sometimes wholly prevented their moving out of their house. They amused themselves as well as they could under privations of so unusual a nature, and endeavoured to beguile the time in relating their adventures; but it was evident that the climate, and the absence of nourishing and vegetable food, was slowly though surely working their destruction. They appear to have been 
aware of this themselves, though they were not wholly destitute of a hope that some of the party might survive the severe trial to which they were subjected. One of the party kept a journal, which is interesting on many accounts; for; besides detailing their own sufferings, it contains a minute register of the state of the weather, the progress of the seasons, and the various birds and animals which remain in those seas during the winter. "On the 1st of January," he observes, "having wished one another a happy new year and good success in our enterprise, we went to prayer to disburthen our hearts before God."

The sun was first seen from the hills on the 1st of February, and from their hut on the 25th. The reappearance of this luminary does not seem to have excited in them those lively feelings which were experienced by the former party; indeed it is evident that the progress of their malady was now rapidly working its deadly way in their constitution, for they already began to feel its serious effects in their bones; their legs swelled so that they could hardly bear them, and towards the middle of March, says the journalist, "we were so badly affected with the scurvy that we began to be very heartless," insomuch that, on the 3rd April, there were only two of 
the party in liealth. On this day they dressed their last morsel of fresh meat for their sick companions, who hoping to derive benefit from this species of food, ate heartily of it. But it was clear that it was vegetable and not animal food which they required; for on the 16th one of the party died; on which the narrator exclaims, "Lord have mercy upon his soul, and upon all of us, we being all very sick of the scurvy." They were soon reduced to so deplorable a condition that, with the exception of the journalist, there was not one of them able to help himself, much less to assist any of his companions; and "I," observes the narrator with much simplicity and commiseration, "am just now going to help our commander out of his cabin at his own request, because he imagines by this change to ease his pain; but he is struggling with death." Little did this unfortunate man think whilst he was administering to the wants of his commander, and removing him, as he supposed, to his last resting-place, that he should be himself the first of the party then alive to sink into his grave; yet such was the fact. He had recorded the scarcity of food which existed; that they had been compelled to kill their faithful $\operatorname{dog}$ as a last resource; and had taken up his pen to com- 
mence "April," when a termination to his earthly career, or so near an approach to it from indisposition seems to have occurred, that he was not able to proceed beyond the Latin word "die," with which he usually commenced each day's proceedings. The death of this man must have been an event as melancholy as it was unexpected to his poor suffering companions, all of whom were too feeble to assist themselves, even to the scanty morsels of food which remained; and not less disheartening to them in their distress to find that the only one on whom they could at all rely for assistance, and apparently the strongest of the party, should have so soon fallen a victim to the malady which was gradually bringing them down to their graves. How long they survived their companion has never appeared; we only know, that when the island was revisited in June following, they were all found dead. Near to one of the bodies was lying a box of ointment, with which the unfortunate being had rubbed his lacerated gums and joints, and by the position of one of the arms, he appears to have expired whilst in the act of applying the remedy to his mouth. Within the grasp of another there was a morsel of bread and cheese, and near him a Prayer-Book.

Thus terminated the first experiment which 
ATTEMPT RENEWED AT SPITZBERGEN. 179

was ever made to settle Jan Mayen, the result of which was not known in Holland until after they had despatched a second party to repeat the attempt which had been simultaneously made upon Spitzbergen. I have stated as a fact, that one attempt was made at Spitzbergen in the same year as that just related at Jan Mayen, and following some respectable authors, have described the landing of the party upon Amsterdam island. It does not, however, appear to me quite clear that there is not some confusion of parties, as in both Anderson's and Macpherson's Commerce it is said that the year 1634 was the first in which the Dutch determined upon making this experiment. The question is not of sufficient importance to merit any discussion. If it were as is stated by Beschryving, we must follow the same author, and believe also that they got through that winter without the loss of any lives. In 1634 all agree as to a party of seven men being landed upon Amsterdam island, in latitude $79^{\circ} 42^{\prime} \mathrm{N}$.; and in Churchill's Collection we find the narrative of their sufferings, drawn up from the journal which was kept by one of the unfortunate beings who perished on that occasion.

The early part of this journal has been omitted, as containing nothing of interest, and we are 
informed, first, of the day on which the sun appeared for the last time that season, and for the last time these unfortunate beings were destined to behold it. This occurred on the 21st October. From that date until the 24th November we hear of no complaint; but they now began to feel the effect of the climate, and of their unnatural mode of life in the appearance of that disease which had proved fatal to the settlers upon Jan Mayen. In anticipation of this complaint, they had provided a "scorbutic potion," of which they partook as soon as they perceived symptoms of the disease, but it does not appear to have had any permanently beneficial effect, as the party fell sick and took to their beds, one after the other, until several of them were incapacitated for exertion of any kind. On the 12th December, although total darkness reigned throughout the twenty-four hours, such of the party as could walk, went in search of fresh food, and vegetable diet, to alleviate the disease, which was rapidly insinuating its poison into their constitutions, but, after an unsuccessful search, they returned disheartened to their miserable dwelling, to brood over their misfortunes. They anxiously watched from day to day for the approach of some animal, that should afford them a fresh meal, and on the 23rd their 
vigilance was repaid by the appearance of a bear, which came so near that he was wounded from the hut. The animal struggled very hard, and at length broke away from the party, who were very much weakened. They were, however, determined not to allow this opportunity, indeed their last hope, I may say, of procuring a fresh meal, to escape while they had any strength remaining, and, provided with lanterns, they pursued the animal with all the ardour of men on whose success in this exploit their very life seemed to depend, but to no purpose; the bear escaped, and they made their way back, with feelings which may more easily be imagined than described.

Three weeks after this, the hand of death put an end to the sufferings of the first of the party, the next day another died, and two days after, a third. The four who remained contrived to make coffins for their departed comrades, and placed the bodies in them; but they were not able to carry them out of the house. The daylight now began to dawn in the south, about noon, and, as it increased, the foxes came about the hut, and the party had the good fortune to take one of them; which for a while cheered their drooping spirits, as they hoped to derive great benefit from the use of its flesh. They 
saw also about this time many bears, but they were too weak to pursue them; to use their own expression, they were "so feeble and sore that they could not even bite their biscuit."

Their earthly career was now drawing to a close; debility heightened into "cruel pain;" and they soon experienced the effect of the scurvy, in all the horrors of its most loathsome and afflicting form. In the last stage of their disease, while they yet retained their faculties, one of them penned the following affecting paragraph :

"Four of us that are still alive, lie flat upon the ground in our huts; we think we could still feed were there but one among us that could stir ou of our hut to get us some fuel, but nobody is able to stir for pain. We spend our time in constant prayer, to implore God's mercy to deliver us out of this misery; being ready, whenever he pleases to call us. We are certainly not in a condition to live long without food or fire, and cannot assist one another in our mutual applications, but must every one bear his own burthen."

No words can more feelingly describe the deplorable condition of these miserable beings than those which are given in the last paragraph, which fell from the pen of the historian of this party. Situated as they were, with their intel- 
lect still perfect, having a desire for food, without the means of gratifying it, and feeling the gradual inroad of the frost upon their apartment, without strength to replenish the dying embers, it is to be hoped they did not long survive the time at which that paragraph was penned.

Their bodies were found the summer following, by the ships which were purposely sent from Holland to inquire into their fate; and their discovery is thus related in Churchill's Collection : "The man who got first on shore happened to come to the back door of the hut, which he broke open, and running upstairs, found the carcass of a dog upon the floor, which had been laid there to dry. Making the best of his way down again, he trod upon the carcass of another dog, and from thence, passing through a door towards the front door, he stumbled in the dark over the bodies of the men, whom they saw (after the window was opened) all together in the same place, viz. three in coffins, two in their respective cabins, and the other two upon a sail, spread upon the floor, with their knees drawn up to their chins." Their bodies were placed in coffins, and deposited outside the huts; and as the ground was frozen too hard for graves to be dug, large stones were placed upon the lids to prevent " the ravenous beasts from digging up their carcasses." 
Other attempts have been made to settle this island, by both Dutch and Russians, but they all failed, from the ravages of that dreadful disease the scurvy, which Spitzbergen, in particular, appears to promote. By the numerous graves still visible upon the northern and western coasts of that island, and especially upon the islands of Amsterdam and the Norways, it is evident that the mortality has been very great, as compared with the probable number of the colonists that were landed.

The remains of buildings, consisting of dwelling houses, " cooking houses," or places for boiling oil, \&c., still visible, in a very dilapidated state, are proofs that a long interval has elapsed since the last of these attempts at colonization was made, and indeed we know that for many years past the only inhabitants upon this island have been small parties, which have been annually sent from Russia and Norway, to collect morses' teeth, and peltry. These hardy people contrive to pass the winter upon this inhospitable coast, but they do not remain more than one year, unless by their own desire.

Upon several parts of this coast we noticed small wooden hovels, eight or ten feet square, which we rightly conjectured had been used by parties of these Russian hunters. We are in- 
debted to the late Colonel Beaufoy for much interesting information concerning these hardy adventurers, many of whom it appears are induced to pass the winter upon these inclement shores. It cannot fail of being interesting to the reader to learn something of those establishments, situated within six hundred miles of the pole of the earth, and the most northern habitations of our globe.

From a number of inquiries which were made by the above mentioned author, it appears that a certain number of the servants of Russian merchants are annually sent to Spitzbergen to procure fish, peltry, and walruses' teeth, \&c. The vessel which lands them, takes on board the cargo which has been provided by those who have already wintered there, and returns home before the commencement of the ensuing winter.

The people who pass the winter upon the island on the setting in of the cold weather separate into small parties of two or three, who reside in small wooden hovels, such as we met with at Fair Haven. There is, however, one general place of rendezvous at each of the principal stations, consisting of a house, about twentyfive feet square, near the place where the vessel anchors, and where their boats may be seen drawn up. These labitations in every respect corre- 
spond with the dwellings which are found upon Dane's Island and at Hamburgh Cove. The accounts which have been furnished by these people do not describe the winter as being extraordinarily severe; but they all seem to agree in the very boisterous nature of the weather: in storms being very frequent and terrific, and in the snow being of prodigious depth in places, occasionally burying their houses, so as to oblige them to cut their way out, and frequently falling for many days together, until the general depth upon the plains is from three to five feet. Occasionally during the winter, these storms of wind and snow are said to be so severe, that the Russian hunters are obliged to lie flat upon their faces, until their fury is past, and indeed, if it lasts long, these poor wretches often perish. They are careful to carry out with them a supply of salt and cured meats and fish, meal, pease, oil, honey, and some antiscorbutics, of which a raspberry, baked with rye flour, and the tops of the spruce fir, are considered the best. They are also careful to provide themselves with a supply of a small herb, probably a species of Cochlearia, which grows upon the island, and of which they either make a salad, or steep it in hot water, and drink the infusion.

Although thus provided, and from their in- 
fancy accustomed to a rigorous climate, there have been instances of these poor wretches suffering, and being found dead within their huts.*

It appears, from the above-mentioned source of information, that all the bays in Spitzbergen are frozen over during the winter, but that in the large gulfs, in which there are rapid tides, the ice is occasionally, indeed continually, in a broken state.

The reindeer, foxes, both black and white, and bears, remain at Spitzbergen during the whole winter, but all the sea-fowl migrate to the southward, about the end of the month of September.

Something more of Spitzbergen might be gleaned from various sources, but I think I have given enough to convey to the reader a just idea of the nature of the country, and of the attempts which have been made to form settlements upon it.

I shall now return to the expedition, which, during its stay in Dane's Gat, had been repairing the damage sustained by its encounter with the ice. Toward the latter end of August this was accomplished, under the judicious management of the carpenter, who is entitled to great credit for his skill, and personal exertion. On the 30th of August the expedition put to sea, and, for

* Scoresby’s " Arctic Regions." 
the last time, steered to the northward, to examine the state of the ice. No alteration appeared to have taken place in its position since the 30th July, and it was still the compact and, to us, impenetrable body it had ever been.

It was not Captain Buchan's intention to attempt any thing more to the northward; his vessel was too much shattered to encounter even sailing ice, but he thought he might still be able to trace the margin to the westward towards Greenland, and perhaps obtain a sight of the eastern shore of that country.

TVe accordingly bore away to the westward, and carefully kept along the ice, as far as $11^{\circ} 30^{\prime}$ W., in the parallel of $74^{\circ} \mathrm{N}$., without finding any opening to the northward. As we were at this time within ten or twelve leagues of the coast of Greenland, as laid down by Mr. Scoresby, in 1817, we anxiously looked out for the land, but none was seen. The weather soon after became foggy, and several streams of ice appeared to windward, which induced Captain Buchan to postpone his endeavour to proceed further. The next day there was every appearance of bad weather, and of the continuance of the fog, and as the Dorothea was not at all in a condition to encounter the ice in any form, and scarcely better able to outlive a gale of wind, and as by 
remaining she would incur both these risks, Captain Buchañ determined upon proceeding to England forthwith, where the expedition at length arrived on the 22nd October, and was paid off soon afterwards at Deptford.

Thus terminated the third endeavour made under the auspices of the British government, to reach the Pole,-an attempt in which was accomplished everything that human skill, zeal, and perseverance under the circumstances could have effected, and in which dangers, difficulties, and hardships were endured, such as have rarely been met with in any preceding or subsequent voyage. It has always been regretted by the officers engaged in this expedition that the endeavour to reach a high northern latitude should have been made in a season extremely unfavourable for the purpose, as must appear from the fact that vessels of our own country in other years attained a higher latitude, by upwards of a degree, without even entering the ice, than we were enabled to reach with our utmost exertions of warping and dragging the vessels through it. On comparing, also, the relative position of the margin of the ice this year with that which it appears to have held during several preceding years, as published in Mr. Scoresby's " Arctic Regions," it would seem, that, in the season of 1818 , 
the ice was closer down upon the Spitzbergen coast than in any former year that we are acquainted with, and consequently that the difficulties of getting to the northward were proportionably increased.

This obstruction to the northward in 1818 was coincident with a remarkable dispersion of the ice in low latitudes. In the parallel of $76^{\circ}$ $\mathbf{N}$., for instance, it appears that there was a facility of getting westward, such as had not occurred for many years before. The cause of this was, in all probability, the prevalence of southerly and southwesterly gales, for which this year was remarkable, the tendency of which would be to disperse the ice in a low latitude, and drive it to the northward; in which direction, meeting with its usual obstruction, it would accumulate, and encumber the sea, in the manner in which we found it.

On comparing this season, also, with that in which Captain Parry made his attempt to travel over the ice to the Pole, the unfavourableness of the period (1818) is further confirmed; as it appears from his journal, that on returning from Treurenburg Bay on the 25th August, it was the opinion of every officer on board the Hecla that they might have sailed to $82^{\circ} \mathrm{N}$., whereas, in no part of the season of 1818 did we find the 
edge of the ice within a hundred miles of this parallel, or to the northward of $80^{\circ} 16^{\prime} \mathrm{N}$.

Notwithstanding this very unfavourable state of the northern seas, the expedition attained nearly as high a latitude as any that had previously been reached, if we except Mr. Scoresby's singular advance to $82^{\circ} \mathrm{N}$.; and, from the fact that no other expedition has since been undertaken for the same purpose, it would appear that the fulness of the attempt made by Captain $\mathrm{Bu}$ chan has been admitted.

Here, strictly speaking, the Polar voyages have been brought to a close, but there is yet one attempt so immediately connected with this subject, and of so enterprising a character, besides reflecting so much lustre upon our hardy countrymen by whom it was executed, that it must on no account be omitted. It was a project no less bold and daring than that of endeavouring to reach the Pole by means of two small boats, so constructed that they might either be used as sledges upon the ice, or rowed in the open water.

The expedition consisted of twenty-eight persons, under the command of our great Polar navigator, Sir Edward Parry, distinguished alike for his courage and perseverance, as for his patient endurance and humane consideration of those under his command. His former ship, the 
Hecla, was appointed to take him to Spitzbergen, and left England in April 1827. On the 14th May she reached Amsterdam Island (Spitzbergen), and being compelled to run into the ice for shelter from a gale of wind, she got beset, and drifted about for three weeks before she could be extricated. At length, on the 8th June, a southerly wind dispered the ice, and Sir Edward Parry proceeded towards the Seven Islands, upon one of which (Walden Island) he deposited a reserve supply of provision, for the use of his little party on its return. The sea was now so clear of ice, that the Hecla stood to the northward to the latitude $81^{\circ} 5^{\prime} \mathrm{N}$., and then proceeded to Treurenburg Bay in Henlopen Strait, where the ship was left in charge of Lieutenant Henry Foster,* who was directed to await the return of his captain. Sir Edward Parry now set out on his arduous undertaking, having under his command Lieutenant (now Captain James) Ross, Mr. (now Commander) Bird, and Mr. Beverly, surgeon, and twenty-four seamen.

This party was equally divided between two boats, called the Enterprise and Endeavour, Sir Edward being in the former, and Lieutenant

* A highly scientific and promising officer, who had the misfortune to lose his life, by falling overboard from a canoe in the river Chagré. 
James Ross in command of the other. Thus appointed, and with provision and clothing for seventy days, the party set out for Little Table Island, where they left a reserve supply of provision, as they had done at Walden Island, to fall back upon in case of necessity.

From Table Island, the most northern known land upon the Globe, Sir Edward Parry proceeded at once to the performance of one of the most singular and perilous journeys of its kind ever undertaken, except perhaps that of Baron Vrangle, upon a similar enterprise to the northward of Behring's Straits. "Let but any one conceive for a moment the situation of two open boats, laden with seventy days' provisions and clothing for twenty-eight men, in the midst of a sea covered nearly with detached masses and floes of ice, over which these boats were to be dragged, sometimes up one side of a rugged mass, and down the other, sometimes across the lanes of water that separate them, frequently over a surface covered with deep snow, or through pools of water. Let him bear in mind, that the men had little or no chance of any other supply of provision than that which they carried with them, calculated as just sufficient to sustain life, and consider what their situation would have been in the event, by no means an improbable one, of 
losing any part of that scanty stock. Let any one try to imagine to himself a situation of this kind, and he will still have but a faint idea of the exertions which the men under Captain Parry had to make, and the sufferings and privations they had to undergo."**

It was at first intended to employ reindeer, procured at Hammerfest, in drawing the boats, but these animals proving useless, the seamen were obliged to perform this laborious office, but our adventurous countrymen, in no way disconcerted by this failure, set out in excellent spirits. Their plan of proceeding, we learn from Sir Edward Parry, was " to travel wholly at night and to rest by day, there being of course constant daylight in these regions during the summer season. The advantages of this plan, which was occasionally deranged by circumstances, consisted, first in our avoiding the intense and oppressive glare from the snow, during the time of the sun's greatest altitude, so as to prevent in some degree the painful inflammation in the eyes, called snow-blindness, which is common in all snowy countries. We also thus enjoyed greater warmth during the hours of rest, and had a better chance of drying our clothes; besides which, no small advantage was * Quarterly Review, LXXIV.p. 524. 
derived from the snow being harder at night for travelling.

"When we rose in the evening, we commenced our day by prayers, after which we took off our sleeping dresses, and put on those for travelling, the former being made of camblet, lined with racoon skin, and the latter of strong blue box cloth. We made a point of always putting on the same stockings and boots for travelling in, whether they had dried during the day or not, and I believe it was only in five or six instances that they were not either still wet or hard frozen.

"Being rigged for travelling, we breakfasted upon warm cocoa and biscuit, and after stowing the things in the boats and on sledges, so as to secure them as much as possible from wet, we set off on our day's journey, and usually travelled from five to five and a half hours, then stopped an hour to dine, and again travelled four, five, or even six hours, according to circumstances. After this we halted for the night, as we called it, selecting the largest surface of ice we happened to be near. . . . The boats were placed close along-side each other, with their sterns to the wind, the snow or wet cleared out of them, and the sails, supported by bamboo masts, and three paddles, placed over them as 
awnings, an entrance being left at the bow. Every man immediately put on dry stockings, and fur boots. ... Most of the officers and men then smoked their pipes, which served to dry the boats and awnings very much, and usually raised the temperature of our lodging $10^{\circ}$ or $15^{\circ}$. This part of the twenty-four hours was often a time, and the only one, of real enjoyment to us; the men told their stories, and 'fought all their battles o'er again;' and the labours of the day, unsuccessful as they too often were, were forgotten. A regular watch was set during our resting time, to look out for bears, or for the ice breaking up around us; we then concluded our day with prayers."

With this daily routine of labour and rest, of privation and comfort, and occasionally encountering every species of fatigue and disheartening obstacles, in peril of their lives almost every hour, the little party advanced to the latitude of $82^{\circ} 43^{\prime} \mathrm{N}$. on the 22nd of July; but here, and for several days before, they found, in addition to the many impediments which they had to encounter, they had to contend with a current setting nearly in the opposite direction to that in which they were travelling. This new and unexpected impediment was disheartening in the extreme; still Sir Edward kept up 
the spirits of his party, and concealed from all whom he could the true state of the case, which was, that instead of advancing each day as they imagined ten or twelve miles, they sometimes lost three or four. At length, finding it impossible to overcome this difficulty, and half their resources being expended, it was hopeless to think of attempting anything further. "For the last few days," says Captain Parry, "the eighty-third parallel was the limit to which we had ventured to extend our hopes; but even this expectation had become considerably weakened since the setting in of the northerly wind, which continued to drive us to the southward during the necessary hours of rest, nearly as much as we could gain by eleven or twelve hours of daily labour. Had our success been at all proportionate to our exertions, it was my full intention to have proceeded a few days beyond the middle of the period for which we were provided, trusting to the resources we expected to find at Table Island. But this was so far from being the case that I could not but consider it as incurring useless fatigue to the officers and men, and unnecessary wear and tear for the boats, to persevere any longer in the attempt. I determined, therefore, on giving the people one entire day's rest, which they very 
much needed; and then to set out on our return on the following day."

Such are Captain Parry's most satisfactory reasons for abandoning an enterprise, so hopeless, as it had latterly become. The highest point reached was $82^{\circ} 45^{\prime} \mathrm{N}$., in $19 \frac{1}{2}^{\circ} \mathrm{E}$. Their distance from the ship at this time was one hundred and seventy-two miles, and to arrive at this station the party had travelled two hundred and ninety-two miles, of which about one hundred were by water, previously to their entering the ice. "As we travelled by far the greater part of our distance on the ice three, and not unfrequently five times over, we may safely multiply the road by $2 \frac{1}{2}$; so that our whole distance, on a very moderate calculation, amounted to five hundred and eighty geographical miles, or six hundred and sixty-eight statute miles; being nearly sufficient to have reached the Pole in a direct line."

At this extreme point of the journey the ice did not show any indication of a proximity to a permanent body of ice, either by its evenness or its extent; on the contrary, it was "so full of hummocks that it occupied just six hours to cross one of the floes, the extent of which, in a straight line, did not exceed two miles and a half;" and the continued drift of the body 
of ice showed that there was an open space, both in the direction of its course and in that it had drifted from; the sea was five hundred fathoms deep; and there seemed to be nothing more to impede a vessel's course than there was met with near the margin, that is, a sea covered with broken fields of ice, which might open or close according to wind and tide.

With minds filled with disappointment, and limbs weakened by fatigue, the party retraced their steps, and on the 11th of August arrived at the open sea, in latitude $81^{\circ} 34^{\prime} \mathrm{N}$., and finally quitted the ice, after a sojourn of fortyeight days upon it. The following day they arrived at Little Table Island, where, it may be remembered, a supply of provision had been left on the advance route, but the bears had devoured all the bread. Putting to sea again, a storm obliged the boats to bear up for Walden Island. "Everything belonging to us," says Captain Parry, "was now completely drenched by the spray and snow; we had been fifty-six hours without rest, and forty-eight at work in the boats, so that by the time they were unloaded we had barely strength left to haul them up on the rocks. However, by dint of great exertion, we managed to get the boats above the surf; after which a lot supper, a blazing 
fire of drift wood, and a few hours quiet rest quite restored us." They reached their ship in Treurenburg Bay, after an absence of sixty-one days, and met with the most cordial reception and hearty congratulations from their shipmates, who had been most anxiously watching for them.

"I cannot conclude the account of our proceedings," says Captain Parry, "without endeavouring to do justice to the cheerful alacrity and unwearied zeal displayed by my companions, both officers and men, in the course of this excursion." And we may add, what, of course, Sir Edward could not, that no small portion of this zeal arose from the example and high qualification of him who cheered and directed all their movements, and brought them back in health and safety to their ship.

From this brilliant little exploit we learn, as before remarked, that the great barrier of ice, as far as the eighty-third degree nearly, maintains the same rugged broken appearance as it presents near its margin, and does not show any indication of an approach to a solid continent of ice, which has by some persons been imagined to extend from the Pole southward. On the contrary, we may infer from its motion day after day in a south-westerly direction, that there must be a considerable space of open water in its 
rear. Sir Edward Parry's most distant position was one hundred and fifty miles beyond the situation occupied by the ice when Captain Buchan entered it; and, as Sir Edward, when he quitted the ice says, a vessel might have sailed to $82^{\circ}$, it is evident that at least one hundred miles in width of this great icy belt had cleared away since it was encountered by Captain Buchan. Must not such well-authenticated changes afford a reasonable ground for indulging the hope of one day being able to penetrate still further into the heart of the Polar region.

As a conclusion to the present volume we have given a brief relation of the several early voyages which have been set forth for the purpose of discovering a northern passage to the Pacific eastward of Greenland. We have traced the progress of each, and have recounted the difficulties that attended them, in order that the reader may form his own judgment on the merits of the present undertaking, and of the prospect of success that awaits any other attempt. But, commending to the reader the perusal of these at his leisure, we think it best to introduce here our concluding remarks upon the result of the whole, whilst the experience more recently gained from the latest modern voyages is still fresh in our minds. 
It will be seen that the great obstacle which has hitherto frustrated every endeavour, has been a vast barrier of ice stretching across the northern seas from Nova Zembla on the one hand, to the shores of Greenland on the other. This vast barrier has been encountered by all, with different degrees of success it must be allowed, but with the same invariable result, and yet so great are the changes which occasionally take place in its position, that, notwithstanding the many failures, the question does not seem to be entirely hopeless; especially now that we can call to our aid that powerful agent steam, which enables us to set wind and currents at defiance. It has been shown that the western shores of Nova Zembla, and Spitzbergen, have both been found navigable to their northern limits, whilst their eastern sides, and that of Greenland also, have, with very few exceptions, been so encumbered with ice as to frustrate every attempt to explore them; Spitzbergen has, it is true, been sailed round by the Dutch, and the eastern side of Greenland has been visited twice or thrice, but to this day the hardy Russians have not been able to survey the eastern side of Nova Zembla; and the ships which passed through the Waigatz Strait have never been able to proceed far, owing to the quantity of ice driven into the 
sea of Kara. This peculiarity of feature indicates a current,* prevailing in a westerly direction, and carrying with it the great body of ice, which as it sweeps past the several islands and promontories leaves the sea open in their drift. It is remarkable, that in the sea which divides Asia and America the same peculiarity is observable, as though the whole body of ice had acquired a circular motion about the Pole from east to west. If it has not been found to set in this direction upon some parts of the American Continent, it may be that the observation was made close to the shore, where an eddy or counter current would, naturally, prevail.

The experience of these early voyages has clearly proved, that there is no advantage at all adequate to the labour, to be gained by the wearisome operation of endeavouring to force a passage through the ice in the manner attempted by Captain Buchan. On that occasion he fairly put to the test the powerful efforts of an efficient ship, and yet he was surpassed in position by some of the old navigators, whose vessels, scarcely larger than our modern fishing boats, were in no way competent to such a formidable encounter, and who, Hudson excepted, never dreamed of entering the icy barrier, much less of endea-

* See also Remarks upon Currents in Appendix. 
vouring to accomplish their object by dragging their vessels through it. The fact is, this great moving mass of ice is not only subject to considerable changes of position, but to occasional openings, which, if a vessel chance to be on the spot, may afford an opportunity of success, that might not happen again in a lifetime. Thus we find Hudson, in 1607, advancing with little difficulty to a latitude on the eastern coast of Greenland which no ship was afterwards able to approach for two hundred years, or until 1816, when Mr. Scoresby, who had been for many consecutive years to Greenland, perceiving the ice unusually open in the west, boldly directed his course in that quarter, and was the first to confirm the discoveries of Hudson.

Again, on the northern coast of Spitzbergen, the same enterprising navigator was able to reach the latitude of $82^{\circ} \mathrm{N}$., without entering the barrier, nearly in the same meridian where both the government expeditions and many early navigators were repulsed, and indeed unable to come within a hundred miles of the spot.

So with Sir Edward Parry in 1827. When he quitted the ice for Walden Island, as has been alrealy shown, he found an open sea as far as $81^{\circ}$ $34^{\prime}$ N., a degree beyond the latitude reached by Captain Buchan. At an earlier period again, 
when discovery was first prosecuted in the northern seas, there appears to have been a facility of reaching Greenland, which has not since occurred. That country was then annually visited by the Icelanders and Nordmen, who are said to have formed settlements upon a part of the coast, which from that time to the present has been wholly unapproachable. All these facts serve to show that there are periods when the Arctic seas are less encumbered with ice than at others; and that large openings do occasionally take place in the barrier, which, if taken advantage of at the moment, might lead to a glorious result.* Hence the reason why the public interest has never been long permitted to slumber, nor the hope of success ever been wholly withdrawn from this project.

It will perhaps appear strange, that I should favour another trial in this quarter, notwithstanding the very limited success which $I$ have stated as having attended the full attempt of Captain Buchan; but it must be borne in mind, that Captain Buchan only proved that the service was not

* This passage may seem to be at variance with those in pages 68 and 117, but it must be borne in mind that at the time of Captain Buchan's voyage Sir Edward Parry's attempt to reach the Pole had not been made, and that the opinions expressed in the early part of this narrative were such as were entertained at the time. 
practicable in the year in which he was sent out, which was a very unfavourable one; and, moreover, there can be no doubt that the most open time of the year was just commencing when his ship had the misfortune to be disabled. Besides which, we are now calling to our aid inventions which will entirely change the character of arctic research. The screw-propeller, for instance, as an auxiliary power, seems so peculiarly adapted to this service, that it opens an entirely new field for hope to indulge in.

The openings in the ice are generally of short duration, perhaps for eight or twelve hours only, during which time an ordinary sailing vessel, threading the many tortuous channels, does not advance above ten or twenty miles in a direct line, before the closing of the fields puts a stop to her progress; whereas a steamer, regardless of wind-and it is in calm weather mostly that the ice opens-would be able to accomplish three or four times the advance in the same period; and perhaps to come to some land in the north, which if reached, would materially improve her prospect of success. In the event of the ice closing, the propeller could be instantly drawn up into the body of the vessel, and when wanted could be as expeditiously replaced, especially as smooth water generally prevails between 
the floes of ice. In case of frost, the screw is wholly under water, and entirely free from that accumulation of ice, which would take place about the paddle floats and boxes of an ordinary steam-vessel, to the great detriment, if not the entire destruction of the wheel. Should the vessel be caught and compelled to winter, a steamapparatus for warming the vessel throughout could be fitted with little trouble. And as the propeller is only intended to be used as an auxiliary power, a small high-pressure engine would be all that would be required, and consequently it would take up but little of the stowage of the vessel. In short, it seems as if this invention had appeared about this time to stimulate us to further exertion, and the auspicious return of Captain James Ross from the Antarctic seas, with officers and seamen already accustomed to the ice, and with two vessels ready strengthened, to which the propellers could be applied at a moderate expense, appears to mark the present as a period at which arctic research might be most advantageously resumed.

In connexion with this attempt, that most interesting and important question, of the compression of the earth at the Poles, might undergo an investigation, by a direct measurement of an extensive arc of the meridian at Spitzbergen. 
This important consideration was brought under the notice of the President and Council of the Royal Society in $\mathbf{1 8 2 5}$ by Sir J. Herschel, in consequence of a paper written by Colonel Sabine,* who, having conducted a valuable series of pendulum observations at Spitzbergen, for the purpose of determining the figure of the earth, felt the very high interest and importance that would attach to a direct comparison of these results with a compression determined by the actual measurement of an arc of the meridian, or rather by extending the measurement of arcs to higher latitudes than has been hitherto attempted. His proposition met with the warm support of Mr. Davies Gilbert, the late Sir Humphrey Davy, then President of the Royal Society, Sir J. Herschel, and others, and was so far entertained by the Council of the Royal Society, that in the autumn of the same year the propriety of recommending the subject to the Government was taken into consideration.

So deeply were Colonel Sabine's feelings engaged in this most important inquiry, that he sought from remote foreign sources the most useful information with regard to the localities of Spitzbergen; and on the question being put to him by the President of the Society, he

* See Appendix. 
immediately communicated his readiness to conduct the undertaking. In a letter to Mr. Davies Gilbert, Colonel Sabine pointed out the great facility that would attend the operations at Spitzbergen, from the favourable nature of the ground, and that an arc of upwards of four degrees might be measured in that high latitude, which would be equal in value to one of nine degrees in the mean latitude of France. But I feel that I am weakening the importance of the subject, which has been so forcibly argued by that zealous and enterprising officer, and beg to refer the reader at once to his most interesting letter, which by permission I have placed in the Appendix. The question is one of paramount importance, and of itself worthy of an expedition, but when it can be combined with another of equal interest, it seems as though there could be but one opinion as to the propriety of its becoming a national undertaking.

With such an undertaking, other interesting objects might be connected. Many of the scientific inquiries, mentioned in the Instructions at the beginning of this book, have unavoidably been but imperfectly investigated. Much requires to be done in magnetism. The correct determination of the position of the magnetic poles; the present Dip and Magnetic intensity, as compared with 
results obtained twenty years ago, during which period the needle has begun to retrograde, would be particularly desirable. And, amidst other natural phenomena, the stupendous ice formations, which have recently excited much attention, are not unworthy of investigation: whether they really have a progressive motion, tearing their icy bases from the firmly-frozen earth beneath, or whether they remain immovably fixed, and are thus icy monuments of at least four thousand years' antiquity, are inquiries full of interest, although they sink into insignificance compared with the magnitude of the propositions above mentioned.

It has been shown that the highest latitude has been reached in the vicinity of Spitzbergen, and, consequently, that is the point from which any expedition sent upon this service should start. And as the sea here does not become clear of ice until the summer is well advanced, the ships would have ample time to land, and to settle the party engaged in the measurement of the arc of the meridian, and to push other useful inquiries, before they would be required to start on their grand enterprise.

If they should chance to arrive at an auspicious moment during one of these favourable openings 
in the ice, and if any land should be discovered in, or near the situation marked in an old Dutch chart, and its coast should stretch to the northward, and be approachable, there is but little doubt that the expedition would be able to advance along its western side, owing to the prevailing motion of the ice, ${ }^{*}$ and perhaps attain a very near approach to the Pole. In any case we shall have acquired knowledge, and a positive benefit to science, by a more accurate determination of the figure of the earth than we have hitherto possessed.

In concluding these remarks, I cannot withhold the expression of my cordial agreement in the opinion maintained by the Quarterly Review, $\dagger$ "that neither the country nor the naval service will ever believe they have any cause to regret voyages, which in the eyes of foreigners and posterity must confer lasting honour upon both." And long may our country continue to enjoy that peace and prosperity, which shall enable her to exercise in such honourable and useful services those energies of her seamen, which, in the event of war, must be directed to so opposite a purpose.

* See "Currents," Appendix No. III.

† Quarterly Review, Lxxiv. 539. 



\section{PART II.}

EARLY ATTENPTS TO REACH THE PACIFIC BY WAY OF THE POLE. 



\section{CHAPTER I.}

Events which led to the prosecution of Arctic discovery.-Extent of geographical knowledge in the 15 th century.-Oriental commerce.-Monopoly.-Columbus.-Jealousy of the Portuguese leads to the discovery of the Cape of Good Hope, and a navigable route to Cathay. - England desirous of participating in oriental commerce attempts a passage through the Arctic seas.-First Polar voyage.

The northern seas, in defiance of the boisterous nature of the climate, appear to have been more extensively navigated at an early period than parts of the Atlantic lying nearer the equator. Partly from accident, such as vessels being driven away by gales of wind, and partly from the restless ambition of those piratical northern nations whose fleets spread terror around them, Iceland and Greenland were colonised, and Newfoundland, and, in all probability the continent of America, were discovered before the commencement of the eleventh century. The relations of these very early enterprises, however, have been so imperfectly handed down to us, that notwithstanding the interesting matter they contain, I must pass them over, and proceed to those 
which are better authenticated, and more immediately connected with the origin of modern Northern Discovery. It would, however, be the extreme of indifference if $I$ withheld the expression of my admiration at the courage of the many individuals amongst those barbarous tribes, who, without compass or quadrant, traversed thousands of miles of these stormy seas at a time when the more southern nations of Europe scarcely dared lose sight of their own coasts.

But that which enterprise and intrepidity alone failed to accomplish, the desire of aggrandisement was soon destined to effect. From very early periods the commodities of the east had excited the attention of the western European nations, and about the period when Marco Polo's discoveries became known, the desire of trading with the countries which he described as abounding in riches, became so great, that a regular overland conveyance was established between the Persian Gulf, the Red Sea, and the shores of the Mediterranean. The Venetians, Genoese, and Florentines, were at this time the great carriers by sea, and for the most part monopolised the trade of the east, or exacted a tribute from the vessels of other nations trading to those ports which had become the depôts for 
EXTENT OF GEOGRAPHICAL KNOWLEDGE. 217

oriental merchandise. At length the Portuguese; jealous of the exclusive privilege enjoyed by those countries, and desirous of participating in this lucrative commerce, conceived the idea of circumnavigating Africa, and of opening out a route by which she might partake of those profitable sources of wealth. They were greatly encouraged in this idea by the successful issue of a voyage, performed along the coast of Africa, in the short, but brilliant reign of Prince Henry of Portugal, a voyage which had dispelled the preposterous notion of the equatorial regions being uninhabitable on account of the excessive heat of the climate, and of the inevitable fate which would attend the navigator who should attempt to double Cape Boyador.

It was this desire of transporting to the shores of Europe the golden treasures of the east, that gave so powerful a stimulus to early discovery. It may, indeed, be said to have been almost the only great incentive which actuated the merchants of the fifteenth and sixteenth centuries to engage in distant and hazardous enterprises.

The extent of the geographical knowledge of the Globe was at this time extremely limited. All the southern part of Africa was unknown, and a full third part of the Globe toward the west was a blank, which the most daring navi- 
gator shrank from the task of exploring. Navigation, also, was quite in its infancy, for, although the compass had been brought into pretty general use, yet the important desiderata for determining the position of a ship at sea were wanting, and the mariner scarcely ever wilfully ventured out of sight of land.

An eventful period was, however, at hand. Whilst the Portuguese were tardily maturing their project, the master mind of Columbus, aided by the almost contemporaneous application of the astrolabe to marine purposes, by Martin Behaim, about 1489, swept from the performance of distant voyages the terrors and obstacles which hitherto attached to them, and navigation at once broke from the trammels by which it had so long been confined.

It is useful to observe what rapid strides are made in either art or science, when a way has been opened by the enlightened genius of some favoured individual. No sooner had Columbus dashed across that immeasurable waste of waters, over which the maritime nations of Europe had long and wistfully cast their eyes in vain, than his example was followed by the other principal naval powers of Europe. In England, his brilliant discovery was no sooner known than it became a subject of deep interest at court; and 
Henry the Seventh, mortified, no doubt, that he had lost the opportunity of engaging the services of that great man who, under frequent disappointment from the court of Spain, had offered himself to the English king, took advantage of the presence of Sebastian Cabot, a well-known skilful navigator, and determined to employ him in searching for a passage to Cathay and the East Indies, to the northward of the lands discovered by the Spaniards. Cabot was, accordingly, granted a patent, authorizing him to search for unknown lands, and to conquer and settle them; the king reserving to himself one-third of the profits.

Cabot sailed from England in the spring of A.D. 1497, and although unsuccessful in acconplishing the passage, became the first authenticated discoverer of Newfoundland, and of the coast of America down to Florida. On his return, he found the attention of the court occupied in preparing for a war with Scotland, and his discoveries were not then followed up.

The Portuguese, with the brilliant example of Columbus before them, and encouraged by the important voyages of Diaz and Covilham, now forsook the tedious, and dilatory navigation of the coast, and boldly launching out into the ocean, strove to outrival the Spaniards in the 
A.D.
1519. Spain was pursuing the promising avenues to wealth, which Columbus had opened in the west, the Portuguese, under the skilful direction of Da Gama, and Magelhanes, accomplished the long ardently sought routes to the golden shores of Cathay.

For several years the Spaniards and Portuguese continued to enrich themselves with the trade they so justly earned, without any attempt being made by other maritime nations to participate in oriental commerce. At length the spirit of enterprise, which had lain dormant in England during nearly thirty years, was revived. Its efforts were, however, directed to a totally different route to that pursued by either Spaniards or Portuguese. The voyages round the Cape of Good Hope and Cape Horn, or by the Strait of Magelhanes, were so very objectionable on account of their duration and expense, that it was determined to try whether a navigable passage to India might not exist by the north - a question which from that period to the present day has excited the deepest interest in this country, and from which we may date the commencement of Aretic discovery.

A.D. 1527.

It was now well known that this route to Cathay could only lie either along the northern 
coasts of Europe; to the north of the newly- ${ }_{1520}^{\text {A.D. }}$. discovered continent of America; or directly across the Pole; either of which would lead through the heart of the Polar regions, and through seas "encumbered with mountains of ice, and where continued snows fell from the skies." It was a bold experiment, especially if we bear in mind the state of navigation of those early days, and the inferiority of the ships in use, compared with those of the present age; and many persons will, no doubt, agree with Hakluyt, that the boldness of the mind which first contemplated a voyage across those stormy, and icy seas, falls little short of that which first suggested the idea of bringing the ends of the known world into communication with each other. "Wil it not (observes Hakluyt) in all posteritie be as great a renowne vnto our English nation, to have been the first discouers of a sea beyond the North Cape (neuer certainly knowen before) and of a conuenient passage into the huge empire of Russia by the Baie of S. Nicholas and the riuer of Duina; as for the Portugales to have found a sea beyond the Cape of Buona Espiranza? : . . . or for the Italians and Spaniards to haue discouered vnknown landes so many hundred leagues westward and south-westward of the Straits of 
A.D. Gibraltar and of the Pillars of Hercules? . . . -True it is, that our successe hath not bene correspondent vnto theirs: yet, in this our attempt, the vncertaintie of finding was farre greater, and the difficultie and danger of searching was no whit lesse. . . . But besides the foresaide vncertaintie, into what dangers and difficulties they plunged themselves, animus meminisse horret, I tremble to recount. For, first, they were to expose themselues unto the rigour of the sterne and uncouth northern seas, and to make triall of the swelling waues and boisterous winds, which there commonly do surge and blow; then were they to sail by the ragged and perilous coast of Norway, to frequent the unhaunted shoares of Finmark, to double the dreadful and misty North Cape, and to beare with Willoughbies land . . . and as it were, to open and vnlock the seven-fold mouth of Duina, .... a and vilto what drifts of snow and mountains of yce euen in June, July and August, vnto what hideous overfals, vncertaine currents, darke mistes and fogs, and diuers other feareful inconueniences, they were subject, and in danger of." *

This idea of braving the Arctic seas, was the bold suggestion of Master Robert Thorn, who

* Hakluyt's Voyages, Preface to second edition, vol i. pp. xv. and xvi. 
exhorted Henry the Eighth, " with very weighty $\begin{gathered}\text { A.D. } \\ 1527 .\end{gathered}$ and substantial reason, to set forth a discouery even to the North Pole."

The king was pleased to accede to the proposal, and sent "two faire ships well manned, and victualled, having in them divers cunning men to seek strange regions." * The particulars of this voyage, which was the first ever undertaken for the purpose of searching a passage to the East Indies across the Pole, appear to have been lost, as Hakluyt says, "by reason of the great negligence of the writers of those times, who should have used more care in preserving the memoires of the worthy actes of our nation;" but it seems that one of the ships was named the Dominus Vobiscum, that the expedition left England in 1527, and having navigated far to the north-west, at length entered a dangerous gulf between Greenland and Newfoundland, where one of the vessels was cast away, and that the other, having visited Cape Breton, and landed occasionally upon that coast, returned home in the autumn of the same year. This is all that is known of this voyage, from which much was anticipated; and the great disappointment which the disastrous fate of the expedition occasioned was in all probability the reason that no other

* Hakluyt's Voyages, vol. iii.p. 129. 
attempt of a similar nature was made for upwards of five and twenty years.

At length, in the year 1553, Purchas informs us, "The trade of this kingdome waxing cold, and in decay, and the merchants, incited with the fame of the great masse of riches which the Portugals and Spaniards brought home yearely from both the Indies, entered into a resolution, notwithstanding the prohibition of the Hans Law,* to discouer the northerne seas, which so long had beene frozen and shut vp, and to see whether they could not affoord a passage to Cathay and the East Indies." $†$

* "The northerne parts of the world have euer beene held to be better furnished with inhabitants, than any other part of the earth, and from whence those notable inundations came, first of the Cymbrians and Teutons, in the time of the antient Romans, and secondly of the Gothes and Vandals, vnder Attilla, to the confusion of things both Diuine and humane in all the southerne parts of Europe, as farre as barbarism could preuaile against ciuilitie and religion. For remedie whereof the townes along the Baltic sea entered into a confederacy, vnder the name of the Hans Townes, and vndertook the keeping of those northern people, and the securing of these southerne kingdomes, from any of the like overflowings, vpon such privileges, and immunities as were granted and agreed vnto them, ... amongst which the supreme and fundamental lawe was, that none of these nations so secured should have trade or commerce in any parts beyond the Baltike seas, to the end the barbarous people might not be enabled thereby to practice, or moue against the Hans Townes."-Purchas, vol. iii. p. 4.62.

+ Purchas, his Pilgrims, vol. iii. 
This revival of the spirit of northern dis- a.b. covery very shortly succeeded the return of ${ }^{1553 .}$ Sebastian Cabot to England in 1549. His reputation as an able navigator was at that time so firmly established, that Edward VI. constituted him "Governour of the mysterie and discouerie of regions, dominions, islands, and places vnknowne," and granted him a pension of 166l. 13s. $4 d$. per annum, "in consideration of the good and acceptable services done, and to be done." * Cabot who originated this expedition, drew up a code of instructions for the persons engaged in it, which a modern writer of great eminence observes, "do him infinite honour, not only for the chaste style in which they are written, but also for the liberal and enlightened sentiments which run throughout this early performance." $\dagger$

The expedition consisted of the Bona Esperanza, of 120 tons, the Edward Bonaventura of 160 tons, and the Bona Confidentia of 90 tons.

There were several candidates for the command of this expedition, but the choice fell upon Sir Hugh Willoughby, "both by reason of his goodly personage, as also for' his singular skill in the seruices of warre." He was accordingly

* Hakluyt, vol. iii. p. 31.

+ Chronological History of Voyages in the Arctic Regions. 
A.D. appointed Captain General of the fleet, and sailed in the Bona Esperanza. Richard Chancellor was appointed Pilot Major of the fleet, and took command of the Edward Bonaventura, having Stephen Burrough for his captain. Cornelius Durfoorth was appointed captain of the Bona Confidentia. The ships " being fully furnished with their pinnesses, and boats, well appointed with al maner of artillerie, and other things necessary for their defence, with al the men aforesaid, departed from Ratcliffe, and valed unto Deptford the 10th May 1553." The next day the fleet passed Greenwich, and saluted the court,* which was assembled there: on which " the Privie Council, they lookt out at the windows of the court. The courtiers came running out, and the common people flockt together, standing very thicke vpon the shoare." On the 30th they passed Yarmouth, and reached over to the coast of Norway, where they anchored in two small ports near Rost and Lofoot islands, and at length doubled the North Cape of Norway. Here the Bonaventura was separated from the fleet by a gale of wind. When this abated, the admiral pursued his course towards Wardhuys,

* Purchas, Pilg. vol. iii. p. 213.

$\dagger$ The king was absent on account of ill health, and died soon after. 
a port in which, in case of separation, the fleet were appointed to rendezvous, and on the 14th A.D. August, early in the morning, discovered land in lat. $72^{\circ} \mathrm{N}$, bearing $\mathrm{E}$. by N. 160 leagues from Seynam. This land has been affirmed by Purchas to be Spitzbergen, but there is nothing in Sir Hugh Willoughby's journal to authorize such a presumption; on the contrary, his courses and distances clearly prove that it could not be part of that island.*

* This land could not be Spitzbergen, for that island, from Seynam bears to the west of north, whereas Sir Hugh's courses are all N. E., and S. E. And further, from this newly-discovered land he stood three days to the northward, and then steered S. S. E. Thence he sailed many leagues to the westward, before he came to Arzina. Whereas, S. S. E. alone from Spitzbergen would hardly fetch the North Cape. One of two conclusions, therefore, is evident, that, if this latitude be correct, the discovery in question was Nova Zembla, and if the distance from Seynam, it was the coast of Lapland, about Suetoi Noss, at the mouth of the White Sea. But if we adopt the last-mentioned case, the latitude would be $69^{\circ}$ instead of $72^{\circ}$, an error of too great a magnitude even in those days, to have been made, and less probable, in this instance, as we find Sir Hugh's latitudes of Rost and Seynam Islands nearly correct. It seems more probable, then, that the distance was in error, and that the land was part of Nova Zembla, which supposition is strengthened by instructions given to Pet and Jackman, only twenty-seven years after, in which they are directed to stretch over from Wardhuys, to Willoughby's land. $t$ If it were Nova Zembla, the latitude and bearing from

+ See Hakluyt's Voyages, vol. i. p. 488. 
From this land of Sir Hugh Willoughby, he 1553. and his consort, the Bona Confidentia, stood to the northward to about the latitude $75^{\circ}$; and then, the Confidentia being leaky, returned to the coast of Lapland; and finding it impossible to reach Wardhuys, they put into a port at the mouth of the river Arzina, where the "yeare being farre spent, and having very evil weather, as frost, snow, and haile," the Admiral determined to winter. There were no inhabitants at this place, nor could several parties, which were despatched in various directions, find any traces of them inland. The ships were soon frozen up; and, on the place being visited the following year by some fishermen, Sir Hugh Wil-

Seynam would be correct, but the distance, instead of 160 leagues, would be 230 leagues; an error, however, not much to be wondered at, considering the bad weather the fleet encountered between those places. It is worthy of remark, that Sir Hugh Willoughby's courses and distances from the time when he quitted Seynam, to the day after he struck soundings in 160 fathoms, and was in expectation of making Wardhuys, place him actually within a few leagues of that place, as laid down in the charts of the present day. The reckoning after this period is not given regularly; on the eighth and thirteenth days it is omitted altogether; and without these days (on one of which it blew so hard at west that he "strooke his sayles, and lay adrift,") he made good the before-mentioned 160 leagues, so that by his own account his distance exceeded that which he has given from Seynam. Everything, therefore, favours the presumption that Willoughby's land was part of Nova Zembla. 
loughby, and the crews of both vessels were a.D. found frozen to death.

Master Richard Chancellor, in the Bonaventura, after his separation from Sir Hugh Willoughby, succeeded in reaching Wardhuys, but not being rejoined by the Admiral, after waiting the appointed time, he again put to sea, and ultimately anchored in the Bay of San Nicholas (now called Archangel): here he effected a successful negotiation, and undertook a journey to Moscow, where he was well received, and sumptuously entertained by the king, who astonished our countrymen with the display of gold, and silver, and jewels, which appeared at his court. The discreet and able conduct of Chancellor won the good opinion of Juan Vasilovich the Emperor, and laid the foundation of a commerce with Russia, which, with very few interruptions, has continued to the present day. Having wintered at S. Nicholas, the following season Chancellor returned to England, bearing a very courteous letter to King Edward VI.

CHANCELLOR AND BURROUGH.

THE successful issue of Chancellor's voyage 1556. was considered, in some degree, to compensate 
A.D. for the melancholy fate of poor Sir Hugh 1556. Willoughby, and was a sufficient encouragement for the merchants to fit out another expedition to Archangel, to improve the opening that had been thus propitiously begun. This expedition was under the command of Chancellor. But at the same time, it was determined to follow up the attempt to discover the muchdesired northern passage to Cathay; and, accordingly, the next year, 1556, Stephen Burrough was directed to take command of the Serchthrift pinnace, and to endeavour to navigate as far as the river Obe. He quitted the Thames in April 1556, and touching at Cola, Pechora, and other places on the coast of Russia, on the 25th July (St. James's day) he discovered Nova Zembla, and shortly after the Waigatz, were he had communication with some Russians, who were there for the purpose of taking sea-horses. He had here also some interesting interviews with the Samoyeds, of whose customs Richard Johnson, a companion of Burrough, gives a very amusing description in Hakluyt's, vol. i. p. 317. On the 22nd August, Burrough, "being out of all hope to discover any more to the eastward this yeere," thought it desirable to return; partly on account of the strong northeast winds, which had set in, and partly because of the "great and terrible 
abundance of ice which we saw with our eies," A.D. and partly also " because the nights waxed darke, and the winter began to draw on with his stormes." On the 11th he anchored at Colmagro, or Archangel, whiere he wintered, and the next year returned home.

Chancellor's voyage, although advantageous to the Company in improving their connexion with Russia, was very disastrous to the persons immediately engaged in it, as all the ships were wrecked on their homeward voyage, and Chancellor and almost all the crew were drowned. To detail the particulars of this voyage would be foreign to my plan, as it is not immediately connected with Arctic discovery; and for the same reason I pass over several voyages by which it was succeeded, with this notice, that between the periods of the return of Burrough in 1557, and the next voyage to the northeast, in 1594, Sir Martin Frobisher had made his three celebrated voyages to Labrador, and discovered the Strait which bears his name. In the first voyage he discovered, and brought to England an ore, which was declared, by the assayers, to contain a considerable portion of gold, and the second and third expeditions were fitted out for the express purpose of collecting a quantity of the metal, and of forming an establishment in Fro- 
A.D. bisher's Strait to superintend the working of the mine; but the loss of one of the vessels, with a large portion of the provision intended for themselves, and also with a part of the house and stores put on board for their use, frustrated the latter ; and the very small portion of the precious metals which the ore was, after all, found to contain, so completely disappointed the expectations of the court, and the individuals who had been engaged in the expedition, that no further attempt was made to procure it.*

1580. The subject of a northern passage to India still continued to occupy public attention, and the Muscovia Company, who were very prosperous in their trade with Russia, determined to follow up the discoveries that had been made along the northern coast of that country. They, accordingly, fitted out two vessels, under the command of Arthur Pet and Charles Jackman, who quitted the river Thames in June 1580, and succeeded in passing Waigatz Strait in August following. This expedition was, in the end, equally unsuccessful with that of Burrough; not having been able to proceed

* For a full account of Sir M. Frobisher's voyage, and geographical discoveries, the reader is referred to a most excellent paper by Commander Becher, R.N., published in the Journal of the Geographical Society, vol. xii. part. i. 
beyond Nova Zembla. Pet got safe home; but his companion, Jackman, after wintering in NorA.D.
1580. way, put to sea, and was never more heard of.

\section{BARENTZ' FIRST VOYAGE.}

IT was many years before any other attempt 1594. was again made by the English. In the meantime the Dutch, who had become a great commercial nation, determined to try their fortune in seeking a northern route to the eastern parts of the world, by which their capital might find its way into the Indies without having to compete with the Spaniards and Portuguese in their lengthened voyages through the South Seas. They therefore fitted out four vessels; two under the command of Cornelius Cornelison and Brands Ysbrants, and two under William Barentz.

Barentz left Holland on the 5th June 1594, and, on the 4th July, discovered a part of Nova Zembla, which, by a midnight observation, he found to be in latitude $73^{\circ} 25^{\prime} \mathrm{N}$. He coasted this land along to the northward, and gave names to several places; and, at length, he came to an anchor in Lomb's Bay, in latitude 
A.D. $74 \frac{1}{3} \mathrm{~N}$., so called from the number of birds* 1594. of that name, Colymbus Troilli, which he found there. Quitting this bay, he continued to coast along the land, until he came to the north-west extremity of Nova Zembla, which he named Cape Nassau. From hence he thought he could discern land in the E.N.E., and sailed towards it several leagues until he came to a large body of ice, to which he could see no end, and which was too close for his vessel to enter. The weather now becoming misty, and having lost his boat by its being filled with a wave, he returned to Nova Zembla, about the situation of the Orange Islands, and found, by the trending of this coast, that he had arrived at the northern extremity of that island; his latitude being $77 \frac{1}{4}^{\circ}$ $\mathrm{N}$. Barentz determined now to seek the other ships, which, on quitting him, had proceeded to Waigatz Strait, and on the 1st August sailed to the southward for that purpose.

In this passage he was much hindered by ice, which obliged him to stand to the westward. At length, on the 15th August, he arrived at the islands Matfloe and Delgoy, at the entrance of Waigatz Strait, where he met the Zealand and

* Purchas says, "from a certayne kind of beare, so called, which they found there in great abundance." The word bear is evidently a misprint for bird. 
Enkhuysen ships, on their return. It appears that these vessels had passed the Strait of Waigatz A.D. and discovered a large sea beyond, now called the sea of Kara: by the Russians, Karskoa, which they supposed to be near the river Obe, and found the coast of Tartary, stretching from thence far to the N.E. They did not, however, attempt to pass this promontory, which we now know separates the sea in which they then were from the river Obe, but, thinking they had done enough for that year, and being desired by their Instructions to return home before the winter set in, they put back, and on their way to Matfloe discovered an islanid, which they called States Island. The ships left Matfloe together on the 16th August and arrived in the Texel on the 18th September.

BARENTZ' SECOND VOYAGE.

THE favourable report of the state of the sea 1595 . to the eastward of Nova Zembla, which Linschoten, who made the voyage in one of the Enkhuysen ships, gave to Prince Maurice and the States General, determined them to send out another expedition. It consisted of seven 
A.D. ships, six of which were laden with various kinds 1595. of merchandise, and the seventh was to accompany them as far as a cape on the coast of Tartary, named Tabin, beyond which it was supposed there would be found no difficulty in making the remainder of the passage to the eastern seas; and, in the event of their succeeding in reaching that promontory, or such a station from which they could sail southward without hindrance, she was to return to Holland with the joyful tidings of their success. Peter Plantius, a learned cosmographer, was also a great furtherer of this expedition, and not only delineated the coast along which it was to proceed, but gave particular instructions to the commander as to how he was to proceed. James Hemskerke was appointed chief factor, and William Barentz chief pilot of the expedition.

It was late in the season before the vessels quitted the Texel, and they did not, in consequence, reach Nova Zembla until the 17th of August. They found this coast greatly encumbered with loose ice, and had some difficulty in approaching the island of Waigatz; they succeeded, however, in reaching the strait which separates that island from the main land; but, found the sea beyond so blocked with ice that there was no possibility of proceeding 
to the eastward, and they anchored in a bay on the south side of the Waigatz, which they named Traen Bay, from a quantity of train oil that was found there. They saw here also a number of carved images, which were worshipped by the Samoyeds, and everywhere observed the traces of men and deer, but saw no inhabitants. On the 23rd they were visited by a party of Russians, who had come in quest of train oil, morses' teeth, and geese; and were informed by them that in about nine or ten weeks the frost would set in, and freeze the sea so hard that they would be able to pass over it to the Tartarian coast. They also met a party of Sa. moyeds, who at first menaced them with their bows; but, on being told by the interpreter that they were friends, immediately threw down their weapons and entered into friendly conversation. One of these savages, who had been upon an excursion to the eastward, informed Barentz that after five days' sail in that direction he would find a promontory, beyond which the sea would be found open, and lead him to the south-eastward. This joyful news determined Barentz to proceed as soon as he could, and on the 2nd of September he put to sea; but, finding the strait of Waigatz, as before, much encumbered with ice, on the 4 th he anchored 
A.D. under States Island, and sent a boat on shore 1595. to search for a sort of crystal, which had been discovered upon this island by the ships the preceding year. Here they had the misfortune to lose two of their men by a ferocious bear, which attacked the party, and was with great difficulty killed.

On the 10th of September they sailed from States Island, and endeavoured to repass Waigatz Strait; but the ice was now so close, that they made no progress until the 14th, when they were driven through by a heavy gale of wind. They did not, however, give up all hope of being able to proceed on their voyage until the 15th, when, after numerous difficulties, the whole fleet set sail on their return homeward; on the 29th September they entered Wardhuys, and on the 18th November anchored in the Maes.

We may here observe, that had the Zealand and Enkhuysen ships the former year persevered a little longer, they would have spared Holland the expense of this expedition, as they must soon have arrived at the neck of land which separates the sea of Kara from the bay of Obe; and, turning along it to the northward, would, without much doubt, have found it encumbered with the southern part of the body of ice, by 
which Barentz was stopped to the north-west A.D. of Nova Zembla; but, instead of adopting this prudent line of conduct, they returned to give information to their countrymen of their supposed fortunate discovery. 


\section{CHAPTER II.}

\section{BARENTZ' THIRD VOYAGE.}

The States General of Holland offer a reward for the discovery of a northern passage to China.-Two vessels are equipped by the merchants. - William Barentz and Cornelison Ryp appointed to command them. - Make Cherie Island.-Discover Spitzbergen.-Mildness of its climate.Barentz and Ryp differ in opinion.-Separate.-Barentz reaches Nova Zembla._-Annoyed by bears. - Pass the northeast point of the Island._Cheering prospect.-Disappointment.-Dangerous situation.-Endeavours to return. - Prevented and compelled to winter.-Builds a house.Death of the carpenter.-Bears become voracious, and endanger the party.--Intense cold.--Sufferings of the party.Cheerfulness under their misfortunes.-Twelfth day.-Reappearance of the sun.-Extraordinary refraction. - Ice breaks up. - Ship rendered unserviceable. - Abandoned. - Two boats prepared.-Party embark on their return home.-Death of Barentz._- Reach Cola.- Meet with Cornelison Ryp. - His unsuccessful voyage. - Return to Holland. - Hudson proceeds on a Polar voyage.-Traces the coast of Greenland to $73^{\circ}$ N.-Visits Spitzbergen and tries to pass to the north of it.-Repulsed.-Returns by the west side of the Island.-Proceeds again towards Greenland. -Imminent peril._Finding no passage, returns, by Cherie Island, to England.

A.D. THE mortification which was occasioned by the unsuccessful issue of the last expedition 
determined the States General not to send out any more vessels on account of the States; but, as an encouragement to individuals who might feel disposed to follow up the attempt, they offered a reward to any person or persons who should effect the northern passage to China, provided that passage "could be sayled." This encouragement had its desired effect, and two vessels were equipped by the merchants, who appointed Jacob Hemskirke Hendrickson master and factor for the wares and merchandise, and Barentz chief pilot of one of the vessels, and John Cornelison Ryp master and factor in the other. Here we find the first encouragement which was held out to the seamen to persevere in the voyage by the promise of additional wages in the event of success; a judicious act, which, had it been more frequently adopted in those days, would probably have rendered several of the early voyages more successful than they were.

On the 10th of May the ships quitted Amsterdam, and on the 4 th June reached the latitude of $71^{\circ} \mathrm{N}$., when they observed one of those remarkable phenomena of the heavens so rarely seen in low latitudes. It consisted of two parhelia and four circles, two of which passed through the sun and its parhelia; the third en- 
A.D. compassed them, and the fourth passed verti1596. cally through the centre.

There was here a difference of opinion as to the course which ought to be steered; Cornelison maintaining, that if they kept to the eastward of N.N.E., they would fall in with Waigatz Strait; Barentz, on the contrary, affirming that they ought to steer to the eastward of N.E. : the matter was, however, compromised by both yielding a point, and steering N.E. by N. In this Cornelison was clearly in the wrong, as the result soon proved; for, instead of making the coast of Nova Zembla, as was intended, they fell in with Cherie Island, and some angry words passed in consequence between the pilots of the ships when they met. A party landed upon the island, and procured a quantity of eggs; and as they were returning they encountered a large white bear, which fought with them while "four glasses ranne out," and swam away with a hatchet which had been "struck into her back;" the ferocious animal was, however, killed at last, and was found to be thirteen feet in length.

In consequence of this formidable encounter the island was named Bear Island; but this was, a few years afterwards, changed to Cherie Island, as will be seen in advance. 
The island was found to be encumbered with ice on all sides, so that there was no possibility of proceeding to the eastward; and, indeed, they had been obliged to pass through a great deal of it before they arrived at the place where they anchored. They therefore determined to stand along this frozen barrier to the northward; in doing which, they discovered high land on the 19th; and, by an observation of the sun, found their latitude to be $80^{\circ} 11^{\prime} \mathrm{N}$. The land lay to the east of them, and they had some difficulty in approaching it in consequence of a strong nortll-easterly wind which was then blowing. This is the first authenticated discovery of Spitzbergen, for Purchas's argument, in favour of Sir Hugh Willoughby having seen it, is not borne out by Sir Hugh's journal, as has already been shown; and that is the only instance in which any doubt could possibly arise.

Our navigators entered a bay, running north and south, and then came to an anchor. The latitude of this place was $79^{\circ} 42^{\prime} \mathrm{N}$., which corresponds with the situation of Fair Haven; to which their description of the port they entered will also correctly apply.

They saw many "harts and bucks" (rein-deer) upon the land; and upon a small island in the centre of the bay there were a great number 
A.p. of geese, some of which they knocked down

1596. with stones. These geese are described as being red, but there must, I think, be here some mistake in the translation, as we know of no geese of that colour visiting Spitzbergen since that period.

Barentz was struck with the luxuriance of the soil of Spitzbergen, as compared with that of Nova Zembla, and remarks,* that "although in this land, which lyeth under $80^{\circ}$ and more, there groweth leaues and grasse," and that there are therein "such beasts, as eate grasse, as harts, buckes, and such like beastes as live thereon ; yet in Nova Zembla, under $76^{\circ}$, there groweth neither leaves nor grasse; nor any beasts that eate grasse or leaves liue therein, but such beasts as eate fleshe, as bears and foxes." This remark will, hereafter, appear to be incorrect. The comparative mildness of the climate of Spitzbergen, however, has been remarked by almost every person who has visited it, and forms a subject of interesting investigation for the curious inquirer.

Barentz remained two days at anchor, and then steered to the north-west, in the hopes of being able to extend his discoveries in that direction, but he was stopped by that great barrier of ice

Purchas, v. iii. p. 458. 
which, from that day to the present time, has arrested the progress of every navigator who has A.D. attempted to reach a high northern latitude. Finding he could not proceed, he returned to his anchorage, and determined the latitude to be $79^{\circ} 42^{\prime} \mathrm{N}$., and the variation on shore $16^{\circ} \mathrm{W}$. He then put to sea, and steered along the western coast of Spitzbergen to the latitude $79^{\circ}$, when he entered the channel which separates Prince Charles' Island from the mainland of Spitzbergen, but finding the passage impeded by a reef of rocks, he sailed back, and renewing his course to the eastward, arrived off Bear Island on the 1st July. The pilots here again differed in opinion as to the course they should steer: Barentz being determined to continue his route to the eastward towards Nova Zembla, and Cornelison to endeavour to find a passage on the eastern side of the land (of Spitzbergen) which they had just quitted. It was, therefore, agreed that the ships should part company, and each pursue his own plan.

Barentz, after numerous encounters with the ice, which extended from Cherie Island along the $73^{\circ}$ of latitude nearly, arrived off Lomb's Bay, Nova Zembla, on the 17th July. He found all this coast much encumbered with heavy ice, some of which was aground in twenty fathoms water; and he had several hair-breadth escapes 
AD. from the squeezing together of the floes and the 1596. disruption of the bergs. His crew were also much annoyed by bears, which were very daring. and numerous, and frequently proved most unwelcome visitors to parties which were despatched from the vessel, and chanced to be unarmed. Indeed, their encounters with these ferocious animals were always attended with hazard, even to the boats of the vessel, which they could in an instant upset by placing their paws upon the gunwale. Nor were the crew at all times safe on board the ship, as the bears sometimes climbed the berg to which she was fastened, and, on more than one occasion, the seamen on her deck were forced to stand upon the defensive against their attacks. Amidst all these difficulties Barentz worked his way along the west side of Nova Zembla, and reached the northeast extremity of the island on the 16th August. Here some of the crew went on shore; and, on ascending a hill, they perceived the land trend away to the southeast, and, to their great satisfaction, observed a clear sea in the east. So great was their joy at this welcome discovery, that they "knew not how they should get soon enough on board to certifie to William Barentz thereof." The ship was still embayed in ice; but at the end of the third day, August 19th, they succeeded in reach- 
ing the clear water in the east. It however ${ }_{1596 .}^{\text {A.D. }}$ proved to be of very limited extent, and finding it impossible to proceed, Barentz was glad to get back again to the land; which he had scarcely regained before the ice enclosed his vessel; his boats were crushed, and the ship narrowly escaped a similar fate. The weather was now stormy, and the wind having changed to the northward, and made the coast a lee-shore for the vessel, she was in the most imminent peril.

On the 25th Barentz gave up all hopes of being able to proceed on his voyage, and thought now only of how he could best get back and return home. The northerly wind had set him down to the eastward of Nova Zembla ; and there was so much ice to the northward of him, that it was almost hopeless to think of returning in that direction, whilst, judging from appearances, he had as little to expect by the strait of Waigatz in the south. This, however, held out the better prospect of the two, and he used every endeavour to reach it, but the ice was so fast in that direction that it resisted all his efforts; and, in despair, he turned back and once more tried to get lome by the north. ' In doing this he nearly lost his vessel by the enormous pressure of the ice, which lifted her four feet on one occasion, broke the rudder, and otherwise da- 
A.D. maged her. The winter also began to set in, 1596. and there seemed to be no alternative but that of securing the vessel, if possible, where she lay, and making the best preparation he could for passing the winter there; which he was encouraged to do by the discovery of a quantity. of drift wood lying upon the shore not far from the vessel.

On the 11th of September Barentz came to this determination, and it was resolved to build a house, "to keepe and defend ourselues both from the cold and the wild beastes." Before this was done, the party had the misfortune to lose the carpenter, who would have been of the greatest assistance to them in their undertaking, another of the crew being also taken ill. This indeed was a melancholy catastrophe; but, in no way discouraged by the foreboding, they worked incessantly at the building, notwithstanding the cold was so intense that, to use the expression of De Veer, "as we put a naile into our mouthes (as carpenters use to do) there would ice hang thereon when wee tooke it out againe, and make the blood follow." The bears, also were a serious inconvenience to them, by obliging the parties to go armed, and in great strength. Amidst all these discouraging circumstances, the crew pursued their occupations, trusting in that 
Divine Providence which had hitherto sustained ${ }_{1596 .}^{\text {A.D. }}$ them.

" The journal of the proceedings of these poor people," observes a well-known writer of northern voyages, " during their cold, comfortless, dark and dreadful winter, is intensely painful, and interesting. No murmur escapes them in their most hopeless and afflicted situation: but such a spirit of true piety, and a tone of such mild and subdued resignation to Divine Providence, breathe through the whole narrative, that it is impossible to peruse the simple tale of their sufferings and contemplate their forlorn situation without the deepest emotion for the unhappy fate of so many wretched beings, cut off from all human aid, and almost from all hope of their ever being able to leave their dark and dismal adode."

October set in with extremely cold weather, and with heavy falls of snow, which greatly hindered the completion of the house. Until this was done, the crew lived in the vessel, but they were almost smothered with the smoke from the fires which it was necessary to keep up, to prevent their being frozen. On the twelfth the house was finished, and some of the party slept in it, but it was the 24th before they could all

* Sir John Barrow. 
A.D. remove to it, on account of one of the crew being very ill.

On the 3rd November they saw the upper limb of the sun just above the horizon at noon, which was the last time it appeared that season.* Up to this period, the bears had proved a great annoyance, and had evidently become more audacious as the days drew to a close. No serious accident, however, had occurred, notwithstanding the lives of the parties were frequently endangered by their attacks. On one occasion three of these animals surprised some of the men, who were employed in dragging things to the house; there were, unfortunately, only two halberts amongst the party, which were seized by the master and De Veer, who stood forth to defend themselves. The rest of the party fled to the ship; in doing which one of the men fell into a cleft in the ice, and the greatest apprehensions were entertained for his safety, lest the bears should fall upon him, and devour him, but most providentially his life was spared, by the bears following those who continued to run away.

De Veer and the master, thus left alone, joined the man who had fallen, and succeeded in getting into the ship on the opposite side; but

* At Melville Island, $12^{\prime}$ south of this station, it set on the 4th November. 
the bears observing them running, gave chase, A.D. and followed them into the ship, where they were for a time diverted by pieces of wood being thrown upon the ice, which they " ranne after as a dogge vseth to doe at a stone that is cast at him." Meanwhile the crew below endeavoured to strike a light for the use of the matchlocks, but in this they failed, so that they could not shoot their assailants, and the bears growing fierce with disappointment at the loss of their prey, made a desperate attack upon the few who remained upon the deck of the vessel. Most fortunately, the largest of these ferocious beasts received a wound upon the snout with a halbert, which occasioned him so much pain that he withdrew from the vessel, and was immediately followed by the others. "And we thanked God that we were so well delivered from them."

No sooner had the sun sunk below the horizon for the last time, than the bears also took their departure, and were seen no more until the return of sunshine. This was a great relief to the party, who were occasionally obliged to go in search of wood, which, in the darkness of the winter, would have been a viery hazardous duty, had they been subjected to the attacks of these animals : their place, moreover, was supplied by white foxes, which now ventured to range about, 
A.D. and often afforded a most welcome mess of 1596. fresh meat, which in taste resembled "conies' flesh, and seemed as daintie as venison to us."

As the winter advanced the cold became almost insupportable; the beer and all the spirits were frozen, "even our sacke, which is so hot, was frozen very hard;" the walls and roof of the house were covered two inches thick with ice, and the clothes on the backs of the people, even near the fire, were covered with white frost. It is needless to say, these poor creatures resorted to every contrivance in their power to keep life within their bodies, by making dresses and cloaks of the fur of the animals they killed, and supplying their fire with wood; but the cold was occasionally so intense that all the warmth they could create was inadequate to render the apartment supportable. They even heated stones, and billets of wood, and put them upon their bodies; but this gave only a partial relief, for whilst they were thus applied, even before a large fire, the opposite side of their bodies was covered with hoar frost. Yet, amidst all this misery and intense suffering, the spirits of the party never drooped, nay, they even derived consolation from the increase of the bitterly cold temperature they were forced to endure, declaring that "the cold beginning to strengthen was a sign the days were beginning 
to lengthen," a pleasing recollection, which " put A.D.

us in good comfort, and eased our paine."

The new year set in without any relaxation of the severe frost above mentioned. A great deal of snow had fallen, and their house was at this time completely buried, so that the inmates were obliged to unhang their door and cut their way out. This was undoubtedly the best thing that could have happened to them, as it must have rendered the apartment less penetrable to the cold than any contrivance they could themselves have resorted to. The frost was, however, so intense on the outside that no one dared venture from the house for several days together, and they were occasionally greatly straitened for fuel; yet, amidst all this suffering did those hardy people retain their cheerfulness, and even Twelfth Day was not suffered to pass without its usual festivities; for, on that night, they prayed their master that they might be merrie, and said, "We were content to spend some of the wine that night which we had spared, and which was our share every second day; and whereof for certayn dayes we had not drunke, and so that night we made merrie, and drunke to the three kings, and therewith we had two pound of meale, whereof we made pancakes with oyle, and every man a white bisket, which we 
A.D. sopt in wine; and so supposing that we were in our owne countrey, and amongst our friends, it comforted vs, as well as if we had made a great banquet in our owne house: and we also made tickets, and our gunier was King of Nova Zembla."

On the 8th January the weather was more moderate, and a few of the party went out to examine some traps that had been set for foxes, and were greatly cheered by the observing the dawn of the returning sun. On the 16 th there was a "certaine rednesse in the skie," and on the 24th, contrary to the expectation of all, De Veer and Jacob Hemskirke, who had gone to the sea-side, observed the upper limb of the sun. This was so unaccountable an occurrence to them, that they ran immediately to William Barentz to give him the information, but Barentz would not credit their statement, and affirmed it to be impossible that the sun could reappear for fourteen days from that period, which, indeed, under ordinary circumstances, would have been about the right time. De Veer and Hemskirke were, however, quite positive of the fact, and anxiously looked out for another clear day, that they might have an opportunity of confirming their statements. On the 27 th this occurred, and at noon they had 
the satisfaction to behold the sun "in his full roundnesse above the horizon." Barentz him1.1). self could now no longer doubt the fact, but he was at a loss to account for so extraordinary a phenomenon, in any other manner than by supposing that after their clock was rendered useless by the freezing of the works, they had omitted to turn the glass, which ran twelve hours, and that a considerable error in the register of the time had in consequence crept in. De Veer, however, is at some pains to show that this was not the case, and ingeniously refers to the almanac published at Venice, for a corroboration of his opinion, and in that it appeared that on the day the sun was first seen the moon and Jupiter were in conjunction; and on examining the heavens on the 24th, they actually saw these two planets on the meridian together. But they had a better opportunity of deciding the question on the 19th February, when they observed the mean altitude of the sun's lower limb to be $3^{\circ}$ above the horizon; their latitude had been determined on two occasions to be $76^{\circ} \mathrm{N}$., which would give $90^{\circ}-76^{\circ}$ $=14^{\circ}-3^{\circ}=11^{\circ}$, for the sun's declination, which is nearly what it would have been on the 19th February, the very day on which the observation was made by their reckoning. They had also 
A.D. Similar observations on the 20th and 21st March, 1597 . which give the same results.

If the facts be as they are stated, this is the most extraordinary instance of refraction upon record. At Melville Island, in latitude $75^{\circ} 48^{\prime}$ $\mathrm{N}$., only twelve miles to the southward of Barentz' station, the sun set on the 4 th November, and reappeared on the 9th February, sixteen days after it was first seen by De Veer.

As the daylight increased such of the party as were able ventured out, whenever the weather would permit, to stretch their limbs, after their long and painful confinement, and occasionally to collect wood for the consumption of the house. This last mentioned occupation was anything but a recreation, as the snow was very deep, and the strength of the people was so reduced, that it was with the utmost difficulty they could drag the fuel to the house. The number of working hands was also greatly diminished by sickness, and by the severe effects of the frost, one man having had his great toe frozen off; they had, however, as yet lost but two of their companions by death. Upon all their excursions they were now again obliged to go well armed, on account of the bears, which, since the return of the daylight, had renewed their visits, and appear to have become 
more audacious than ever, even following the A.D. people to the door of their house, which they 1597. attempted to force; and one was killed on the eve of entering the room where the people slept. On opening this animal there was found in his stomach "part of a buck, with the hair and skinne and all, which not long before she had torne and devoured," a fact which I mention only to rectify an error in supposing deer did not frequent Nova Zembla.

On the 22nd February, as a party were returning from the vessel, they had the satisfaction to see the ice break away from the shore, which put them all in "good comfort;" and on the 8th March they were further gratified at finding it drifted entirely away, so that there was not a particle of ice to be seen in the north-eastern quarter, and in the south-east alone was there any visible. This remarkable disruption of the ice would have put them in the highest spirits had the weather relaxed in its severity, but the continuance of the cold satisfied them that it was only a temporary occurrence, as in fact it proved, for, toward the end of March, it closed again with the land, and with such a tremendous reaction that it was piled up along the coast as though there had been "whole townes made of ice with towers and bulwarks round 
A.D.
1597. about them." The cold was most unrelenting in its severity, and the falls of snow so heavy and frequent that, during the greater part of April, the party were shut up in their house. On the 17th, however, they moved out to visit the vessel, and found the ice again in motion; and, in an open space near the shore, observed a diver, the first bird they had seen. On the 30th they observed the sun at midnight just above the northern horizon; a circumstance which, if further evidence of their reckoning being correct were required, would fully establish the fact.

Although they had thus occasionally mild days on which they could venture abroad, yet on the whole the weather was so intensely cold to their debilitated frames, that the 29th of May had arrived before they could make any preparation to depart, and then they found themselves too weak to recover their boat from the snow, in order to repair her for their voyage,-which it was necessary to do, as their ship was bilged and rendered unserviceable, so that they were "wholly out of heart." It is so painful to follow these miserable creatures through all their sufferings, that I have only touched upon them occasionally, and contented myself with recording the most material occurrences in the interesting narrative before me. 
As the month of June set in, they saw the a.D. urgent necessity of preparing for their departure, and by great efforts repaired their boats; and on the 12th everything was ready. Before this period the sea had been frequently seen clear of ice, both in the east and west; the weather was comparatively mild, and on the 6th they had a heavy shower of rain, the first that had fallen that season.

On the 13th June, it remained only to get the sick down to the boats. Amongst these was poor Barentz, who had long been ill; and who, with a seaman named Adrianson, was obliged to be drawn to the sea-side on a sledge. The faculties of this enterprising and skilful navigator continued to the last; he directed all their undertakings, cheered the crew in their work, and seems to have commanded the greatest respect from his subordinates during all the difficulties and sufferings of the long and dreary winter they were compelled to endure. Previous to quitting the house he wrote a letter, detailing all his misfortunes; and stating that, after passing ten months in that miserable and wretched abode, he and his party had put to sea in two boats, to endeavour to regain their native land. Having placed the boats side by side, he caused every man to subscribe his name 
A.D. to the statement, which when done was placed

1597. in a conspicuous part of the dismantled hut.

Barentz now put to sea, but the prospect was discouraging in the extreme; the ice had been driven down upon the land, and in an attempt to round the north-eastern part of Nova Zembla the boats were beset, and so pressed that the crews were obliged to draw them upon the top of the floes to prevent their being crushed. They remained here several days, almost in despair of ever being able to proceed; and, to add to their misfortunes, poor Barentz, in whom they "reposed themselves next under God," their chief guide and only pilot, having grown gradually worse since his removal, at length sunk under his misfortunes. Such is the melancholy fate of this great and good seaman, a skilful and enterprising navigator, whose name will always stand conspicuous in the annals of early Arctic discovery. On the same day as poor Barentz breathed his last, died also Adrianson, the other invalid.

With extreme difficulty, and many dangers from the ice, gales of wind at sea, and the attacks of bears, the two boats made their way down the western side of Nova Zembla, and crossed over to the northern coast of Russia, where they obtained some provisions from the 
inhabitants, and were greatly refreshed and comforted. They had also the good fortune to hear A.D.
1597. from the inhabitants at Kilduyer that there were three Dutch ships at Cola, which was not far from them, and which they now became extremely anxious to reach before they should depart for Holland. On the 2nd September, they had the good fortune to arrive at this port, and, to their great surprise and joy, found that one of the vessels was the very one which, under the command of Cornelison Ryp, had left them off Cherie Island the preceding year, to endeavour to get to the eastward by passing along the eastern coast of Spitzbergen. Ryp treated them with great kindness, and receiving them all on board his vessel, conveyed them safely to the Maes, where they arrived on the 29th October, after an absence of seventeen months, ten of which had been passed in great misery upon Nova Zembla, and three in much wretchedness and peril upon the voyage from that place to Cola. In all this voyage, and under all their sufferings, they had lost but three of their crew besides Barentz.

The journal does not give any information as to what was done by Cornelison Ryp, in his attempt to the northward; nor do we find any mention of it in any book that I am acquainted with. 
A.D. Whether he had wintered at Cola, or had made 1597.

a voyage there after having returned home from Spitzbergen, is not even alluded to; but, as nothing is said of any discovery of his, it is probable that he made none worthy of note. If he circumnavigated Spitzbergen, as some have supposed, it would, without much doubt, have been known to those persons, at least, who were interested in northern discovery; but so far from this being the case, we find the Muscovy Company, fourteen years afterwards, fitting out a vessel to ascertain whether Spitzbergen "be an island or a mayne."*

\section{HUDSON'S FIRST VOYAGE.}

1607. For several years the English had confined their attempts to discover a near route to China to the northwest, in which direction they had sent out no less than five expeditions between the years 1602 and 1607 ; besides that of Stephen Bennet, who had also made a voyage to Cherie Island. All these voyages were unsuccessful; and on the return of the last, under Knight, the Company determined to try the practicability of a passage directly northward, either across the

* Purchas, Pilg. vol. iii. p. $70 \%$. 
Pole, or round the north coast of Spitzbergen. Henry Hudson, an experienced seamen and an A.P.
1607 . enlightened navigator, was chosen by the Muscovy Company to conduct this expedition. He was not fitted out, it must be admitted, on a very liberal scale, having only ten men and a boy, and a vessel of eighty tons' burthen. But he appears to have been quite satisfied with the arrangement, and quitting Gravesend on the 1st of May, he steered to the northward, and stretched over to the coast of Greenland, which he made about the latitude $69^{\circ} \mathrm{N}$., and gave the name of Young to a cape in that vicinity, and to a remarkable mountain, like a round castle, Mount of God's Mercy; but having had no observation for five days, it is not presumed that the situations of these places are at all accurate. There appears to have been no difficulty in getting along this coast, which has almost ever since been so encumbered with ice that it is only by great chance any person has been able to revisit it. Close in-shore there was, certainly, some ice seen, but Hudson found no difficulty in working his way in the offing as far as $73^{\circ}$, where he gave the name of Hold with Hope to the land then in sight, "which was mayne high land, with very high mountains," but without any snow upon them. 
A.D. Hudson was prevented making further dis1607. covery upon this coast by the ice, which was now seen to the northward, and with which he soon became much hampered. "It may be objected to us," says Hudson, "as a fault for haling so westerly a course,"-but he gives good reasons for so doing. Greenland was not at that time known to extend so far north as he had found it, and the great barrier of ice lying between that country and Spitzbergen was not known to be so connected with the western shore as it has since been found. If he found no land, he thought his passage to the Pole would have been easier, as he would have had more sea-room; and if he found land, he knew it would be a discovery "worth the seeing." Being now hindered by the ice from holding a northerly course, he stretched over towards Spitzbergen, and on the 27 th saw the coast, in about the latitude $77^{\circ}$, and the ice lying very thick along it. There was, however, a navigable passage, and Hudson sailed as far as Vogel Hook, from whence he stood to the northwest, and was stopped by the ice in the same situation, nearly, as Barentz had been. He made several attempts in this direction, and being unsuccessful, on the 1st of July he directed his efforts to the northeast, hoping to find 
a passage between the land and the ice. IIe was here, however, nearly embayed in the ice, 1607. and, to prevent being beset, was abliged to stand to the southward. After beating about in extremely cold thick weather, and strong winds, it cleared up, and he found that he had entered the channel between Prince Charles' Island and Spitzbergen, and it was the 6th of July before he could get clear. On the 7 th, finding the ice again in the northwest, and having the wind at N.N.E., he seems to have formed the determination of passing round the south end of Spitzbergen, and of trying, as Cornelison Ryp had done, to pass along the eastern side of the island; "hoping by this meane either to defray the charge of the voyage, or else, if it pleased God in time to give us a fair wind to the northeast, to satisfie expectation." The next day it was calm, and on that following he had a contrary wind, which compelled him to stand to the northeast, and again to encounter the ice, by which he was soon encompassed. He managed, however, to escape being beset, and the wind shifting to S.S.E., "it behooved me," says Hudson, "to change my course, and to sayle to the northeast by the southern end of Newland;"* but being come into a "green sea," he again * Spitzbergen. 
A.D. changed his determination and steered north, 1607. along the western coast of Spitzbergen, and though occasionally hampered with ice, which always prevented his getting westward, he reached the latitude of $80^{\circ}$ on the $12 \mathrm{th}$, and saw the land of Spitzbergen bearing S. S. W. twelve leagues. He had here a narrow escape from being swept into the ice by a heavy sea during a calm. As he proceeded eastward he at first found the sea more clear, but it ultimately stopped him off a small island, which he named Cape Collins. Where this island is situated it is not easy to determine, as no latitude is given, but, from its being said to lie to the north of a deep bay, or sound, in the entrance of which the soundings increased from thirty-six fathoms to upwards of a hundred, it was perhaps Moffin Island, and the deep bay was Liefde Bay, or Wyde Bay. The crew landed in this bay, and found the traces of deer, foxes, and other beasts, and a great deal of drift wood upon the shore. There was nothing, however, to detain Hudson in this bay, and having a fair wind, he, "minding his voyage, and the time to perform it in," stood away to the northeast, and at midnight observed the meridian altitude of the sun to be $10^{\circ} 40^{\prime}$. 'This observation might have determined the position 
of Cape Collins, had it been correctly recorded, but there is evidently some error, as the latitude A.n. deduced from it is to the southward of the coast line of Spitzbergen. He worked to the northeast all night, but on the morning of the 16th he was almost encompassed with ice, the southwest being the only quarter that was free from it. The day was warm and clear, and land was seen in the northeast, extending far into $82^{\circ}$, and "by the bowing, or showing of the sky, much further." It is quite evident that Hudson must here have over-estimated the distance of this land, as we, indeed, find he had done on a former occasion, when he stated it to have been seen twenty leagues; whereas, no part of this northern coast of Spitzbergen can be distinguished at much more than half that distance. His latitude also was probably in error, for we know that no part of Spitzbergen reaches the latitude of $81^{\circ} \mathrm{N}$., much less far into $82^{\circ} \mathrm{N}$.

We now come to a passage which has been supposed to apply to the north coast of old Greenland; but there is no difficulty whatever in tracing Hudson up to this point of his proceedings, and it is most clear that he was at this time within sight of the Seven Islands. The passage runs thus: "When I first saw (the land stretching into $82^{\circ}$ ) I hoped to have had a 
A.D. free sea betweene the land and the ice, and meant 1607. to have compassed this land by the north. But now, finding by proof it was impossible, by means of the abundance of ice compassing us about by the north and joyning to the land, and seeing God did blesse us with a faire wind to sail by the south of this land to the northeast, we returned, bearing up the helme." It was, no doubt, the circumstance of Hudson asserting he saw land stretching far into $82^{\circ}$ when it was known that Spitzbergen did not extend to $81^{\circ}$, that has given rise to a supposition that Iudson could not have been off that Island, an opinion, however, which has been somewhat strengthened by another remark of Hudson's, which will be found in advance, in which he observes that "there is no passage north of Greenland, which if there had been I intended to have sailed round it, and returned home by Davis' Straits." But this passage occurs long after Hudson had given up the attempt to the north of Spitzbergen, and had stood over from that island to Greenland, where his progress was arrested by the ice. Much more might be said in proof of the land in question being the north-eastern part of Spitzbergen, if it were required; but I should think sufficient has already been stated to set the matter at rest. 
From the advanced situation which Hudson, a.p. through skilful management and good fortune 1607. had been able to attain, he bore away to the W.S.W. sixteen leagues, and then S.W. eighteen leagues, and then, having rounded the northwest promontory of Spitzbergen, bore away still further, with a northerly gale down the western side of that island, evidently with the design of carrying out his before-mentioned intention of passing round its southern promontory and of endeavouring to push his discoveries to the north-east. But before he reached the promontory he met with contrary winds, and with such tempestuous weather that he was driven back again to the latitude of $78^{\circ} \mathrm{N}$., when the land of Spitzbergen bore N.E. fifteen leagues. Here he observes, "Now, seeing how contrarie the winde proved, to doe the good which wee desired this way, I thought to prove our fortunes by the west once again. And this evening, at eight ... we steered away west, with the wind at south-east." He continued his course to the westward two days, and then fell in with the ice, which was the first he had seen since he quitted Cape Collins. Here Hudson had a very narrow escape from being swept into the heavy ice, then rolling and knocking about with a fearful noise. The wind, as is often the case, close to the packed 
A.D. ice, had failed him, and there being a heavy sea still running towards it, his vessel was unmanageable, and in the utmost peril. But a westerly wind springing up at a fortunate moment, he escaped uninjured. "God give us thankfull hearts, for so great a deliverance."

The weather was now very clear, and the ice was seen extending from W.S.W. to N.N.E., showing a bright sky, from which, and his nearness to the coast of Greenland, Hudson observes that "there is no passage that way, which if there had been, I meant to have made my return by the north of Greenland, to Davis' Straits, and so for England." And this is the passage to which I have alluded above.

The wind now setting in strong at west, Hudson stretched across to the eastward, and once more made the south promontory of Spitzbergen, and thence sailing to the southeast, made Cherie Island on the 31st July; and on the 1st August, finding the wind was contrary, the fogs very troublesome, many things were wanting on board his vessel, and that "the time was well nigh spent to doe good that year," he ordered the ship to bear away for England, where he arrived on the 15th September.

This expedition of Master Henry lludson is one of considerable importance among northern 
voyages. It furnishes us with the first account A.D. we have of the north and north-eastern parts of 1607. Spitzbergen, and shows the difficulty of effecting a passage round the Seven Islands.

It brings us acquainted with a part of the east coast of Greenland, before unknown, and which no navigator was afterwards able to approach for two hundred years; and it assists us to trace, with tolerable accuracy, the position of that great icy boundary, which, since Hudson's day, at least, has extended from the Seven Islands to Greenland.

In 1816 a remarkable opening was observed in this ice by Mr. Scoresby, whose enterprising spirit at once determined him to take advantage of it; and he had thus the good fortune to become the first to rediscover the coast, which, for upwards of two hundred years had been shut out from the navigator.

In 1824 this coast was again approached, and a portion of it surveyed, by the late Captain Clavering, R.N., in H. M. ship Griper. 


\section{CHAPTER III.}

Hudson's second voyage.-Jonas Poole's first voyage.-Jonas Poole's second royage. - Poole's third voyage.-Baffin's first voyage.-Baffin's second voyage with Fotherby,-Baffin and Fotherby again. - Suspension of artic research. Voyages resumed. - Wood and Flawes.-Russian enterprise under Tschitschagoff.

\section{HUDSON'S SECOND VOYAGE.}

THE subject of a northern route to the East Indies was still considered of so much importance to the commercial interests of England, that the merchant adventurers seem to have been determined not to abandon it while a chance of success remained. The several voyages expressly made for this purpose had shown only where that passage could not be effected, and it was yet possible that there might be found some spot where their efforts and perseverence would be crowned with success. The route directly north had baffled the attempts of two of the most skilful navigators that either England or Holland had sent forth, and that by Nova Zembla, both by its northern coast and by the Waigatz, had been as fairly tried, 
but no person had as yet fully examined the A.D. space between Nova Zembla and Spitzbergen. It is true, that the sea was known to be occasionally much encumbered in the vicinity of Cherie Island, and that Barentz, in his voyage from that island to Nova Zembla, had been greatly impeded by ice, and Ryp's unsuccessful attempt to get to the eastward of Spitzbergen could not have been forgotten. Still it was possible that there might exist a passage between Cherie Island and Nova Zembla; at all events, such was the feeling which still attached to this subject that the merchants were unwilling to abandon it until every hope of its attainment had vanished.

Hudson was, accordingly, fitted out again, and sailed from the Thames in April 1608. He steered to the northward, passed within sight of the North Cape on the 3rd June, and on the 9th fell in with a great quantity of ice in latitude $75 \frac{1}{2}^{\circ}$ $\mathrm{N}$, but whether to the eastward or westward of Cherie Island does not appear ; but the latter is most probable, as we find him in soundings almost all the way, which would not have been the case had he held a course to the westward of the island. Before he reached this spot he had encountered some heavy weather, and experienced sharp frosts, and several of his crew, small 
A.D. as it was, were indisposed, Hudson says, by 1608. reason of the cold. But a favourable change had now taken place, both in the health of his crew and the state of the weather, and he determined to attempt a passage with his little bark through this barrier, hitherto held so formidable, and so ruinous to the prospects of his predecessors. It is really quite impossible to contemplate the exploits of this daring and worthy navigator, without entertaining the highest respect for his character. In his first voyage, with only ten men and a boy, he really did more than some of our best equipped expeditions of modern times have been able to accomplish; and we now find him boldly facing the great icy barrier, with serious expectations of being able to master it. We are now sufficiently acquainted with the nature of this mass of ice to know that with his means he could not be otherwise than unsuccessful, as it turned out; for after penetrating about fifteen miles, he found it impossible to proceed, and was forced to give up his intention; indeed, he thought, not without reason, that he had endangered himself somewhat too far. He however made his way out with only a few rubs of the vessel against the ice. Foiled in this direction, he stood along the ice to the eastward until the 25th June, 
when he had approached so near to Nova Zembla A.D. that he had not the smallest hope of being able 1608. to effect the passage in this direction. The next day he saw the island, and on the 27 th sent a boat on shore, in latitude $72^{\circ} 12^{\prime} \mathrm{N}$. They found here a cross erected near the beach, and the remains of a fire, which had, possibly, been left by the crew of poor Barentz' vessel, whose sufferings along this coast have been already related. They also saw an abundance of driftwood, the traces of deer, bears, and foxes, and brought on board the horns of a deer.

Hudson now considered it hopeless to attempt a northern passage to the westward of Nova Zembla; and, giving the efforts of Barentz to the northward of that Island their due weight, he determined to try and accomplish his purpose by effecting the passage of the Waigatz. This resolution was, however, abandoned a day or two after, for, on moving his vessel to a point of land, he discovered an opening in the coast, and saw so many walruses upon the shore, that he considered it his duty to endeavour to defray the expense of the voyage by means of the quantity of oil, and teeth, he hoped to obtain from their capture. He was also not without some expectation, from the appearance of the opening, that it might afford an easier passage to the eastward 
A.D. than that by the Waigatz. On entering it he 1608. found thirty-four fathoms water, and carried twenty fathoms for six leagues up it. Beyond this he could not proceed in his vessel at that time, on account of a shift of wind and a strong current setting from the eastward; but the next day he sent his boat to explore it, and found, after a long row of seven leagues, that the water shoaled to four feet, and that the channel, for such it is now known to be, was completely blocked up with ice. The party landed, and again found traces of people, by a broken oar, and some embers of wood. They saw flowers in bloom, fine herbage, and many deer; several herds of which had also been seen from the ship. It has been supposed that Hudson was mistaken in this particular, and that he is the only visitor to Nova Zembla who mentions these animals. This, however, is an error, for Barentz, on landing at the place where he wintered, saw the foot-marks of deer, and it has been already observed, that he found in the stomach of a bear the hair and skin of one of these animals, which had not long been devoured. Numerous traces of this species were also found upon the southern part of Nova Zembla, by the expedition in $\mathbf{1 5 9 5 .}$

The opening which Hurlson had thus partially 
explored was, he says, first discovered by Oliver Brunell, a Dutchman, and by him named Casting A.D. Sarch. The opening was also seen by Barentz, who fixes its latitude at $71 \frac{1}{3}^{\circ} \mathrm{N}$., nearly the same as that given to it by Hudson.* Hudson accuses Brunell of an error in the latitude of this strait; which, he observes, he has placed too far north, but for what reason he cannot imagine, unless it be to make it accord with the compass; meaning thereby, that if a course were steered for the strait, which Hudson places in $71 \frac{1}{3}^{\circ} \mathrm{N}$., and no variation allowed to the compass, it would conduct a vessel to the strait in the situation assigned it by Brunell. In this, however, Hudson is altogether mistaken. Brunell very properly placed his Casting Sarch in the latitude in which the only strait dividing Nova Zembla into two islands is known to exist, about $73 \frac{1}{3}^{\circ}$ N. The supposed strait of Hudson has since been found to be nothing more than a channel, between an island lying off the coast (called by the Russians Mejdoucharsky) and Nova Zembla, and had his boats succeeded in passing through it, they would have arrived in the very same sea they had quitted a few hours before, and have seen their vessel at anchor. The want of a compass in the boats sent to explore this channel was, no

* Modern surveys place it in $71^{\circ} \mathrm{N}$. 

A.D.
1608. Hudson. Had they been furnished with this instrument they would have found that their course, which at first was northeast, gradually varied to northwest; and on their return on board, Hudson would have been convinced that this channel could not conduct him to the eastern coast of Nova Zembla; whereas, on the contrary, he quitted that island with the conviction that this was a strait which communicated with the Sea of Tartary, and that the passage into that sea was obstructed only by ice. It may have been an omission of a similar kind to that above mentioned, which occasioned the mistake as to the Strait of Juan de Fuca, about which there has been such a diversity of opinion; but which, since accurate surveys of the coast have been made, has been found to exist, not however in the direction at first supposed, but, like that mistaken by Hudson, to have been nothing more than a wide channel, lying between the mainland and an island. We have now accurate surveys of almost the whole of the island of Nova Zembla, and are able to speak with confidence as regards the supposed strait of Hudson.

It is extremely interesting, with this chart in our hand, to go over the early voyages of the English and Dutch to this coast. On comparing 
it with the text of Barentz, and De Veer, Hudson, and others, notwithstanding their egregious misA.D. takes in bearings and distances, we are able to trace almost every bay and promontory which they describe. Such remarkable incidents as this, like that which was found to exist between the modern survey of Baffin's Bay and the outline given by its first discoverer, gives additional value to the records of our early navigators, whose statements have been often discredited, from the very erroneous situation they have assigned to their discoveries, and from the errors into which they have unavoidably fallen, from the want of those instruments necessary to the determination of their position, but many of which the more they have been examined and compared with recent surveys, the higher they have risen in public estimation.

Hudson was very much disappointed at finding the strait did not admit of a passage to the eastward, as he had spent several days in its examination. He was also much concerned to find that the morses, from which he had at first great expectations, had all quitted the coast and taken to the ice in the offing; or had, according to Hudson's conjecture, gone to Willoughby's Land. He seems now to have quite given up all thoughts of the Waigatz, and to have adopted 
A.D. a new plan, which was to search for Willoughby's Land; but we hear nothing more of this, as he put to sea, and made the best of his way to England, where he arrived on the 26th of August, having on the passage formed one or two new schemes, such as that of exploring Lumley's Inlet, and "Davis' furious overfall," which were as speedily given up. In fact, Hudson appears to have been of a restless ambitious turn of mind, and not being governcd by any precise instructions, to have thought himself at liberty to put in execution any schemes which his fertile imagination might suggest. With all this, however, he was an indefatigable, courageous, zealous, and scientific navigator. He seems to have thought his little vessel, which could not have been much bigger than a modern fishing boat, equal to any service; and upon a single voyage in such a vessel, with ten or fifteen men only, to have planned for himself work which might well have formed the occupation of two or three regular expeditions. His scientific attainments do him credit; he was the first who had ever attempted to observe the dip of the needle on board a ship; and his Journal commences with a remark, which shows that he was before his contemporaries in science. "My courses," he observes, "were by a compasse that the needle 
and the north of the Flye were directly one on the other," meaning that his compass was not, A.D
1608. as was usual in those days, corrected for the variation, which was, of course, done by turning the north or "flye" of the card as many degrees to the east, or west of the north of the needle, to which it was attached, as were equal to the variation of the place when the card was made. This Hudson knew was founded upon an erroneous supposition, viz. that the variation was nearly the same in all places; and he lost not a moment in correcting an error which, he knew, might lead to the most serious consequences in a region where the variation of the needle underwent so great a change in so very short a distance.

This enterprising navigator was afterwards engaged in several voyages; in one of which he discovered the Bay that bears his name. Here his crew mutinied, and put him and his son, and seven others, into a small sloop, with a scanty supply of provision, and they were never after heard of.

I cannot close this account of Hudson's without transcribing his ludicrous mention of one of those nondescript species of the ocean, termed mermaids, which are said to have been seen by early navigators. "This morning," says Hudson, "one of our companie looking overboard, 
A.D. saw a mermaid: and calling vp some of the 1608. companie to see her, one more came vp, and, by that time shee was come close to the ship's side, looking earnestly on the men; a little after, a sea came and overturned her; from the navill vpward, her backe and breasts were like a woman's, (as they say that saw her,) her body as big as one of vs, her skin uery white, and long haire hanging down behind, of colour blacke: in her going downe they saw her tayle, which was like the tayle of a porpoise, and speckled like a macrell."

\section{JONAS POOLE.}

1610. For several years the Muscovy Company had sent vessels to Cherie Island for the purpose of taking walruses, in which they were very successful : and, in 1609, the island was taken possession of in the name of the Company. These voyages were strictly mercantile; but, in 1610 , they despatched a vessel to this place, with orders to proceed northward from thence, and to search for " the likelihood of a trade or passage that way." Jonas Poole, who had already made several voyages to Cherie Island, and was well acquainted with the northern seas, was chosen for this service by the Company; who placed under his 
command a vessel called the Amitie, of seventy tons, and a crew of fourteen men and boys.

Poole met with an unusual quantity of ice to the southwestward of Cherie Island, and had several severe encounters with it in his attempt to get near the island. Finding he could not approach it, he stood to the northwest, and on the 16th May was close in with the south Cape of Spitzbergen.

Poole was much hindered with fogs and ice along this coast; but by perseverance he reached the northwest extremity of the island, in latitude $79^{\circ} 50^{\prime} \mathrm{N}$., when he found the ice close down upon the land; and, seeing there was no passage, he returned. He discovered, and entered, several bays and sounds, and was, evidently, more intent upon picking up a cargo of blubber and teeth, than in attempting a passage. In the description of this part of the coast of Spitzbergen consists the chief merit of this voyage, which, after all, was more of a mercantile than of a scientific character.

To a sound, in latitude $77^{\circ} 0^{\prime} \mathrm{N}$., he gave the name of Horn Sound, from having found a deer's horn upon the beach; and to a hill, four leagues south of it, Muscovy Mount; to a sound north of this, Lowe Sound. He also named Fair Foreland, Ice Sound, Cape Cold, Gurnard's Nose. 
A.D. Foul Sound, Deer Sound, Close Cove, and several 1610.

other places, which may be seen in any modern charts of this coast. In some of these places he found the weather so mild that he observes, "A passage may be as soon attayned this way by the Pole as any unknowne way whatsoever, by reason the sun doth give a great heat in this climate." $\mathrm{He}$ is also of opinion that the island is habitable, for if the deer, of which he saw and killed many, "having nothing but the rocks for a house, and the starry canopie for a covering, doe live here, why may not man?"

Notwithstanding Poole's remark about the likelihood of the passage this way, we do not find him persevering in any endeavour to effect it, for, after he had seen the ice to the northward of his farthest point, he returned without making any second attempt, and arrived in England in the end of August.

1611. In the following year, Poole's services were engaged for a period of years by the Muscovy Company, for the purpose, as it would appear, of making discoveries.

The commission given to him is thus transcribed in Purchas' Pilgrims : *- "Inasmuch as it hath pleased Almighty God, through the industry of yourself and others, to discover unto our nation a land, lying in $80^{\circ}$ toward the North * Vol. iii. p. 707. 
Pole: we are desirous, not only to discover A.D. farther to the northward along the said land, to 1611. finde whether the same be an island or a mayne, and which way the same doth trend, either to the eastward or to the westward of the Pole; as also whether the same be inhabited by any people, or whether there be an open sea farther northward than hath beene already discovered. For accomplishing of all which our desires we have made choice of you; and, to that end, have entertayned you into our service, for certayne years, upon a stipend certayne: not doubting but you will so carrie yourself in the businesse for which you were so entertayned, as God may be glorified, our country benefitted, yourself credited, and we, in our desires, satisfied."

By the sequel of this commission Poole was directed to take under his convoy the Mary Margaret, which was fitted solely for mercantile purposes, and in which were six Biscayners, expert in the killing of the whale, and to accompany her first to Cherie Island, and thence to Whale Bay in Spitzbergen, where Poole was to wait to get a little experience in the manner of killing whales, as this was the first year in which any English vessel had ventured upon that hazardous occupation; and having learnt the mode of taking these animals, in case he should see 
A.D. occasion to use it, he was to proceed upon dis1611. covery, and on his return to call at the-Sound, and at Cherie Island for the Margaret, \&c.

The instructions are extremely well drawn up; but it is almost laughable to observe throughout the continual reference that is made to the main chance. He is not only to assist in killing whales with the Margaret, but he is at the same time to send his shallops and search the coast for whale fins, ambergris, morses' teeth, \&c., and whilst on his discovery he is to examine the bays, and "gather up all the finnes" he can find; he is also directed to leave a copper kettle at Cherie Island for him to boil his blubber in, \&c.; and that he may have no excuse for a premature return on account of want of provision, an invoice is given of the several kinds put on board, which is calculated to last for seven or eight months. By this each man was allowed per day, half a pound of beef, three-quarters of a pound of biscuit, five pints of beer, besides fish, cheese, oatmeal, and peas; and a quarter of a pint of aqua vite per month. This allowance, upon the whole, was very liberal, but we cannot say as much for that of candles, of which they were furnished with only six dozen for the voyage.

Poole, in charge of the Elizabeth, left England in company with the Mary Margaret, Stephen 
Bennet master, the Amitie, and the Resolution; A.p.

but the two last-mentioned vessels were to leave 1611 . him off the North Cape, from whence the Amitie was to proceed to Nova Zembla, and the Resolution to Archangel. The ships were separated by a gale of wind, in latitude $65^{\circ} \mathrm{N}$. But the Margaret and Elizabeth met again off Cherie Island, and proceeded to Spitzbergen together, and anchored in Crosse Bay on the 29th May.

Poole remained in this bay until the 16th of June, and then proceeded on his discovery to the north. He found the ice close upon the land, in latitude about $80^{\circ} \mathrm{N}$., and seeing no prospect of a passage that way, he returned, and kept the ice in sight all the way to Greenland, which he expected to see about Hudson's Hold with Hope, but having sailed forty leagues, by his own account, to the westward of its position, without any indications of land, he returned to Cherie Island. Here Poole found part of the crew of the Margaret, which had been wrecked at Spitzbergen, and returned with them to that place, to take on board the cargo they had provided for their vessel before she went down. They reached their destination, and found a ship of Hull in the port, a most fortunate occurrence for all parties, for as the Elizabeth, Poole's ship, was discharging her 
A.D. cargo she upset, and sunk immediately; and 1611. the Hull ship became the carrier of not only the cargo that had been collected upon the land for the Margaret and her consort, but of the crews of both vessels as well.

1612. The next year, Poole sailed again for Cherie Island and Spitzbergen, where he found the ice driven down about Foul Sound, but he attempted no discovery; indeed he was too successful in the taking of whales to relinquish an employment so decidedly profitable, for an attempt so apparently unpromising. But whilst at anchor in this port he was joined by the Hopewell, which had taken him home after the loss of his vessel the preceding year, and was informed by the master, Thomas Marmaduke, that he had sailed to $82^{\circ} \mathrm{N}$, or two leagues beyond Hakluyt's Headland; but we are furnished with no other notice of this approach to the Pole, by which we can judge of the accuracy of the statement, and I shall merely observe, that as Hudson was nearly a degree in error in the same spot, it is equally probable that Marmaduke was not a whit less correct in his observation. In this voyage of Poole he was so successful in taking whales, that the following year the ground was resorted to by the ships of France, Spain, and Holland, besides those of the Company, which consisted 
of six vessels, under the command of Baffin, the celebrated discoverer of the Bay which bears his name, making in all twenty vessels. All these ships seemed to have been too much engaged in whaling to attempt any discovery, so much so, that Marmaduke met with a reproof from the commander of the convoy for proposing to search for a passage round the South Cape of Spitzbergen.

In this voyage we are first made acquainted with the scientific attainments of Baffin, who was the first to observe the great difference in the refraction of the heavenly bodies at different altitudes in high latitudes, and also to assign a right cause to this remarkable phenomenon, but which, he modestly observes, he leaves for " better schollars to discusse."

FOTHERBY AND BAFFIN.

IN 1614, we find discovery again becoming an 1614 . object of attention, proceeding, however, from a motive totally different from that which actuated it before. The coasts of Spitzbergen had become so much frequented by foreign vessels that the Company determined to take possession of all its bays and harbours; and with this 
A.D. view they intended to extend their researches, 1614. as far as possible, along that part of the northern coast which had been discovered by Hudson.

The Company felt themselves authorised to do this in virtue of a Patent which they had obtained under the Great Seal of England, which granted to them exclusively the right of fishing in the Greenland seas. Ten vessels were accordingly prepared, and placed under the command of Fotherby and Baffin. No discovery of consequence was, however, made; indeed this season is remarkable for the closeness with which the ice adhered to Spitzbergen, for, on the 14th July, even the ships' boats were not able to get beyond Red Beach, in consequence of the ice there being: unbroken; and so late as the middle of August they had the greatest difficulty in reaching into the sound two leagues beyond it. This sound, although it had been seen by Hudson, had never been entered, until Baffin and Fotherby rowed up it in their boats. They named it Wiches Sound; and quitting their boats, walked to the eastward and southward, until they could see the end of another sound adjoining, which Hudson had named Sir Thomas Smith's Sound. There was no further passage along this shore, even for a boat. Nor were they much more successful in another attempt, which was made about a fort- 
night afterwards, as the ice was found hard set against the land four leagues to the eastward of ${ }^{1615}$. Red Cliff.

The next year Fotherby was again sent upon discovery to the northward of Spitzbergen, and Baffin was again appointed his pilot; but he could not succeed even as well as he had done the year before; nor was he as fortunate to the southwestward as Hudson had been, for in several attempts which he made to reach the eastern coast of Greenland, he encountered mountains of ice, many leagues to the eastward of it. In this part of his voyage he fell in with Jan Mayen island, of which he gives a very good description, and estimates its length within a mile of what it has since been accurately determined by Mr. Scoresby. This island is said to have been discovered in 1611 by Jan Mayen, and was certainly the same island upon which a ship of Saint Sebastian was lost in 1613.*" The discovery, however, appears to have been unknown to Fotherby, who gave it the name of Sir Thomas Smith, and to the mountain now known by the name of Beerenburg, Hakluyt's Mount. Fotherby appears to have made several attempts both to pass Spitzbergen and to get a sight of Greenland about Hudson's Hold-with-Hope, in

* See Purchas' Pilgrims, vol, iii. p.718. 
A.D. both of which he was unsuccessful, and returned 1615. home in September.

The passage to the East Indies, by the north, and north-east, had now been so repeatedly tried, and found impracticable, that but very little hope remained of its ever being effected; Fotherby, nevertheless, recommended the Company to expend a small sum annually in discovery, " $150 l$. or 200l. at the most;" and we find, accordingly, that a small vessel, fitted for this purpose, occasionally accompanied the ships which were employed in whaling. No advance was, however, made beyond what has been already stated. In 1618, we find the ice close down upon the coast, about Hakluyt's headland; in 1621, that it was set into Sir Thomas Smith's Bay beyond Red Beach; and, in short, in every account that has reached us from that quarter, there appears to have been no possibility of passing to the northward of Spitzbergen. Discovery was, however, pushed along the eastern shore of that island, and a large inlet,* extending into the centre of the island, explored. Several straits and islands have also since been discovered, and in short, the whole coast of Spitzbergen has in course of time been laid down; but we have, I believe, no authenticated account of any vessel having ever circumnavigated the island.

* Wyde Jansz Water. 


\section{CAPTAIN JOHN WOOD.}

The question of a northern route to the Pacific had failed to occupy attention for upwards of A D. sixty years, when it was revived by various reports and accounts, partly from Holland, but chiefly by the publication of a paper in the "Transactions of the Royal Society of London in 1675 ;" in which it was stated, that a vessel had sailed several hundred leagues to the north-east of Nova Zembla, and that the sea was there found free from ice. It was also reported, that some Dutch vessels had circumnavigated Spitzbergen, and that one had even reached the latitude of $88^{\circ}$ $56^{\prime} \mathrm{N}$., and found the sea there quite hollow and free from any incumbrance. To these statements were added many hearsay stories, of an encouraging nature; and the subject finding a zealous advocate in the person of Captain John Wood, who advanced many specious reasons in support of his opinion, the practicability of a passage was entertained with as much earnestness as though no efforts to accomplish it had ever been made.

Hitherto the vessels which had been sent upon this service were in the employment of Companies or of private individuals, being, besides, extremely small, and ill adapted to the occasion ; 
A.D. but the enterprise was now patronised by the 1675. Government; and the Admiralty, at the head of which the king in those days presided, ordered the Speedwell to be equipped for this service, and the command to be given to Captain Wood, who had so warmly espoused the cause. At the same time the Duke of York, with several noblemen and gentlemen, purchased the Prosperous, a pink of one hundred and twenty tons, to accompany her, and she was placed under the command of Captain Flawes.

1676. These two vessels left England in May, 1676, and appear to have held a course between Spitzbergen and Nova Zembla; but on what meridian it is impossible exactly to determine, as "the Journal of Captain Wood," observes the author of "Chronological History of Voyages to the Arctic Regions,' "is so meagre that, if it were not for his supposed latitudes, and his situation 'according to judgment,' it is not easy to follow his track or to trace his place on any particular day." He appears, however, to have kept along the ice towards Nova Zembla, which he saw on the 26th June; and before he had time to make any discovery, or even advance along that coast, he had the misfortune to lose his vessel. His consort was prevented rendering him any assistance at this time, and a fog coming on, he lost sight of her for several days; at length, 
on the 8th July, she made her appearance, and, to the great joy of Captain Wood and all his crew, A.D. she took them on board, and conveyed them safely to England, with the exception of two seamen, who were drowned in landing upon Nova Zembla when the ship went to pieces. The failure of this expedition is attributed by Wood to the error in which he was led by following the opinion of poor Barentz, but in what way we are not told, nor can we easily imagine; for, if that worthy navigator gave any opinion, it would certainly be against the probability of a passage by the route pursued by Wood. Indeed Wood seems to have been greatly at a loss for an excuse for his failure, as we find him accusing all the statements of both Dutch and English as false, and asserting, in the most unaccountable manner, that Nova Zembla was connected with Spitzbergen on the north, and with the coast of Tartary on the south, notwithstanding it was well known that both its extremities had been rounded on several occasions. In short, he seems to have been determined that, as he could not effect the passage himself, he would create an imaginary barrier which should deter any other person from renewing the attempt.

We cannot suppose that these unfounded assertions had much weight in the minds of 
A.D. any sensible persons. Such individuals would,

1676. of course, attribute the disastrous failure of the expedition to the proper cause; but certain it is that the ardour which the subject formerly excited, appeared from that period entirely to subside; nor was it revived for nearly a century.

During this interval the Russians made repeated attempts to pass along the northern shores of Europe and Asia by a coast navigation, each expedition adding a small portion to the hydrography of those parts, until nearly the whole of the coast-line was ascertained from the North Cape to Kamtschatka. But this acquisition to Arctic geography was not acquired without great difficulty and innumerable perils, or without the loss of many lives.

\section{TSCHITSCHAGOFF.}

1764. In 1764, the Russian Government, finding that a navigable passage in an eastern direction was hopeless, planned an expedition to the north by the way of Spitzbergen; and in the same year sent a vessel to form an establishment in Bell Sound, as a depôt for the intended ex1765. pedition, which, the next year, sailed under the command of Vassili Tschitschagoff. The expedition was directed to proceed to Spitzbergen first, and then to endeavour to proceed north- 
westward to Behring's Strait; and, failing in that quarter, to trace the ice along to the northA.D. east, and to take advantage of any opening that might afford a prospect of success.

Tschitschagoff appears to have executed these instructions like a bold and persevering navigator. To the westward his progress was arrested by the ice in a very low latitude; and to the north, after three unavailing attempts, in which he reached the latitude of $80^{\circ} 26^{\prime}$, a few leagues north-east of Cloven Cliff, he found it an equally hopeless case, and returned to Archangel.

A difference of opinion now arose in Russia as to the efficiency of this attempt of Tschitschagoff, and he was sent out again the year following, but he was not more successful on this than on the former occasion, having reached only the latitude of $80^{\circ} 30^{\prime} \mathrm{N}$. He found the ice occupying nearly the same position as before; and, having ascertained its connexion with the coast of Spitzbergen in the vicinity of Grey Hook, his opinion of the impracticability of the passage was confirmed, and he returned to Russia in the autumn, when his efforts were more appreciated than at first, and no other expedition to the same quarter was again thought of in that country. 


\section{CHAPTER IV.}

The British Government equips an expedition under the command of the Hon. Capt. Phipps, R.N.-Racehorse and Carcass appointed to this service.-Departure.-Spitzbergen. - Barrier of ice.-Fair Haven.-Seven Islands.-Ships beset and abandoned.-Crew take to the boats.-Ice opens. - They regain their ships._Effect an escape.-Put into Port.-The Pendulum set up.-Return of the expedition to England.

A.D.

In the year 1773 the Honourable Daines Bar1773. rington laid before the President and Council of the Royal Society a series of papers, in which he advocated the practicability of approaching the North Pole, stating that, from various information which he had been able to collect, several vessels, principally Dutch, had succeeded in attaining a much higher latitude than was generally supposed possible, and that one had actually approached within a degree of the Pole.

Such a communication, coming from the enlightened hydrographer of the navy, at a time when the public mind was elated by the brilliant discoveries of Wallis and Cook, could not fail to obtain a favourable reception from the Royal Society, who lost no time in applying to the 
first Lord of the Admiralty to obtain his majesty's sanction for an expedition to try how A.D. far navigation was practicable towards the North Pole.

The expedition of Captain Wood was as yet the only one that had been equipped for this purpose by the Government, and that had failed, apparently not from insurmountable obstacles, but from an untoward accident at the outset of the voyage. The arguments in favour of a passage which had been used on that occasion were applicable to the present, and besides which a very favourable change was about this time reported to have taken place in the state of the ice, in the Arctic seas, and, moreover, it then seemed particularly desirable, whilst Cook was pursuing his observations with the pendulum in the southern hemisphere, that corresponding experiments should be made in a high northern latitude, especially as these delicate observations could then be conducted with greater accuracy than before, owing to the material improvement which about that time had been made in the construction of the pendulum.

These important considerations had their due weight with Earl Sandwich, then at the head of the Admiralty, who immediately submitted the application of the Royal Society to his 
A.D. Majesty George III, in whose memorable reign

1773. the spirit of discovery reached a higher standard than it had perhaps ever before attained, and who was pleased to command that two ships should be appropriated to this service, "with every encouragement that could countenance such an enterprise, and every assistance that could contribute to its success."

The Racehorse and Carcass bombs were accordingly ordered to be prepared, and the command of the expedition was given to the Hon. Captain Constantine J. Phipps (afterwards Lord Mulgrave), who hoisted his pendant in the former, and Captain Skeffington Lutwidge was appointed to the command of the latter. This class of vessel was selected on account of the comparatively superior strength and stowage of the ships, a choice of which the judiciousness has been fully confirmed by all the expeditions which have been employed subsequently upon a similar service.

Nothing was spared that could render the expedition effective, or that could tend to promote the health and comfort of the seamen engaged in it, and prevent the occurrence of that species of sickness which had heretofore attended the lengthened voyages of almost all their predecessors. The first expedition of 
Cook had about this period furnished information of the first importance as regarded the preA.D. vention of this dreadful malady, and accordingly several alterations were made in the nature of the provision supplied; and the comfort of the seamen was farther considered by a gratuitous issue of clothing, adapted to the rigour of the climate. Among the useful articles with which the ships were supplied, was an apparatus for distilling fresh water from the sea, the invention of Dr. Irving, who accompanied the expedition as surgeon.

The possibility of some serious accident befaling the ships, suggested the propriety of adapting the boats to the conveyance of the crews, consisting of ninety persons in each vessel, and of protecting them against the inclemency of the climate, to which the people would in such an emergency be exposed.

Captain Phipps was considered an officer of great experience and scientific attainment, and Mr. Lyons, of mathematical reputation, was engaged to accompany him as astronomer. The Royal Society supplied every requisite information upon subjects to which it wished to direct attention; very full instructions in the branch of Natural History were furnished by Mr. (afterwards Sir Joseph) Banks, and the best instruments in use in those days, were supplied, in- 
A.D. cluding a seconds' pendulum, with which Mr. 1773. Graham, the inventor of the mercurial compensation pendulum, had made some of his most valuable observations in London. In short, every consideration that could tend to render successful and complete so important an expedition was bestowed upon it. And when we reflect on the ample manner in which everything was provided, as compared with the earlier expeditions, the size and strength of the vessels, the number of the seamen, the improvement in the provision, and in short, in every other respect, - we must confess that, as far human efforts could be made available, there was every reason to believe that more would now be accomplished than had hitherto been performed, and that this expedition would have the advantage of all that had preceded it.

On the 26th May, Captain Phipps received instructions from the Admiralty, to take the Carcass under his command, and to proceed to the North Pole, or as far towards it, and as nearly upon the meridian of Greenwich, as the ice, or other obstructions would admit. In the event of being successful in this undertaking, or even in finding an open navigation beyond the Pole, he was not to proceed any further, but to secure his return to England at all 
events before the winter should set in. He was a.D. directed to make all the useful observations in 1773. his power that might tend to improve navigation, or promote natural knowledge, and in the event of being obliged to abandon his own ship, he was directed to prosecute the voyage in that of his consort, the Carcass.

On the 30th May the two ships joined company, the Carcass having been fitted in a different port to the Racehorse, and on the 2nd June the expedition quitted the Nore, passed Flamborough Head on the 9 th, and was off the Shetland Islands on the 14th. On the 19th Captain Phipps crossed the Arctic Circle; and had the gratification of observing the meridian altitude of the sun at midnight. The following day Mr. Cavendish's thermometer was sunk 4680 feet, by which the temperature of the water at that depth was ascertained to be $26^{\circ}$, whilst that of the surface was $48^{\circ}$; and a few days after similar results were obtained. The observations with this instrument, however, should be received with great caution. Dr. Irving's apparatus for distilling fresh water from that of the ocean was now tried, for the first time, and succeeded beyond expectation, producing from thirtyfour to forty gallons of pure water in the course of the day, with no other fuel than that employed 

A.D. in the cooking of the ship's provisions, a result

which fully established the utility of this invention of Dr. Irving, which in long voyages might be of the greatest advantage to a small crew. This instrument, however, although it answered its intended purpose very well, was, it must be admitted, less useful upon this service than it would have been to almost any other, as the passage from England to the Frozen Sea could be of short duration only, and, after its arrival there, there could be no necessity for it, as fresh water could always be procured from the ice and snow, of which there was no probability of any deficiency. It, however, marked a disposition on the part of the government to omit nothing that might be useful.

On the 23rd, in latitude $72^{\circ} \mathrm{N}$., a piece of drift wood was picked up, which was not in the least wormeaten, a fact which Phipps seems anxious to mention, as much stress had been laid upon the occurrence of drift wood in the Arctic seas, as indicating a prevailing current from some distant country in which this material was grown, and upon that ground founding an argument in favour of a navigable passage. Five days afterwards the island of Spitzbergen was seen in the distance, and the following day the ships stood close in with the land, which Captain 
Phipps describes as being in appearance neither habitable nor accessible; it being formed of high A.D. barren black rocks, without the least marks of vegetation, in many places bare and pointed, and in others covered with snow; being so high that its summits towered above the clouds, whilst the valleys were filled with snow or ice. This appearance in the middle of summer, he adds, might have suggested the idea of perpetual winter, had not the mildness of the weather, and the brightness of the sunshine, added to the constant daylight which they now enjoyed, given a congenial and cheerful sensation, which was in opposition to that produced by the black and dreary appearance of the coast.

Captain Phipps now continued his route to the nortliward, along the western side of Spitzbergen, making his remarks upon the land, and pursuing his observations at sea, in which, we must do him the justice to observe, that, throughout the voyage he was particularly attentive. On the 29th he had arrived at a high magnetical latitude, the dip being $80 \frac{1}{2}$, and where, the directive power of the needle being greatly diminished, the local attraction of his vessel was sensibly felt. At that period, however, the nature of this disturbing force had not been discovered; and he confesses himself at a loss to account for the 
A.D. wide discrepancy in his observations on the varia-

1773. tion made at sea. In the sequel of the voyage, however, we find this enlightened navigator glancing at a probable cause of the disturbance, as did also Captain Cook, about the same period, in the Pacific; but it is well known that it was left to the penetration of the indefatigable Flinders, satisfactorily to explain the phenomenon.

On the 3rd July, the expedition arrived off an island on the western side of Spitzbergen, which had received the name of Prince Charles', and Captain Phipps determined the height of one of its mountains to be 4509 feet. As this was by no means one of the highest hills, some idea of the scale and grandeur of the coast may be formed from its altitude. He here fell in with a whale ship, the master of which informed him that the ice was only sixteen leagues to the westward, and that three ships had already been lost in it.

The following day he anchored in Hamburgh Cove, in lat. $79^{\circ} 30^{\prime}$ N., a small place, situated about three miles to the southward of Magdalena Bay, where he replenished the water of the ship, and would have made some astronomical observations had he not been obliged by wind and fog to put to sea almost immediately. The ships again 
steered to the northward, along the land, until the afternoon of the 5th, when, the weather being A.D. very foggy, the attention of our voyagers was arrested by a noise resembling the surf upon a beach, which increased as they proceeded, until they at length discovered an extensive body of ice, consisting of large masses driven closely together, heaving and subsiding with the waves as they rolled in from the southward, and so close to the ships that there was hardly room for them to be put about.

When the weather cleared up the main ice was seen at no great distance from the ships, bearing from W.N.W. to E.N.E., and presenting a prospect as cheerless to our navigators as could well be imagined, as it precluded the possibility of advancing to the northward much beyond the situation of the ships at that time, and left the only hope of being able to make any progress dependent upon a narrow channel leading to the eastward, between the ice and the northwestern point of Spitzbergen. Captain Phipps lost no time in availing himself of even this small opening, and being favoured with clear weather and smooth water, he sailed close along the edge of the ice. He however very soon came to the end of the opening, and finding no chance of being able to proceed further, turned about to retrace his 
A.D. course, and very narrowly escaped being beset

1773. by the ice, which was in rapid motion, and which indeed enclosed the ships in a manner that rendered it necessary to have recourse to ropes and ice-anchors to extricate them.

Foiled in an eastern direction, Captain Phipps determined to try in the northwest, and, after contending with fogs and blowing weather, he succeeded in attaining the latitude of $80^{\circ} 36^{\prime}$, which was the most northerly point ascertained by observation, which he reached during the voyage; this was in longitude $2^{\circ} 2^{\prime} \mathrm{E}$. He was not able, however, to proceed thus far without considerable difficulty, and the risk of being beset, for the ships were already surrounded by loose ice. The weather was at this time cold and wet, and the duty of the ship becoming very harassing to the seamen, many of them were laid up with pains in their limbs. After searching in vain in every quarter for an opening that would admit of the expedition proceeding to the northward, and having run ten degrees along the edge of the pack, and in that space made several attempts to push through it, and having always encountered an impenetrable body of ice a short distance within the loose pieces at the edge, Captain Phipps directed his course once more to the eastward, to ascertain whether what he 
termed the main ice was connected with the northern coast of Spitzbergen; a point he had 1773. before been unable to determine, in consequence of the quantity of loose ice floating about.

Two days' calm, succeeded by a thick fog, however, prevented the execution of this plan for the time; and, there being every appearance of very boisterous weather, the ships put into Fair Haven for shelter.

Fair Haven is a name which has been given (by the Dutch navigators) to all the anchorages between Cloven Cliff and Amsterdam islands; but that part of it in which Phipps now anchored is situated between Vogel Sang, Cloven Cliff, and the Norways, and is sometimes called the North Harbour. This is the most convenient port in Spitzbergen for observing the motion of the ice in the offing, which can be plainly discovered from the hills or from the islands under which the ships are anchored.

The Norways are two islands, situated to the north-east of Cloven Cliff, and have been used by the Dutch whalers at various times for the purpose of boiling their blubber previous to their return home. There were several ships anchored there at the time Captain Phipps put into Fair Haven, but he does not appear to have had any communication with them. 
$\Lambda$ D. As there was a prospect of being detained 1773. several days at this anchorage, the pendulum was landed upon a small rocky island near the Norways. The weather, however, proved so unfavourable, that no satisfactory observations were obtained ; and, indeed, we may add, that the same remark will apply to all that was done upon this island, for nothing can be more incorrect than the survey of the Haven, which Phipps states was made from that spot, or the heights of the hills and islands about it, notwithstanding all the precautions he appears to have taken in order to render them accurate. From the account of these operations given in the Appendix, we cannot suppose Captain Phipps to have been ignorant of the practical part of the work; and we must consequently conjecture, either that some error occurred in writing down the observations, or that he could not devote his attention to it, as he has not even given the number of islands correctly, and of course he has not attended to their relative dimensions. As regards the heights of the mountains, it is evident also that there has been some great error, either in distinguishing them upon his chart, or in recording his observations; but which, it is impossible now to determine, as his plan is so incorrect, that it is quite out of the power of 
any person to identify the hills with those which exist near the anchorage.

Captain Sabine, who visited this place in $\mathbf{1 8 2 4}$ for the purpose of determining the length of the seconds' pendulum, observes, in his paper read before the Royal Society, that, "After" having been nearly three months on the spot, I am even more perplexed than on the day of my arrival to assign in the plan the island which is intended to represent the one upon which Phipps' observatory was placed, or the position of the hill in question."

The latitude of the small island upon which Phipps landed and fixed his observatory is stated to be $79^{\circ} 50^{\prime} \mathrm{N}$., and the longitude $10^{\circ}$ $2^{\prime} 30^{\prime \prime} \mathrm{E}$. ; the variation on shore was $20^{\circ} 38^{\prime} \mathrm{W}$., and the dip of the needle $82^{\circ} 7^{\prime}$. The tide rose about four feet, and the flood came from the southward.

On the 18th Captain Phipps embarked the instruments, and put to sea to try if there was yet any possibility of penetrating the ice, and the following day was stopped off Red Bay, nearly in the same situation in which his progress had been arrested twice before. There was no opening to be seen in the ice in a northerly or easterly direction, and not the smallest prospect of being able to proceed further. The 
A.D. ships were, in consequence, put about, and kept 1773. along the ice, which led them in a north-west direction until they reached the latitude of $80^{\circ}$ $34^{\prime} \mathrm{N}$., being nearly in the situation they occupied on the 9 th instant. From this point the ice trended to the south-west, and was so compact that Captain Phipps, after pursuing that direction for several miles, abandoned all hope of being able to effect anything in a western direction for the present; as a last alternative, therefore, he determined to make another trial in the quarter where he had been already three times repulsed.

On the 24th he reached this spot, and the ships, after receiving several hard knocks in forcing through some loose ice, succeeded in advancing beyond it. The next day the sea to the eastward was so free from ice that the greatest hopes were entertained of being able to get to the northward. At two in the afternoon they were in sight of Moffen Island, a low patch of ground about two miles across, with a lake in its centre, surrounded by a circular bank of gravel and shingle, about a quarter of a mile broad, which had been raised, no doubt, by the repeated pressure of the ice against the shore, as such embankments are by no means uncommon on the shores of seas encumbered with 
ice. There was a piece of drift wood upon the edge of the lake, about eighteen feet long and A.v. five feet girth, with a root to it; and, as there are no trees of this dimension upon either Spitzbergen or Nova Zembla, it is very probable that this one had been brought down some of the great rivers to the eastward, and drifted by the currents to the resting-place which it had found upon Moffen Island. This small barren spot of ground was the resort of numerous sea-fowl, wild geese, and ducks, which had made nests all over the island.

Upon one part of the shore there was a grave, with a Dutch inscription, bearing date 1771 . On the western side of the island they found a fine sandy bay, with a shelving even bottom, and good anchorage in five fathoms water at half a mile distance from the shore.

Quitting Moffin Island, the ships worked to the north-eastward, in a sea so clear of ice, that the only pieces in sight were those which they had already passed. The next day they saw land to the eastward; and on the 27 th were in latitude $80^{\circ} 48^{\prime} \mathrm{N}$. by reckoning, and in longitude $14^{\circ} 59^{\prime} \mathrm{E}$. Here they again encountered the main body of ice, which arrested their further progress northward, and the following day were obliged to run several miles to the 
A.D. southward to avoid being beset. The expedi1773. tion was at this time about twenty-one miles to the westward of the Seven Islands, which appeared to be surrounded by ice; the sea to the southward of them, however, seemed to be clear, and Captain Phipps shaped his course in that direction, in the hope of being able to pass the islands, and of finding the sea to the eastward of them clear of ice. In doing this, he opened out Henlopen Strait, and found a heavy swell from the southward; from which it may be inferred that the sea was clear of ice in that direction, for a considerable distance at least. The wind here fell light; and the ships being near a low island, a boat was sent to examine it: they found it to be about seven miles in length, and very low. Dr. Irving, who accompanied the party, stated that there were lying upon the beach, sixteen or eighteen feet above the level of the sea, several large trees, about seventy feet long, which had been torn up by the roots, and others which had apparently been felled with an axe, and marked out in twelve-feet lengths. The timber was in no ways decayed, nor the strokes of the axe in the least defaced. There were likewise some pipe-staves, and wood, fashioned for use. The beach was formed of old timber, sand, and 
whale-bones. The island was composed prin- A.D. cipally of "stones, of an hexagonal form, and 1773. about thirty inches diameter, commodiously placed for walking over." The middle of the island was covered with moss, scurvy-grass, sorrel, and a few ranunculuses, then in flower. Two reindeer were feeding upon this pasturage, one of which was shot, and found to be in good condition and well flavoured. The island abounded with snipes, geese and ducks, which were hatching their eggs. The officers of the boat, in their way back to the ship, wounded a sea-horse, which dived immediately, and bringing up with it a number of other's, commenced an attack upon the boat and wrested an oar from one of the seamen. So furiously was this assault conducted, that it was with great difficulty the animals were prevented staving and upsetting the boat; and the event might have proved alarming, had not a boat from the Carcass* come to their assistance and dispersed their assailants. This was the second attack that had been made by these animals on the boats of the expedition.

On the 30th the ships had reached the latitude of $80^{\circ} 31^{\prime} \mathrm{N}$., in longitude $18^{\circ} 48^{\prime} \mathrm{E}$.

* From Mr. Southey's "Life of Nelson," we are informed that Nelson had charge of this boat. 
A.D. They were at this time among the group called 1773. the Seven Islands, and were surrounded by ice, to which it was found necessary to moor the ships with ice anchors. Captain Lutwidge and the master of the Racehorse went on shore and ascended a mountain, from whence they commanded a prospect of ten or twelve leagues to the north-eastward, and found the sea so covered that "it presented a plain of smooth unbroken ice, bounded only by the horizon." To use Captain Lutwidge's own words: "Here (from the top of the hill) I had an extensive view of the sea to the eastward, which was entirely frozen over, not like the ice we had hitherto coasted, but a flat even surface as far as the eye could reach, which was undoubtedly ten leagues at least; a compact body of ice joined to all the islands and lands in sight, and no appearance of water except a few streams in the direction which the ships came in."

The main body of ice which the ships had traced from the westward joined the Seven Islands, and extended from them to the northeast point of the mainland, thus shutting out all prospect of the expedition being able to proceed further.

This unpromising prospect from so elevated a situation determined Captain Phipps to endeavour 
to extricate the ships from the danger of being A.D.

beset between the ice and the land, which the 1773. gradual accumulation of broken ice about the vessels, and a general closing of the main body with the coast momentarily threatened. Being favoured with a light breeze from the eastward in the morning of the 31st, the ships cast off and steered to the westward, but were soon obliged to make fast again, as the ice became packed in every direction, being evidently acted upon by some very great external force, as it was piled up, occasionally, in heaps higher than the ships' main-yard. This immense pressure was no doubt occasioned by a gale of wind from the southwestward, which being kept off by the land of Spitzbergen, was not felt by the ships, which were becalmed all day. That such was really the case was shortly rendered more evident by the ice driving bodily to the eastward, as well as by the space in which the ships had advanced from the westward becoming so closed up, that there was not any open water to be seen. The pilots, who had never been so far before, now became alarmed lest the ships should become permanently fixed in the ice, and recommended the saws to be set to work with a view to the liberation of the vessels by means of a canal, but the ice was so thick that, with the utmost ex- 
A.D. ertions of a whole day, the ships were moved only the sixth of a mile, while they were during the same time carried back two or three leagues by the current. It was quite obvious therefore that nothing could be effected with the saws, and they were carried on board again. The ships were now quite immovable, and drifting gradually with the ice to the eastward, by which the prospect of liberating them became hourly less apparent.

Here it was that Nelson, who was coxswain of one of the boats of the Carcass, went in pursuit of a bear, followed at a distance by one of his shipmates, and had so narrow an escape of his life.

Early in the following morning three bears were killed upon the ice.

On the 5th August, the probability of liberating the ships becoming less every day, and the season being far advanced, Captain Phipps was of opinion that some speedy resolution was necessary towards the preservation of the crews of the ships, and as their proceedings in this endeavour would entirely depend upon the distance to which the packed ice might extend to the westward, $\mathbf{M r}$. Walden, one of the midshipmen, and two pilots, were sent to an island about twelve miles distant to survey the state of the sea from its summit. They returned on the following day, with the 
information that the ice, though close about the A.D. ships, was still open to the westward round the 1773. point by which they had come in, and that the wind was there blowing fresh from the eastward.

As it had been nearly calm all day in that part where the ships were moored, Captain Phipps was of opinion that this circumstance considerably lessened the prospect of a speedy release, and that he had but the alternative either of patiently awaiting the effect of the weather upon the ice, or of abandoning the ships and betaking to the boats. The ships had driven into fourteen fathoms' water, and he apprehended that should either they or the ice take the ground, there would be no possibility of saving them. The hopes of getting the ships out was certainly not hastily to be abandoned, nor obstinately adhered to till all other means of retreat were cut off. To use Captain Phipps' own words: "Having no harbour to lodge them in, it would be impossible to winter in them where they were, with any probability of their being again serviceable; our provisions would be very short for such an undertaking, were it otherwise feasible; and supposing, what appeared impossible, that the crews could get to the nearest rocks and make some convenience for wintering, being now in an unfrequented part, where ships never even 
A.D. attempt to come, we should have the same diffi1773. culties to encounter the next year without the same resources: the remains of the ships' company in all probability not in health, no provisions, and the sea not so open, this year having certainly been uncommonly clear. Indeed, it could not have been expected that more than a very small part should survive the hardships of such a winter with every advantage, much less in our present situation. On the other hand, the undertaking to move so large a body for so considerable a distance by boats, was not without very serious difficulties. Should we remain much longer here the bad weather must be expected to set in."

As it was Captain Phipps' intention, in the event of taking to the boats, to proceed immediately to Fair Haven, where he had left some Dutch ships at anchor, he knew that if he came to this resolution there was no time to be lost, as the Dutchmen quit the harbour directly the ice sets in, and remain only until the 1st September, under the most favourable state of the sea. He therefore made up his mind to abandon the ships, and summoning his officers together, made them acquainted with his intentions.

The boats were immediately hoisted out, and the necessary fittings to render them secure and comfortable begun, and the following morning, 
August 7th, Captain Phipps set out with the A.D.

Launch, and by noon the crew had succeeded in 1773. dragging her two miles. About this time the ice about the ships beginning to open, and a breeze springing up from the eastward, the sails were set, which had the effect of moving the ships about a mile to the westward in the course of the day. Still there was no certainty of liberating them, and Captain Phipps determined upon dragging the boats to the edge of the packed ice, keeping sail upon the ships at the same time, and if on the 14th instant they were not clear, upon finally abandoning them, and proceeding in his boats direct to Fair Haven.

On the 8th the people worked hard at the boats, and succeeded in moving them three miles. The weather was foggy, so that they could form no correct idea of what effect had been produced upon the ships by the sails, but it was evident by what could be discovered of the land, that they were moving slowly in the desired direction; and what rendered the prospect more cheering was, the advantage they were deriving from a current in their favour. In the afternoon of the following day the fog cleared off, and they were agreeably surprised to find that the ships had been drifted a considerable distance to the westward, and that the ice began to slacken, so that 
A.D. by keeping a press of sail on the ships, they managed to get them past the Launch; and the progress of the ships now exceeding that of the boats, they were all got on board.

Hopes of a speedy liberation were now momentarily increasing; all sail was kept on the vessels, which began to move briskly through the water, and to make their own way through the ice, by turning aside pieces which would have resisted a less forcible impetus; in doing this the Racehorse lost her best bower anchor, by the stock coming in contact with a large piece of ice, which broke it in the shank. By noon on the 10th the ships had cleared the ice, and the crews enjoyed the indescribable gratification of once more finding themselves in a navigable sea. The next day, Captain Phipps put into the port of Smeerenberg, and anchored off the low point of Amsterdam Island, where, as he had anticipated, he found four Dutch whalers; so that had he been obliged to abandon his own ships, he would thus have been provided with the means of returning to England.

Being now convinced, from his experience amongst the ice, that it was quite impossible to penetrate the great icy barrier, which he had found extending from the northeastern point of Spitzbergen, round by the Seven Islands to the 
longitude $2^{\circ} 2^{\prime}$ E., he determined upon return- ${ }_{17 . D}^{\text {A.D. }}$ ing to England, as soon as he had given the ships such temporary repair as they needed, and recruited his crew after the fatigues they had undergone. And in order that the time which this would require might be employed advantageously, the pendulum was landed upon Amsterdam Island, and the survey of the coast, which had been begun at North Harbour, continued, but, most unaccountably, with as little approach to accuracy as before; and ships must on no account attempt to sail by the chart which has been published in the account of this voyage.

A base was measured with great care, apparently, upon Amsterdam Island, for the purpose of comparing the geometrical measurement of the height of a mountain with its altitude by the barometer-in which there was so great a difference, that Captain Phipps expresses himself wholly at a loss to account for it, as both experiments were made with the greatest care; the former by himself, and the latter by Dr. Irving. It is a great pity that Captain Phipps has omitted to inform us in his narrative of the position of this mountain, as Captain Sabine would have been able to determine which of the measurements was correct, and his observations would, perhaps, have rescued this and other parts 
A.D. of Captain Phipps' operations from a blemish, which has been cast upon them, evidently through an oversight in affixing the letters to the improper places on the chart.

Nearly opposite the anchorage of the ships, there was situated one of those stupendous formations of ice for which the island of Spitzbergen is remarkable. It occupied a deep valley, formed between black rocky mountains; its face was about three hundred feet in height, and nearly perpendicular, and towards its southern extremity there was a stream of water gushing out of it. Near its centre, according to the view given of it by Mr. D'Auvergne, who accompanied Captain Phipps, there was a deep cavern, which presented nearly the same appearance as it did when visited by Captain Buchan's expedition, forty-five years afterwards. Large pieces of ice frequently broke away from the face of this glacier during the time the ships were at anchor, one of which grounded in 144 feet water, and reached 50 feet above the sea, making its whole length 194 feet.

Upon the point of Amsterdam Island where the pendulum was landed, Captain Phipps dișcovered the remains of some conveniences for boiling oil, and remarks, that the Dutch once attempted to make an establishment at that place, and left some people to winter there, all of whom perished. 
From similar remains being found also upon the Norways, two islands a few miles to the A.D. northward of Amsterdam Island, and from the occurrence of a far greater number of graves, bearing nearly the same date, it is likewise probable that the Dutch, who had there also an establishment, had also attempted to pass the winter upon these islands, and that the miserable beings had shared the same melancholy fate with those on Amsterdam Island.

It is somewhat remarkable, that so great a mortality should have attended this attempt, provided, as the settlers must have been, with the necessaries of life, when, many years before, a boat's crew of Englishmen, we are told, were cast away upon the same place, and contrived to pass six dreary winters, unprovided with anything but their boat and the clothes they stood in, without losing a man.

If a conclusion may be drawn from these facts, it is, that the Dutch, having no necessity to labour during the winter, shut themselves up in their huts, and thereby generated the disposition to scurvy, to which fresh air and exercise are so great an antidote; whilst the English, compelled by necessity to wander out in the depth of winter to collect even their fire-wood from the drift timber upon the beach, were driven to the use of 
A.D. both these preventives, and so escaped the ravages of that dreadful malady. Hence we may infer the propriety, nay the necessity, of giving occupation both to the mind and body of persons, whose fate it may be to pass a long and dreary winter in a climate unusually severe.

Captain Phipps, in concluding his journal observes, that he perceived no minerals of any kind on that part of Spitzbergen which he visited, nor were there any appearances of active or extinct volcanoes. There were no rivers or springs, but the fresh water, which was always found in great abundance, was produced by the melting of snow. There was no thunder or lightning whilst he was upon the coast; and the sky was in general loaded with hard white clouds, so that he does not remember to have seen the seas and the horizon both free from them even in the clearest weather. The drift-wood, which from very early times has given rise to various conjectures as to the place of its growth, was, with the exception of the pipe-staves discovered upon the low island by Dr. Irving, all fir, and not perforated by the worm, but he had no opportunity of ascertaining from whence it had drifted.

He next remarks upon the nature of the ice which he saw, and from his description of it, as well as from that given rby Captain Lutwidge of 
what was seen from the Seven Islands, it is clear A.D.

that both these officers were of opinion, that the barrier was a firm consolidated mass, unbroken by any of those channels in which the ships sailed near its margin, as the former remarks that the "loose fields and glaciers, as well as the interior part of the fixed ice, were flat and low," and the latter, that the sea to the eastward of the Seven Isles was " entirely frozen over, not like the ice we had hitherto coasted, but a flat even surface as far as the eye could reach."

Such an opinion however, has since been proved incorrect; but, coming from high official authority, it must not only have cast a doubt over the alleged successes of some of the early voyagers, but it may with reason be assigned as the cause of the long interval which elapsed between the return of this expedition and the revival of discoveries towards the Pole.

While Captain Phipps remained at the anchorage the weather was so unfavourable for astronomical observations that he could obtain no satisfactory' results with the pendulum; but, by such as he was able to make, the compression of the earth at the Pole appeared to be as 212 to 211 , or $\frac{1}{21} \overline{2}$. Modern observations, however, seem to fix it at $\frac{1}{30} \bar{g}$, nearly -a difference which is to be imputed partly to the absence of the necessary observations in Captain 
A.D. Phipps' case, and partly to the improved method by 1773. which results are now deduced from these delicate experiments; he having been able to observe but two passages of the opposite limbs of the sun, whilst a considerable number of these transits are necessary to give accuracy to observations involving so much delicacy and precision. His magnetical observations were more satisfactory.

On the 19th August the expedition quitted Spitzbergen, and sailed along the edge of the ice to the westward until the 23rd, when Captain Phipps observes, that " the season was so very far advanced, and fogs, as well as gales of wind, so much to be expected, that nothing more could now have been done, had anything been left untried," and he accordingly directed the course of his expedition for England, where it arrived on the 29th September.

The expedition of Captain Phipps ends what may properly be considered early Arctic voyages, the next undertaking being that by Captain Buchan, already narrated. These early enterprises, which may be appropriately termed the pioneers of the way, have tended to remove that veil of obscurity which, previously, hung over the geography, and indeed over all the phenomena of the Arctic regions. Before these all was darkness and terror; all beyond the North 
Cape a blank upon the chart; the northern limits of either Asia or America were unknown; and to sail by "the unhaunted shores of Finmark, to double the dreadful and misty North Cape, and to vnlocke the seven-fold mouth of Duina," were exploits hardly to be ventured upon. But since that period each succeeding voyage has added to the geographical knowledge of its day; each year has swept away some gloomy superstition; has brought to light some new phenomenon of the northern regions; and tended to the advancement of natural knowledge. 



\section{A P PE NDIX.}

CONTAINING

I. Abstract of Experiments made at SpitzBERGEN.

II. Temperature of the Sea.

AND

III. Currents of the Ocean. 



\section{P A R T III.}

\section{APPENDIX.}

OF the various scientific observations made during the absence of Captain Buchan's expedition from England, those on the length of the pendulum vibrating seconds; on the dip, intensity, and magnetic force, of the needle; the temperature of the sea at various depths, as compared with that at the surface, and on the currents of the ocean, are the most interesting; and of these a short notice will not, we trust, be considered superfluous.

No. I.

An Abstract of Experiments made at Spitzbergen, to determine the length of the pendulum vibrating seconds, 1818. By the Rev. George Fisher, Astronomer to the Expedition.

THE pendulum was attached to a clock made by Shelton, the property of the Royal Society. The rod was cylindrical, the bob of a lenticular shape, and the whole of brass, cast in one solid mass. It vibrated upon blunt edges of steel, in hollow cylinders of agate; and the clock was supported upon a strong, oaken, tripod stand. The plane of vibration was adjusted to a vertical 
position by means of a screw attached to the hindermost leg, and a level fixed to the agates. There was a contrivance also for making the usual lateral adjustment for equalising the beats ; and the experiments were all made with the same face of the pendulum outwards. The barometer, thermometer, and arc of vibration, were observed every two hours.

Immediately before the embarkation of the clock, it was put up in the house of the late Henry Browne, Esq., F.R.S., in Portland Place, London, and the number of vibrations in twentyfour hours, mean solar time, was 86384,41 ; thermometer, Farht. $48^{\circ} 8$; arc $1^{\circ} 31$.

After the voyage, (Dec. 1818, it was put up in the same house; and the number of vibrations, as before, was 86380,5 ; ther. $47^{\circ} 1$; arc $1^{\circ} 616$. It was afterwards taken down, and put up again in the following March, when the number of vibrations was 86379,8 ; ther. $57^{\circ} 3$; arc $1^{\circ} 55$. These results were obtained by a comparison with an excellent clock made by Cummings, regulated by transit observations.

Corresponding observations were made at three different places on the coast of Spitzbergen, at a few miles' distance from each other; at two of which, from the very unfavourable state 
of the weather, no means occurred of effecting the object in view, but by comparing the clock with nine chronometers, some of which went very indifferently. These comparisons were, fortunately, rendered unnecessary, as observations were afterwards obtained at Dane's Island in latitude $79^{\circ} 40^{\prime} 20^{\prime \prime} \mathrm{N}$, and longitude $11^{\circ} 6^{\prime}$ E.; at which place the clock was landed, and fixed upon a solid mass of granite rock, at the height of forty-five feet above the level of the sea, and the sun's passage over the meridian observed for several days. A detail, therefore, of the comparisons will be needless, with the exception of merely stating, that the mean results at each place indicated a very near agreement.

\section{TABLE I.}

Pendulum Otservations upon Dane's Island, Spitzbergen.

\begin{tabular}{|c|c|c|c|c|c|c|c|}
\hline$\stackrel{\infty}{\infty}$ & $\left.\begin{array}{l}\text { Sun's transit by } \\
\text { Clock. } \\
\text { Mean } 5 \\
\text { Wires }\end{array}\right\}$ & $\begin{array}{c}\text { Equat. Time. } \\
+\end{array}$ & $\begin{array}{l}\text { Error of Clock. } \\
\text { M. S. Time. }\end{array}$ & $\begin{array}{l}\text { Mean } \\
\text { Arc. }\end{array}$ & $\begin{array}{l}\text { Mean } \\
\text { Therm. }\end{array}$ & $\begin{array}{l}\text { Mean } \\
\text { Bar. }\end{array}$ & $\mid \begin{array}{c}\text { No. vibrations } \\
24 \text { hours : M. } \\
\text { Sol. Time. }\end{array}$ \\
\hline Aug. & H. M. S. & H. M. S. & H. M. S. & & & & \\
\hline 12 & $24234 \cdot 10$ & 0448.06 & $23746 \cdot 04$ & 10359 & $36^{\circ} 9$ & $29 \cdot 46$ & $86470 \cdot 60$ \\
\hline 16 & $24633 \cdot 15$ & $\begin{array}{lll}0 & 4 & 4.72\end{array}$ & $242 \quad 28 \cdot 43$ & $1^{\circ} 358$ & $36^{\circ} 6$ & $29 \cdot 53$ & $86469 \cdot 03$ \\
\hline 19 & $\begin{array}{lll}2 & 49 & 22 \cdot 20\end{array}$ & 0326.67 & $24555 \cdot 53$ & $1^{\circ} 369$ & $36^{\circ} 4$ & $29 \cdot 61$ & $86469 \cdot 12$ \\
\hline 20 & $\begin{array}{llll}2 & 50 & 17 \cdot 73\end{array}$ & $\begin{array}{lll}0 & 3 & 13.08\end{array}$ & $\begin{array}{lll}247 & 4 \cdot 65\end{array}$ & $1^{\circ} 381$ & $36^{\circ} 5$ & $29 \cdot 63$ & $86469 \cdot 30$ \\
\hline 23 & $253 \quad 2.05$ & $\begin{array}{lll}0 & 2 & 29.51\end{array}$ & 25032.54 & & & & \\
\hline
\end{tabular}


Mean

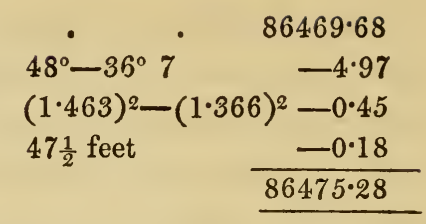

Correction diff. Temp. $044 \quad 48^{\circ}-36^{\circ} 7 \quad-4.97$

$\begin{array}{lll}" \quad \text { diff. of Arc } 1^{\circ} 65 & (1.463)^{2}-(1.366)^{2}-0.45 \\ " \quad \text { diff. of Elevation } & 47 \frac{1}{2} \text { feet } & -0.18 \\ & & \end{array}$

These observations at Spitzbergen are reduced to the same arc, temperature, and elevation, above the sea, as the means between the corresponding ones in London, before and immediately after the voyage. The number of vibrations being 86382.45 ; thermometer $48^{\circ}$; barometer 29.62 ; arc $1^{\circ} 463$. A further correction is also due to the buoyancy of the atmosphere, arising from the difference between the atmospheric pressures at each place; but, as this difference is exceedingly small, and the correction subject to some uncertainty as to its amount, and, moreover, much less than the unavoidable errors which arise from irregularities in the action of the maintaining power, friction, \&c., it is omitted.

Taking the length of the seconds' pendulum in London (at the level of the sea) to be $39 \cdot 13929$,

The length at Spitzbergen is $39 \cdot 2132$

Polar length . . 39.2199

Equatorial length . . 39.0117

Polar compression, or ellipticity of the earth,

Lap. Méc. Céleste, tom. ii. p. 102. 
EXPERIMENTS AT SPITZBERGEN.

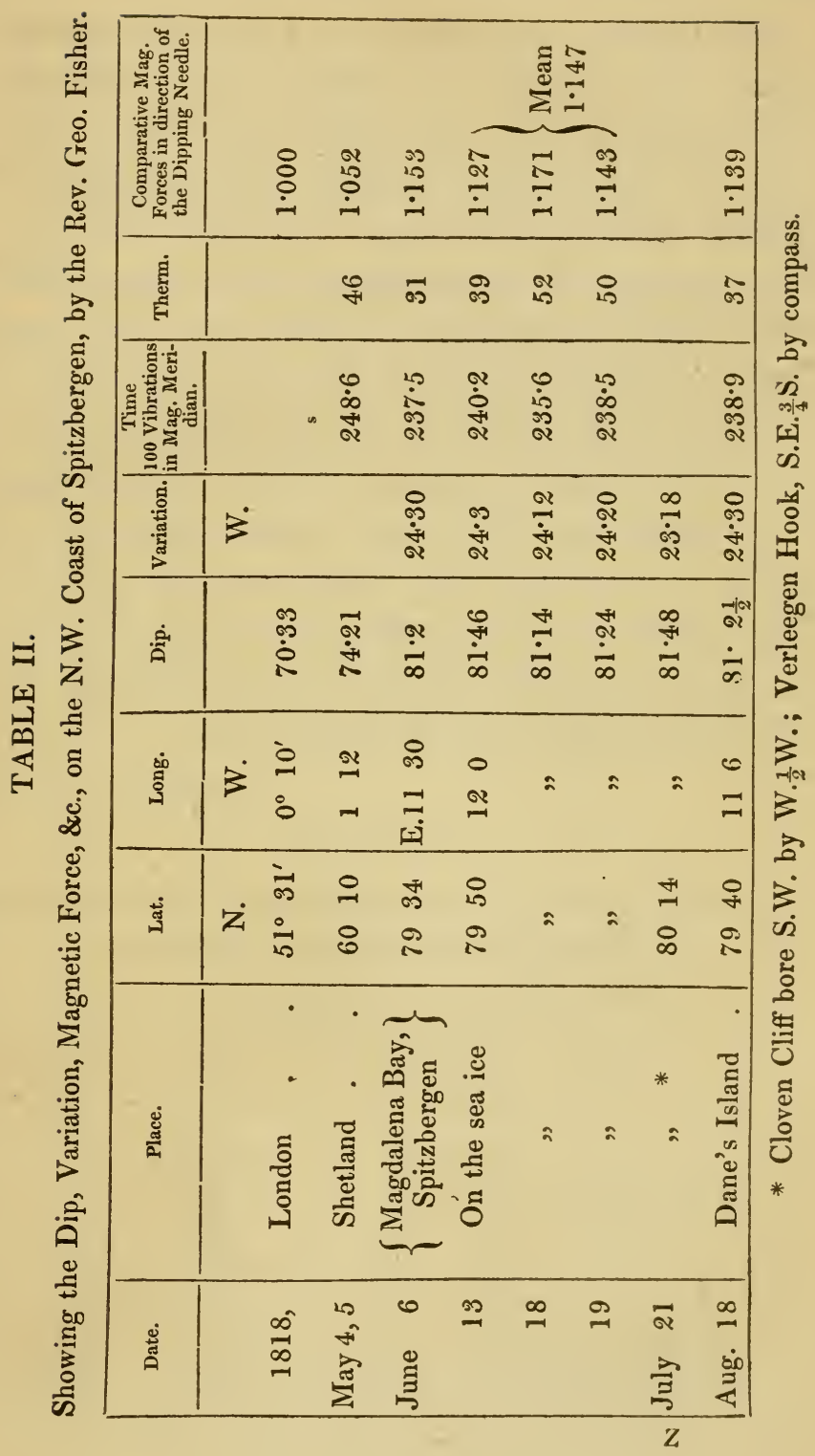


The dipping instrument was one of the usual construction, made by T. Jones, and furnished with polished agate knife-edges, upon which the axes of the needles vibrated. One needle belonging to the instrument was used solely for the purpose of determining the comparative forces, and its magnetism (which was very uniform during the voyage) was therefore never interfered with. The force at Shetland is taken at 1.052, which is a mean of the results from the experiments of Captain Sabine, and subsequent ones of my own near the same place. The variations of the compass were taken, either on shore or on the ice, with Kater's compasses, far removed from any local attraction. 


\section{9}

\section{II.}

\section{TEMPERATURE OF THE SEA.}

WirH regard to the temperature of the sea at depths below the surface, we had few opportunities of making these observations until we reach. ed the $79^{\circ}$ parallel of latitude, but between that and 80 degrees we had a series of results, which were very satisfactory, and fully confirmed $\mathrm{Mr}$. Scoresby's observations, which showed a small increase of temperature with an increase of depth. The following-is Mr. Scoresby's Table, to which I subjoin a short Table of these results, for the sake of comparison.

\section{TABLE III.}

Showing the Temperatures of the Sea at the surface, and at various depths, from Mr. Scoresby's observations.

\begin{tabular}{|c|c|c|c|}
\hline $\begin{array}{c}\text { Temperature at } \\
\text { Surface. }\end{array}$ & \multicolumn{2}{|c|}{ Below the Surface. } & Remarks. \\
\cline { 2 - 4 } & Temp. & No. of fathoms. & \\
\hline $31^{\circ}$ & $31^{\circ}$ & 13 & \\
$"$ & 338 & 37 \\
$"$ & 345 & 57 \\
$"$ & 36 & 100 \\
$"$ & 36 & 400 & \\
$"$ & 37 & 730 & \\
297 & 363 & 120 & In latitude $79^{\circ} \mathrm{N}$. \\
32 & 38 & 761 & In latitude $80^{\circ} \mathrm{N}$. \\
& 38 & & In latitude $78^{\circ} \mathrm{N}$ \\
\hline
\end{tabular}




\section{TABLE IV.}

Comparison of Temperature of the Sea at depths, and at the surface.

From Experiments made by the Expedition.

\begin{tabular}{|c|c|c|c|c|}
\hline \multirow{2}{*}{$\begin{array}{l}\text { Date. } \\
1818 .\end{array}$} & \multirow{2}{*}{$\begin{array}{l}\text { Temperature } \\
\text { at Surface. }\end{array}$} & \multicolumn{2}{|c|}{ Below the Surface. } & \multirow[b]{2}{*}{ Remarks. } \\
\hline & & Temp. & $\begin{array}{c}\text { No. of } \\
\text { fathoms. }\end{array}$ & \\
\hline $\begin{array}{c}\text { June } \\
\text { July } \\
", \\
" \\
" \\
" \\
" \\
" \\
" \\
" \\
" \\
" \\
" \\
" \\
" \\
\text { May }\end{array}$ & $\begin{array}{l}33^{\circ} \\
34 \\
34 \\
33 \\
34 \\
32 \\
31 \\
32 \\
32 \\
31 \cdot 5 \\
32 \\
30 \cdot 3 \\
30 \cdot 5 \\
32 \cdot 5 \\
32 \cdot 5 \\
31 \cdot 5 \\
32 \cdot 5 \\
32 \\
39\end{array}$ & $\begin{array}{l}34^{\circ} \\
34 \\
34 \cdot 5 \\
34 \\
34 \cdot 5 \\
36 \cdot 7 \\
35 \cdot 6 \\
36 \\
35 \cdot 3 \\
36 \cdot 5 \\
35 \cdot 6 \\
36 \\
36 \cdot 5 \\
36 \cdot 5 \\
36 \cdot 3 \\
37 \\
35 \cdot 5 \\
35 \\
43\end{array}$ & $\begin{array}{c}15 \\
30 \\
35 \\
60 \\
72 \\
73 \\
83 \\
94 \\
95 \\
103 \\
108 \\
120 \\
142 \\
173 \\
185 \\
237 \\
270 \\
331 \\
700\end{array}$ & $\begin{array}{l}\text { Between the } \\
\text { latitudes of } \\
79^{\circ} 45^{\prime} \mathrm{N} . \\
\text { and } \\
80^{\circ} 27^{\prime} \mathrm{N}\end{array}$ \\
\hline
\end{tabular}




\section{1}

\section{III.}

\section{CURRENTS OF THE OCEAN.}

Upon a review of many observations on currents in the higher latitudes, which have been publicly recorded, it is quite evident that there prevails, throughout the summer at least, a flow of the waters to the south-westward. We have, in the first place, presumptive evidence of this from the western coasts of all the lands within the Arctic Circle being navigable to their northern limits; whilst the eastern coasts are so encumbered with ice drifted upon them, that they are almost unapproachable. Whether we turn our attention to Nova Zembla, Spitzbergen, Greenland, or Behring's Strait, the same result is obtained. But we have other proof of this still more conclusive: ships, which have been beset in the ice between Spitzbergen and Greenland, have been found to drift in a S.IV. and S.W. by S. directions, at the rates of one hundred and eighty-two miles in thirteen days; one hundred and twenty miles in nine days; four hundred and twenty miles in fifty days; and one thousand three hundred miles in one hundred and eight days; or, at an average rate of 
about thirteen miles a-day, with the exception of the third instance, which gives eight miles a-day, but still in a southwest direction. It has been shown, in the course of this volume, that Sir Edward Parry's attempt to reach the Pole failed partly from the continued set of the current to the southwestward; and, in Captain Buchan's voyage, that the utmost exertions of the crews were inadequate to the maintenance of their position. This south-westerly current, however, does not appear to reach below the parallel of Cherie Island in the east, nor to extend as far as Cape Farewell in the west, and certainly not beyond it; for a southeasterly current has been found to prevail there, from the fact of bottles, which were thrown into the sea in those parts, having been picked up on the shores of Great Britain and Teneriffe; and from the casks of the William Torr whaler, wrecked in Davis' Straits, having been found off the Bay of Biscay, off Rockall, and at intermediate stations between this island and Newfoundland.* Connecting the observations in the

* The drift of these bottles and casks is taken from a "Bottle-track Chart," a very interesting and curious document, which has been compiled with great care, after a laborious collection of widely scattered facts, by Commander Becher, R.N., and published in the Nautical Magazine for March 1843. 
Arctic sea with those upon the "Bottle-track Chart" of Commander Becher, it seems that the southeasterly current sets from Davis' Strait down the coast of Labrador; and, turning eastward, is met by the drain of the Gulf-stream and diverted to the north-east, towards Iceland, the Feroe islands, and the shores of Britain. Nay, there is an indication of this effect of the Gulfstream being felt still further to the northward, and even beyond the North Cape, both by our own observations and those of Mr. Scoresby, as well as by the track of bottles,* and also by the unusually high temperature of the sea, which we carried as far as the 75 th degree of latitude. This warm stratum appears to have been passed through by Sir Edward Parry during his passage from Soroe to Spitzbergen, in about the 73rd degree of latitude, and to have extended to the longitude of $8^{\circ} \mathrm{E}$., where the temperature, as with Captain Buchan, fell from $39^{\circ}$ to $32^{\circ}$, and continued at or below this degree during the remainder of the passage.

* The following results have been kindly furnished me by Commander Becher, R.N.

Lat. Long. 'Drift of Bottle.

Bottles
thrown over.
$\begin{gathered}\text { board } \\ \text { in }\end{gathered}$$\left\{\begin{array}{llllll}60^{\circ} \mathrm{N} . & 7^{\circ} & 5^{\prime} \mathrm{W} . & \mathrm{N} .54^{\circ} & \mathrm{E} . & 1106 \text { miles. } \\ 60 & 25 & 4 & \mathrm{~N} .48^{\circ} & \text { E. } & 274 \\ 56 & 16 & 5 & \mathrm{~N} .8^{\circ} & \text { E. } & 217 \\ 50 & 27 & 0 & \text { N. } 21^{\circ} & \text { E. } & 843\end{array}\right.$


Captain Sabine to Davies Gilbert, M.P. Vice President of the Royal Society.

My dear Sir,

$$
\text { Portland Place, Feb. 8, } 1826 .
$$

I beg to trouble you with a few remarks on the project of measuring an arc of the meridian at Spitzbergen, previous to its discussion at the Council of the Royal Society.

It is not necessary that I should at this time enter on the reasons which have induced, for more than a century past, measurements to be made of portions of the meridian, for the purpose of determining the figure of the earth. The question now is, rather, shall all that has been effected hitherto in this method, with so much labour and expense, remain in its present incomplete and inconclusive state? or, shall the method be pursued until the result which it is capable of giving be attained?

There have been two arcs measured in the vicinity of the Equator; the Indian one, in particular, deserving of the highest consideration from its extent, and from the care bestowed on its details. To give to these arcs their full value in the proposed determination, there 
is wanting a corresponding measurement, or measurements at the Polar extremity of the meridian, with which they may be combined.

Several stations have been named for this purpose besides Spitzbergen; viz., the North Cape, Greenland, and Iceland. From personal knowledge of all these countries (except Iceland, to which, however, the remark equally applies), I can venture to give a practical opinion, that there can be no question as to the superior eligibility of Spitzbergen; a water communication along the whole line of operations, constitutes the superiority; and to those who have thought much on the details of such proceedings, it will not be necessary to explain that this is a point of the very first importance; a view of the chart of Spitzbergen will best show its remarkable fitness in this respect.

An arc, falling a little short of $4 \frac{1}{2}^{\circ}$, is comprised between Hope Island and Seven Islands, being the northern and southern extremities of the group which passes under the general name of Spitzbergen, and which may be seen by the chart to be so connected by intermediate land as to admit of their being united trigonometrically.

The value of an arc of $4 \frac{1}{2}^{\circ}$ in the latitude of Spitzbergen towards the deducing the pro- 
portion of the polar and equatorial diameters by its combination with an are near the equator, is equivalent to one of $9^{\circ}$ in the mean latitude of France, and of $7^{\circ}$ in the mean latitude of Britain; its value, therefore, in the ultimate determination, may be estimated by the known importance which is attached to the national arcs of Great Britain and France. It may be further noticed, that it is equivalent to an arc in Lapland, of nearly six times the extent of the arc measured by the French Academicians; the importance of which at this day is such, in the view of the first geometrician of the age, that M. Laplace has recently proposed, that a fresh commission should be sent to re-determine the latitudes of the extremities.

The expediency, then, of undertaking such a measurement at Spitzbergen, is principally to be considered in reference to the natural difficulties which may impede its execution. And on this point, having myself actually resided some weeks on shore at Spitzbergen, having conducted operations of a similar nature, having personal knowledge of the general character of the country to be traversed, the difficulties it presents to persons carrying astronomical instruments, and the modes and facilities of overcoming those difficulties, and having made observations of much deli- 
cacy, continued through many successive hours, and for successive days, at the summit of one of the hills of principal elevation, such as would probably form the greater part of the trigonometrical stations, I may venture to hazard the opinion which that varied experience warrants. The subject was in my mind when on the spot, and I have since reflected continually, in reference to it, and have heard, I believe, most of the objections which from time to time have been suggested in conversation, against its practical accomplishment. I still, however, entertain the opinion formed on the spot, viz., that there is no reason to anticipate any difficulties, either of climate or country, but such as may be surmounted by the patience and exertion requisite in such operations, or which, being surmounted, would in the slightest degree interfere with the accuracy of the result. I may observe, that I am speaking of difficulties which $\mathbf{I}$ think it not improbable I may be called on myself to meet; and that I am not likely, under such circumstances, either lightly or inconsiderately to underrate them.

It is very satisfactory to me to be enabled to add, that the inferences I had drawn from my own personal experience at Spitzbergen, have been greatly strengthened by the highly interesting and important information, as regards this 
question, which Mr. Crowe, his Majesty's ViceConsul at Hammerfast, the establisher and proprietor of a British settlement at Spitzbergen, has obtained in the last summer. The following extracts are from a communication which Mr. Crowe has made to Lord Melville:

"It having been mentioned to me by Captain Sabine, in a conservation I had with him previously to my leaving England last summer, that the Admiralty might have it in contemplation to send a vessel in the direction of Spitzbergen, for certain scientific objects, and that any information would be acceptable which might tend to facilitate the progress of such a vessel, I directed the master of a small cutter of forty tons, who was to sail from Hammerfast, to the settlement at Ice Sound, to penetrate up Wyde Jansz Water, an arm of the sea which intersects Spitzbergen in a north and south direction, respecting the free navigation of which Captain Sabine had expressed a wish to be informed. The vessel accordingly did ascend to the parallel of Ice Sound $\left(78^{\circ}\right)$, and the master reports it to have been perfectly free from ice. He next went round the west coast as far as Walden's Island, adjoining the Seven Islands, without meeting with any impediment; and although many shoals of ice were visible from thence, there were many open channels through which he 
might have navigated still further in that direction. A vessel belonging to myself, the year before last ascended half a degree further north than Table Island, but nine to the westward. Mr. Sharostin, an intelligent Russian, with whom I have frequently conversed, actually passed thirty-nine winters on Spitzbergen, and resided there for fifteen years without having once left the island. He declares, that during his residence he invariably found the coasts free from ice, for four and sometimes for five months in every year. I am enabled to add, that my own vessels have frequently navigated the coast from Ryke Yse's Islands, the south-east extremity, round the west coast, to the Seven Islands at the north-east extremity, and that four times out of six they might have circumnavigated Spitzbergen."

Mr. Crowe has further acquainted me that his brother, who sailed in the cutter up Wyde Jansz Water, represents the land on either side as being conveniently traversable, the hills of moderate elevation, and the valleys running well into each other.

Mr. Crowe has requested me to express his readiness to attend at any time at the Council of the Royal Society, should his presence appear desirable, and I need not add, that my attendance is always at their command. 
These are, I apprehend, the best sources from whence information can at present be attained; but, without doubt, the most satisfactory mode of ascertaining whether the natural difficulties to be encountered ought to weigh against the value of the result that would be obtained, is to send a vessel in the present summer for the express investigation. For this purpose there would be required no wintering in the high latitudes, no particular cost in strengthening or fitting the ship for the service, no second ship as a consort in case of accident, because there are permanent settlements at Spitzbergen, at which merchant vessels are always to be found; no risk of life, beyond what the Norwegian sailors annually encounter in quest of eider-down. One of the ordinary surveying ships relieved for six months from her accustomed employ, would then place it in the power of the Council to decide, in full and competent knowledge, on the propriety of recommending the measure to be carried into execution.

I conceive that a single season, the present summer for example, would be ample for the most thorough investigation, in which every station should be personally visited, the angles and latitudes observed with inferior, that is to say, more portable instruments, and the situation of a 
base selected, with reference both to the survey generally, and to the nature of the ground. The report should also contain so thoroughly digested a scheme of further proceedings, as should enable the Council to judge of the merits of every part of the proposed plan, previously to its being undertaken. Such a Report would probably prove more than half the labour of the whole operation.

Should the Council think that I could be advantageously employed in conducting such an investigation, my services, as you well know, are at their command. Accompanied by a second officer of the Ordnance, and a steady sergeant of Artillery, I should feel little doubt either of putting the question, as regards Spitzbergen, at rest for ever, by proving the impracticability of the operation, or of furnishing such a report as I have described, whereby its completion, if it were expedient to be pursued, could be looked forward to with certainty.

I remain, my dear, Sir,

Yours very faithfully,

Edward Sabine.

THE END. 


\section{LONDON :}

Printed by S. \& J. Bentley, Wilson, and Fley, Bangor House, Shoe Lane. 





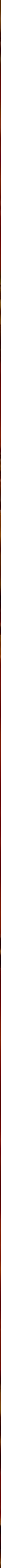


II - br: sian

A)

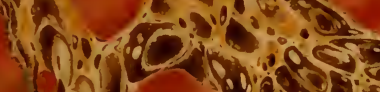

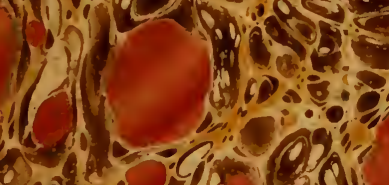

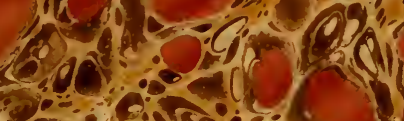

2000040

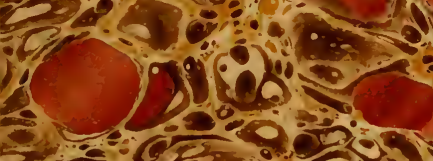

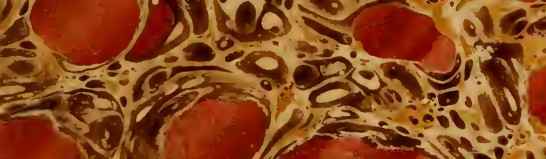

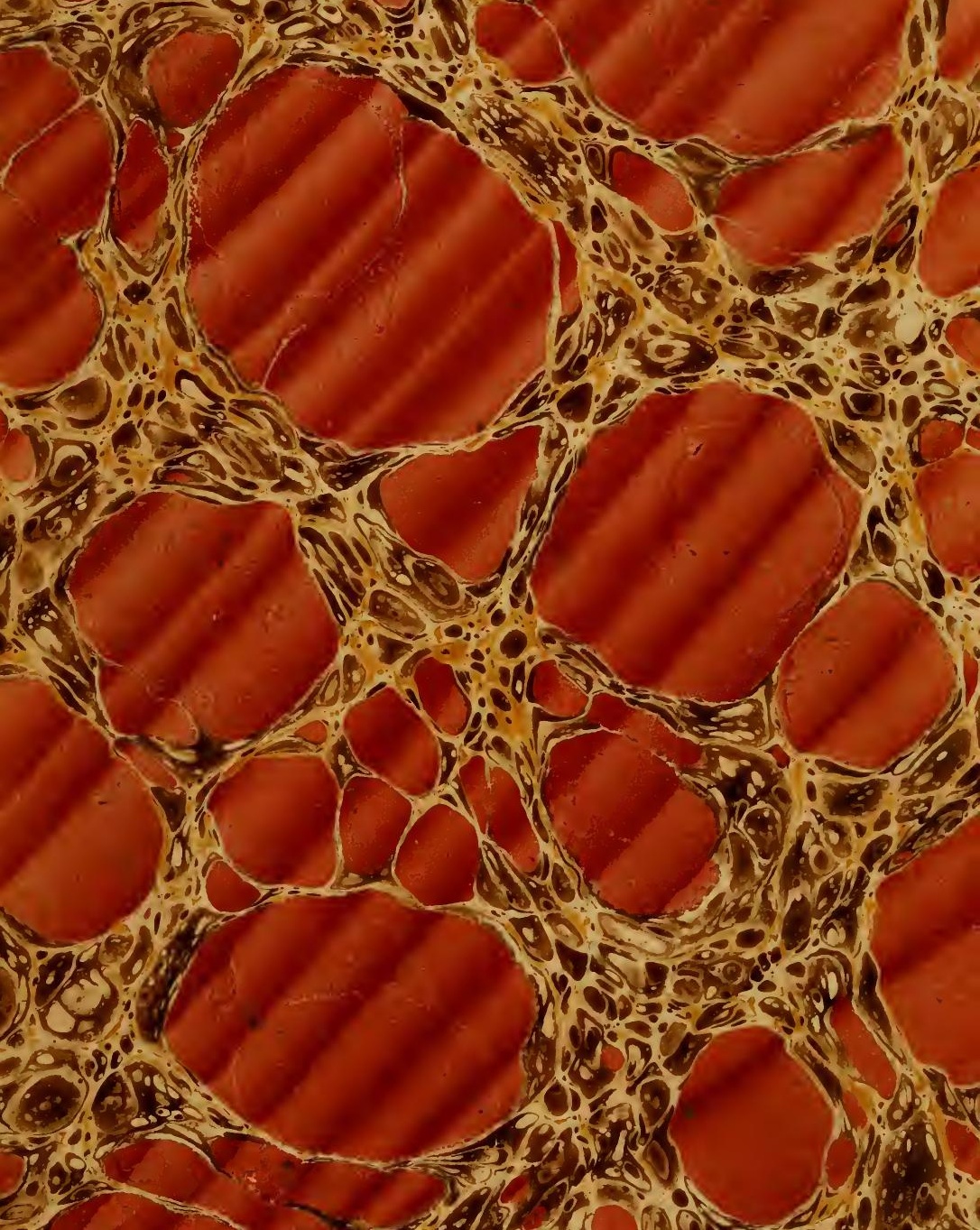


